NBER WORKING PAPER SERIES

\title{
THE EFFECTS OF EXPOSURE TO BETTER NEIGHBORHOODS ON CHILDREN: NEW EVIDENCE FROM THE MOVING TO OPPORTUNITY EXPERIMENT
}

\author{
Raj Chetty \\ Nathaniel Hendren \\ Lawrence F. Katz \\ Working Paper 21156 \\ http://www.nber.org/papers/w21156
}

\author{
NATIONAL BUREAU OF ECONOMIC RESEARCH \\ 1050 Massachusetts Avenue \\ Cambridge, MA 02138 \\ May 2015
}

The opinions expressed in this paper are those of the authors alone and do not necessarily reflect the views of the Internal Revenue Service, the U.S. Treasury Department, or the National Bureau of Economic Research.. This work is a component of a larger project examining the effects of tax expenditures on the budget deficit and economic activity. All results based on tax data in this paper are constructed using statistics originally reported in the SOI Working Paper "The Economic Impacts of Tax Expenditures: Evidence from Spatial Variation across the U.S.," approved under IRS contract TIRNO-12-P-00374 and presented at the Office of Tax Analysis on November 3, 2014. MTO participant data are highly confidential. HUD allowed the authors special access to the experimental data under Data License DL14MA001, approved March 28, 2014. We thank Joshua Angrist, Jeffrey Kling, Jeffrey Liebman, Jens Ludwig, anonymous referees, and numerous seminar participants for helpful comments and discussions. We are very grateful to Ray Yun Gou, Lisa Sanbonmatsu, and Matt Sciandra for help with the Moving to Opportunity data. Sarah Abraham, Alex Bell, Augustin Bergeron, Jamie Fogel, Nikolaus Hildebrand, Alex Olssen, and Benjamin Scuderi provided outstanding research assistance. This research was funded by the National Science Foundation, NIA Grant R01 AG031259, the Lab for Economic Applications and Policy at Harvard, and Laura and John Arnold Foundation.

NBER working papers are circulated for discussion and comment purposes. They have not been peerreviewed or been subject to the review by the NBER Board of Directors that accompanies official NBER publications.

(C) 2015 by Raj Chetty, Nathaniel Hendren, and Lawrence F. Katz. All rights reserved. Short sections of text, not to exceed two paragraphs, may be quoted without explicit permission provided that full credit, including $\odot$ notice, is given to the source. 
The Effects of Exposure to Better Neighborhoods on Children: New Evidence from the Moving to Opportunity Experiment

Raj Chetty, Nathaniel Hendren, and Lawrence F. Katz

NBER Working Paper No. 21156

May 2015, Revised Septemberr 2015

JEL No. H53,I32,I38,R38

\section{$\underline{\text { ABSTRACT }}$}

The Moving to Opportunity (MTO) experiment offered randomly selected families living in highpoverty housing projects housing vouchers to move to lower-poverty neighborhoods. We present new evidence on the impacts of MTO on children's long-term outcomes using administrative data from tax returns. We find that moving to a lower-poverty neighborhood significantly improves college attendance rates and earnings for children who were young (below age 13) when their families moved. These children also live in better neighborhoods themselves as adults and are less likely to become single parents. The treatment effects are substantial: children whose families take up an experimental voucher to move to a lower-poverty area when they are less than 13 years old have an annual income that is $\$ 3,477$ (31\%) higher on average relative to a mean of $\$ 11,270$ in the control group in their mid-twenties. In contrast, the same moves have, if anything, negative long-term impacts on children who are more than 13 years old when their families move, perhaps because of the disruption effects of moving to a very different environment. The gains from moving fall with the age when children move, consistent with recent evidence that the duration of exposure to a better environment during childhood is a key determinant of an individual's long-term outcomes. The findings imply that offering vouchers to move to lower-poverty neighborhoods to families with young children who are living in high- poverty housing projects may reduce the intergenerational persistence of poverty and ultimately generate positive returns for taxpayers.

Raj Chetty

Department of Economics

Harvard University

1805 Cambridge St.

Cambridge, MA 02138

and NBER

chetty@fas.harvard.edu

Nathaniel Hendren

Harvard University

Department of Economics

Littauer Center Room 235

Cambridge, MA 02138

and NBER

nhendren@gmail.com
Lawrence F. Katz

Department of Economics

Harvard University

Cambridge, MA 02138

and NBER

lkatz@harvard.edu 
Individuals who live in high-poverty areas fare worse than those who live in lower-poverty neighborhoods on a wide range of economic, health, and educational outcomes. ${ }^{1}$ Motivated by such disparities in outcomes across neighborhoods, the Moving to Opportunity (MTO) experiment of the U.S. Department of Housing and Urban Development offered a randomly selected subset of families living in high-poverty housing projects subsidized housing vouchers to move to lower-poverty neighborhoods in the mid-1990s. The MTO experiment generated large differences in neighborhood environments for comparable families, providing an opportunity to evaluate the causal effects of improving neighborhood environments for low-income families (Ludwig et al. 2013).

Previous research evaluating the MTO experiment has found that moving to lower-poverty areas greatly improved the mental health, physical health, and subjective well being of adults as well as family safety (e.g., Katz et al. 2001, Kling et al. 2007, Clampet-Lundquist and Massey 2008, Ludwig et al. 2013). But these studies have consistently found that the MTO treatments had no significant impacts on the earnings and employment rates of adults and older youth, suggesting that neighborhood environments might be less important for economic success.

In this paper, we revisit the MTO experiment and focus on its long-term impacts on children who were young when their families moved to better neighborhoods. Our analysis is motivated by recent evidence that the amount of time individuals spend in a given neighborhood during their childhood is a key determinant of that neighborhood's effects on their long-term outcomes. ${ }^{2}$ Crowder and South (2011) and Wodtke et al. (2011) show that the fraction of childhood spent in high-poverty areas is negatively correlated with outcomes such as high-school completion. Chetty and Hendren (2015) study more than five million families that move across areas and find that neighborhoods have causal exposure effects on children's outcomes using quasi-experimental methods. In particular, every year spent in a better area during childhood increases college attendance rates and earnings in adulthood, so the gains from moving to a better area are larger for children who are younger at the time of the move.

In light of this evidence on childhood exposure effects, we test two hypotheses in the MTO data. First, we hypothesize that moving to a lower-poverty area improves long-term economic outcomes for children who were young at the point of random assignment (RA). Second, we hypothesize that the gains from moving to a lower-poverty area decline with a child's age at move. Prior work has

\footnotetext{
${ }^{1}$ See, for example, Jencks and Mayer (1990), Brooks-Gunn et al. (1993), Cutler and Glaeser (1997), Leventhal and Brooks-Gunn (2000), and Sampson et al. (2002).

${ }^{2}$ The idea that the length of exposure to neighborhoods might matter has been recognized since Wilson (1987) and Jencks and Mayer (1990). Importantly, we focus here on exposure effects during childhood; as we discuss below, we find no evidence of exposure effects for adults.
} 
not been able to study these issues because the younger children in the MTO experiment are only now old enough to be entering the adult labor market. We present new evidence on the impacts of MTO on children's earnings, college attendance rates, and other outcomes in adulthood by linking the MTO data to federal income tax returns.

The MTO experiment was conducted between 1994 and 1998 in five large U.S. cities. The experimental sample included 4,604 families, who were randomly assigned to one of three groups: an experimental voucher group that was offered a subsidized housing voucher that came with a requirement to move to a census tract with a poverty rate below $10 \%$, a Section 8 voucher group that was offered a standard subsidized housing voucher with no additional contingencies, and a control group that was not offered a voucher (but retained access to public housing).

We begin our analysis by evaluating the impacts of MTO on young children, whom we define in our baseline analysis as those below age 13 at RA. ${ }^{3}$ These children are 8 years old on average at RA. Among these children, $48 \%$ of those in the experimental voucher group took up the voucher to move to a low-poverty area, while $66 \%$ of those in the Section 8 group took up the vouchers they were offered. Children growing up in the three groups experienced very different childhood environments. On average from the date of RA until age 18, children below age 13 at RA in the control group lived in census tracts with a mean poverty rate of $41 \%$. Children whose families took up the experimental voucher lived in census tracts with 22 percentage point lower poverty rates than those in the control group on average until age 18. Those who took up the Section 8 voucher lived in census tracts with 12 percentage point lower poverty rates than the control group.

We estimate the treatment effects of growing up in these very different environments by replicating the intent-to-treat (ITT) specifications used in prior work (e.g., Kling et al. 2007), regressing outcomes in adulthood on indicators for assignment to each of the treatment arms. We find that assignment to the experimental voucher group led to significant improvements on a broad spectrum of outcomes in adulthood for children who were less than age 13 at RA. Children assigned to the experimental voucher group before they turned 13 have incomes that are $\$ 1,624$ higher on average relative to the control group in their mid-twenties $(p<0.05)$. Given the experimental voucher takeup rate of $48 \%$, this translates to a treatment-on-the-treated (TOT) estimate for those who took up the experimental voucher of $\$ 3,477$, a $31 \%$ increase relative to the control group mean of

\footnotetext{
${ }^{3}$ We limit our sample to children who are at least 21 by 2012 , the last year for which we have data from tax returns. Because of this restriction, our "below age 13" sample only includes children who were between the ages of 4 and 12 at random assignment. As we discuss below, we find similar results when defining "young children" using other cutoffs, e.g. those below age 12 or 14 .
} 
$\$ 11,270$. Children assigned to the experimental voucher group before they turn 13 are also significantly more likely to attend college and attend better colleges. The ITT effect on college attendance between the ages of $18-20$ is a 2.5 percentage point (16\%) increase relative to the control group mean attendance rate of $16.5 \%$. Finally, children assigned to the experimental voucher group before age 13 also live in lower-poverty neighborhoods themselves as adults and are less likely to be single parents themselves (for females). ${ }^{4}$

Children whose families were assigned to the Section 8 voucher group before they turned 13 generally have mean outcomes between the control and experimental group means. For example, the TOT estimate for individual income is $\$ 1,723$ for the Section 8 voucher relative to the control among children below age 13 at RA. This impact is $50 \%$ of the TOT estimate for the experimental voucher, which is consistent with the fact that the Section 8 voucher reduced mean neighborhood poverty rates by approximately half as much as the experimental voucher for those who took up the vouchers. Note that households in the Section 8 group could have chosen to make exactly the same moves as those in the experimental group. The fact that the experimental voucher had larger effects on children's outcomes than the Section 8 voucher therefore suggests that actively encouraging families to move to lower-poverty neighborhoods - either through counseling or by restricting their choice set - increases the impacts of housing vouchers on young children's longterm economic success.

The MTO treatments had very different effects on older children - those between 13-18 at RA, who were 15 years old on average at that point. In most cases, we find statistically insignificant differences between mean outcomes in the three treatment arms among older children. The point estimates suggest that, if anything, moving to a lower-poverty neighborhood had slightly negative effects on older children's outcomes. For example, the ITT impact of the experimental voucher is -\$967 on individual income among children who were $13-18$ at RA. One potential explanation for these negative impacts at older ages is a disruption effect: moving to a very different environment, especially as an adolescent, could disrupt social networks and have other adverse effects on child development (Coleman 1988, Wood et al. 1993, South et al. 2007). ${ }^{5}$

\footnotetext{
${ }^{4}$ We define a mother as a "single parent" if she has a child whose father's name is not listed on the child's social security application, which is typically submitted at birth.

${ }^{5}$ Importantly, these disruption costs appear to be a function of where a family moves rather than a fixed cost of moving to a different home. Most families in both the control and treatment groups moved several times while their children were growing up (Ludwig et al. 2013). However, families who moved using the subsidized housing vouchers - especially the experimental vouchers - moved to very different neighborhoods that were further away from the housing projects where they started. Disruption costs are presumably larger for children who move to a very different area, e.g. because of a loss of social networks (Coleman 1988). Consistent with this explanation, TOT estimates show a somewhat larger adverse impact of MTO moves on older children in the experimental voucher group as compared
} 
We explore the robustness of these findings by estimating models that interact age at RA linearly with the treatment indicators. We find robust evidence that the gains from moving to lower-poverty areas decline with the child's age at move, suggesting that every extra year of exposure to a lowpoverty environment during childhood is beneficial. We do not find any clear evidence of a "critical age" below which children must move to benefit from a better neighborhood, although one cannot obtain very precise estimates of the age profile of exposure effects from the MTO data because of the small sample sizes at each child age.

Putting the results together, the effects of moving to a better neighborhood on children's longterm economic outcomes can be explained by a simple model featuring a disruption cost of substantially changing one's neighborhood environment coupled with benefits that are proportional to amount of exposure to a lower-poverty environment during childhood. The exposure effects outweigh the disruption cost for children who move when young, but not for children who move at older ages. Although our findings are consistent with such a model of exposure effects, the MTO experimental design cannot be used to conclusively establish that childhood exposure to a better environment has a causal effect on long-term outcomes because the ages at which children move are perfectly correlated with their length of exposure to a lower-poverty neighborhood. As a result, we cannot distinguish differences in disruption effects by age at the time of a move from an age-invariant disruption cost coupled with an exposure effect. Moreover, the treatment effects for families with young vs. old children could differ because the set of families who took up the voucher and the areas to which they moved might vary between the two groups. Nonetheless, regardless of the underlying mechanisms, the experimental results are adequate to conclude that providing subsidized housing vouchers to move to lower-poverty areas yields produces larger benefits for younger children.

We find that the MTO treatments had little or no impact on adults' economic outcomes, consistent with prior work (e.g., Ludwig et al. 2013). ${ }^{6}$ The experimental voucher TOT estimate on individual earnings is $-\$ 734$ (a $4.7 \%$ reduction) and the upper bound of the $95 \%$ confidence interval is a $12 \%$ increase, well below the estimated impacts for young children. We find no evidence of exposure effects among adults, in contrast with the observational correlations reported by ClampetLundquist and Massey (2008). The earnings impacts for adults do not increase over time after RA, to the Section 8 group.

${ }^{6}$ Our findings regarding the impacts of MTO on children are also consistent with prior research. If we restrict ourselves to the data available in prior work (up to 2008) and do not split children by age at move, we detect no impact of the MTO treatments on children's economic outcomes. 
despite the fact that cumulative exposure to lower-poverty areas rose significantly.

Prior studies of MTO have detected heterogeneity in short-run and medium-term treatment effects by child gender and experimental site (e.g., Kling et al. 2007). We find no systematic differences in the treatment effects of MTO on children's long-term outcomes by gender, race, or site. In particular, the point estimates of the effect of the experimental voucher on earnings are positive for all five experimental sites, for Whites, Blacks, and Hispanics, and for boys and girls for children below the age of 13 at RA. The corresponding point estimates are almost all negative for children above the age of 13 at RA. Most notably, we find robust, statistically significant evidence that the experimental voucher improved long-term outcomes for (young) boys, a subgroup where prior studies found little evidence of medium-term gains.

Previous explorations of heterogeneity in treatment effects in the MTO data raise concerns that our results - which essentially explore heterogeneity in the new dimension of child's age at move - are an artifact of multiple hypothesis testing. A post-hoc analysis of a randomized experiment will generate some p-values that appear to be "statistically significant" (e.g., $p<0.05$ ) purely by chance if one examines a sufficiently large number of subgroups. To address this concern, we test the omnibus null hypothesis that the treatment effects for the main subgroups studied in MTO research to date (based on gender, race, site, and age) are all zero using parametric $\mathrm{F}$ tests and a nonparametric permutation test. We reject the null hypothesis of zero treatment effects in all subgroups with $p<0.05$ for most outcomes using $\mathrm{F}$ tests of interaction terms of treatment group and subgroup indicators. The permutation test yields $p<0.01$ for the null hypothesis that the MTO treatments had no effect on any of the outcomes we study for children below 13 at RA, adjusting for multiple hypothesis testing across all the subgroups. The results imply that the significant treatment effects we detect for younger children are unlikely to be an artifact of analyzing multiple subgroups. In addition, we returned to the MTO data with a pre-specified hypothesis that we would find larger impacts for younger children, based on the quasi-experimental evidence in Chetty and Hendren (2015). The fact that the experimental results closely match the quasi-experimental evidence makes it less likely that these results are spuriously generated by multiple hypothesis testing.

We conclude that the Moving to Opportunity experiment generated substantial gains for children who moved to lower-poverty neighborhoods when they were young. We estimate that moving a child out of public housing to a low-poverty area when young (at age 8 on average) using an MTO-type experimental voucher will increase the child's total lifetime earnings by about $\$ 302,000$. 
This is equivalent to a gain of $\$ 99,000$ per child moved in present value at age 8 , discounting future earnings at a $3 \%$ interest rate. The increased earnings of children ultimately leads to significant benefits to taxpayers as well. Children whose families took up experimental vouchers before they were 13 pay an extra $\$ 394$ per year in federal income taxes during their mid-twenties. If these gains persist in subsequent years of adulthood, the additional tax revenue obtained from these children will itself offset the incremental cost of the experimental voucher treatment relative to providing public housing. Thus, our findings suggest that housing vouchers which (1) require families to move to lower-poverty areas and (2) are targeted at low-income families with young children can reduce the intergenerational persistence of poverty and ultimately save the government money.

The paper is organized as follows. Section I summarizes the key features of the MTO experiment. Section II describes the data sources and reports summary statistics and tests for balance across the experimental groups. We present our main results in Section III. In Section IV, we reconcile our new findings with prior research on MTO. Section V presents a cost-benefit analysis and discusses policy implications. We conclude in Section VI by interpreting our findings in the context of the broader literature on neighborhood effects.

\section{The Moving to Opportunity Experiment}

In this section, we briefly summarize the key features of the MTO experiment; see Sanbonmatsu et al. (2011) for a more comprehensive description. The MTO randomized housing mobility demonstration, conducted by the U.S. Department of Housing and Urban Development (HUD), enrolled 4,604 low-income families living in five U.S. cities - Baltimore, Boston, Chicago, Los Angeles, and New York - from 1994 to 1998. Families were eligible to participate in MTO if they had children and resided in public housing or project-based Section 8 assisted housing in high-poverty census tracts (those with a 1990 poverty rate of $40 \%$ or more).

Families were randomized into three groups: i) the experimental group, which received housing vouchers that subsidized private-market rents and could initially (for the first year) only be used in census tracts with 1990 poverty rates below 10\%; ii) the Section 8 group, which received regular housing vouchers without any MTO-specific relocation constraint; and iii) a control group, which received no assistance through MTO. Those in the experimental group also received additional housing-mobility counseling from a local nonprofit organization. The experimental vouchers became regular Section 8 vouchers after a year and were no longer restricted to low-poverty census tracts. Families assigned to the experimental and Section 8 groups had 4-6 months to lease an apartment 
and use their vouchers.

Families in all three groups were required to contribute $30 \%$ of their annual household income toward rent and utilities. Those assigned to the experimental or Section 8 voucher groups received housing vouchers that covered the difference between their rent and the family's contribution, up to a maximum amount known as the Fair Market Rent, defined as the 40th percentile of rental costs in a metro area. Families remained eligible for these vouchers (or public housing projects) indefinitely as long their income was below 50 percent of the median income in their metro area.

The proportion of individuals randomly assigned to the three groups at each site was changed during the course of the experiment because take-up of the MTO vouchers turned out to differ from projections. All the statistics reported in this paper use sampling weights in which individuals are weighed by the inverse of their probability of assignment to their treatment group to account for changes in the random-assignment ratios over time. ${ }^{7}$

\section{Data}

We draw information from two datasets: HUD files on the MTO participants and federal income tax records. This section describes the two data sources and key variable definitions. It then provides descriptive statistics and tests for balance across the MTO treatment groups.

\section{A. MTO Data}

The MTO dataset contains information on 4,604 households and 15,892 individuals who participated in the experiment. This study examines the impacts of MTO on outcomes typically observed at age 21 or older. Since the last year in the tax data is currently 2012, we restrict the MTO sample to the 13,213 individuals who are 21 or older in 2012 (those born in or before 1991). We focus much of our analysis on MTO children, defined as individuals who were 18 years old or younger at the time of RA and residing at that time in a household that participated in MTO. There are 11,276 children in the MTO data, of whom 8,603 (76\%) were born in or before 1991.

For each MTO participant, we use two sets of information from the MTO dataset. First, we obtain information on individual and household background characteristics from the MTO Participant Baseline Survey. The baseline survey was administered to each MTO household head at the time of program enrollment (prior to RA). The survey provides demographic and socioeconomic

\footnotetext{
${ }^{7}$ See Orr et al. (2003) for the details on the variation in random-assignment ratios over time and the construction of the MTO sample weights. The weights prevent time or cohort effects from confounding the results. The weights we use are the same as the weights used for the analysis of administrative data in past MTO work.
} 
background information on each household member (adults and children) including information on children's school experiences, household criminal victimization, reasons for wanting to participate in MTO, and household income and transfer receipt. See Sanbonmatsu et al. (2011) for more detailed information on the background characteristics of the MTO participants and the baseline survey.

Second, we obtain yearly information on the residential neighborhood (census tract) for each MTO participant using address history data from the MTO long-term survey conducted in 20082010, as in Sanbonmatsu et al. (2011). We estimate census tract poverty rates in each year by interpolating census tract poverty rates using the 1990 and 2000 Censuses and the 2005-2009 American Community Surveys. We use this information to construct a measure of each MTO child's exposure to poverty (mean tract poverty rate) from the time of RA to age 18.

\section{B. Tax Data}

We link the MTO data to data from federal income tax records spanning 1996 to $2012 .^{8}$ HUD collected social security numbers (SSNs) prior to RA for $90 \%(11,892)$ of the individuals who participated in the MTO experiment and were born in or before 1991. The MTO records were linked to the tax data by SSN. Of the MTO records with a valid SSN, 99\% (11,780) were successfully linked to the tax data. To protect confidentiality, individual identifiers were removed from the linked dataset prior to the statistical analysis.

The tax data include both income tax returns (1040 forms) and third-party information returns (e.g., W-2 forms), which give us information on the earnings of those who do not file tax returns as well as data on other outcomes, such as college attendance. Here, we define the key variables we use in our analysis. We measure all monetary values in real 2012 dollars, adjusting for inflation using the Consumer Price Index (CPI-U).

Income. Our primary measure of income is "individual earnings." Individual earnings is defined as the sum of income from W-2 forms filed by employers (summed across all W-2s for the individual in each year) and "non W-2 earnings." Non W-2 earnings is defined as adjusted gross income on form 1040 minus own and spouse's W-2 earnings, UI benefits, and SSDI payments, and is divided by 2 for married households. Hence, non-W-2 earnings reflects income from self-employment and other activities not captured on W-2s. Non-W-2 earnings is recoded to 0 if negative and is defined as 0 for non-filers. If an individual has no tax return and no W-2 earnings, individual earnings is

\footnotetext{
${ }^{8}$ Here and in what follows, the year refers to the tax year (i.e., the calendar year in which the income is earned).
} 
coded as zero.

We also report effects on household income. For those who file tax returns, we define household income as Adjusted Gross Income (as reported on the 1040 tax return) plus tax-exempt interest income and the non-taxable portion of Social Security and Disability benefits. In years when an individual does not file a tax return, we define household income as the sum of the individual's wage earnings (reported on form W-2), unemployment benefits (reported on form 1099-G), and gross social security and disability benefits (reported on form SSA-1099). ${ }^{9}$

College Attendance. We define college attendance at age $a$ as an indicator for having a 1098$\mathrm{T}$ form filed on one's behalf during the calendar year in which the child turns age $a$. Title IV institutions - all colleges and universities as well as vocational schools and other post-secondary institutions eligible for federal student aid - are required to file 1098-T forms that report tuition payments or scholarships received for every student. These 1098-T data are available from 19992012. Because the 1098-T forms are filed directly by colleges independent of whether an individual files a tax return, we have records on college attendance for almost all children. ${ }^{10}$ Comparisons to other data sources indicate that 1098-T forms capture college enrollment quite accurately overall (Chetty et al. 2014, Appendix B). In particular, the correlation between enrollment counts based on 1098-T forms and enrollment counts in the IPEDS dataset from the Department of Education exceeds 0.95 .

College Quality. Using data from 1098-T forms, Chetty et al. (2014) construct an earningsbased index of "college quality" using the mean individual wage earnings at age 31 of children born in 1979-80 based on the college they attended at age 20. For those not enrolled in any college at age 20, the index equals the mean earnings at age 31 of all U.S. residents not enrolled in college at age 20. We define college quality at age $a$ based on the college in which the child was enrolled at age $a$ (inflated to 2012 dollars using the CPI-U).

Neighborhood Characteristics in Adulthood. We measure the characteristics of the neighborhoods where children live in adulthood using information on ZIP codes from the tax data. ${ }^{11}$ We assign each individual a ZIP code in each year using a sequential algorithm starting with the location from

\footnotetext{
${ }^{9}$ For non-filers, our definition of "household income" does not include the spouse's income. This is likely to be of minor consequence because the vast majority of non-filers in the U.S. who are not receiving Social Security benefits are single (Cilke 1998, Table I).

${ }^{10}$ Colleges are not required to file 1098- $\mathrm{T}$ forms for students whose qualified tuition and related expenses are waived or paid entirely with scholarships or grants. However, the forms are typically available even for such cases, presumably because of automated reporting to the IRS by universities. Approximately $6 \%$ of $1098-\mathrm{T}$ forms are missing from 2000-2003 because the database contains no 1098-T forms for some small colleges in these years.

${ }^{11}$ The tax data do not currently contain information on census tracts, so we are forced to use a broader ZIP code measure when analyzing children's location in adulthood.
} 
which the individual files his tax return (form 1040). If the individual does not file a tax return, we obtain their ZIP code from form W-2, followed by other information returns (e.g. 1099s). We use this information to measure the following characteristics of the individual's ZIP code using data from the 2000 Census: poverty share (share of households below the poverty line), mean income (aggregate income in the ZIP code divided by the number of individuals 16-64 years old), black share (number of people who are black alone divided by total population in 2000) and single mother share (number of households with female heads and no husband present with own children present divided by the total number of households with own children present).

Marital Status and Fertility. We define an individual as married if he or she files a tax return as a married individual in a given year. We measure fertility patterns using data through June 2014 from the Kidlink (DM-2) database provided to the IRS by the Social Security Administration, which contains information from applications for social security numbers (SSNs). SSN applications request the SSN of both the mother and father (if present), allowing us to link parents to their children. $^{12}$ We define a woman as having a birth if she had a child before June 2014 and having a teenage birth if she had a child between the ages of 13 and 19. Most people apply for SSN's for their children at birth because an SSN is required to claim a child as a dependent on tax returns and for various other purposes. We therefore define an indicator for whether the father was present at a child's birth based on whether a father is listed on the child's SSN application.

Tax Filing and Taxes Paid. We define tax filing as an indicator for filing a 1040 tax return and total taxes paid as the total tax field from form 1040 for filers and total taxes withheld on W-2 forms for non-filers.

\section{C. Balance Tests and Summary Statistics}

Prior research has documented that baseline characteristics are balanced between the treatment and control groups for both MTO adults and children, as would be expected in an experiment with random assignment (Kling et al. 2007). Here, we replicate these balance tests on the linked MTO-Tax Data to ensure that we retain balance in the subgroup that we are able to link to the tax data.

In our core analysis, we split children into two groups: those below age 13 at RA and those between ages 13-18 at RA. Table 1 reports summary statistics and balance tests for selected baseline covariates for these two groups. Appendix Table 1a replicates Table 1 for the broader set of

\footnotetext{
${ }^{12}$ The total count of births in the DM-2 data differ from CDC vital statistics counts by less than 2\% from 1987-2006, but the DM-2 data misses approximately $10 \%$ of births starting in 2007.
} 
52 baseline covariates used in the MTO interim and final impact evaluations (Kling et al. 2007, Sanbonmatsu et al. 2011).

We match $86.4 \%$ of younger children and $83.8 \%$ of the older MTO children to the tax data. The match rates do not differ significantly between the control and treatment groups. This is to be expected because the SSN's that we use to link the MTO data to the tax data were collected prior to random assignment and we successfully link $99 \%$ of the individuals with valid SSNs to the tax data. Thus, there is virtually no scope for differential attrition across the three treatment arms in the linked dataset. Consistent with the lack of differential attrition, the distribution of baseline covariates appears to be balanced in the linked MTO-Tax data data. 13 of the 196 differences reported in Appendix Table 1a are significant with $p<0.05$ and 2 of the 196 are significant with $p<0.01$ based on t-tests that do not adjust for multiple comparisons, in line with what one would expect under random assignment.

The summary statistics in Table 1 show that families who participated in MTO were quite economically disadvantaged. Approximately one-third of the MTO household heads had completed high school, only one quarter were employed, three-quarters were receiving public assistance (AFDC/TANF), more than half had never been married, and a quarter had been teenage parents at the point of random assignment. Around three-quarters of applicants reported getting away from gangs and drugs as one of the most important reasons for enrolling in MTO, and over $40 \%$ of the households had been victims of crime in the previous five years. The vast majority of the household heads were African-American or Hispanic females. Among the older children (ages 13-18 at RA), nearly $20 \%$ had been suspended or expelled from school in the past two years.

Appendix Table 1b reports summary statistics on children's long-term outcomes. Mean individual earnings is $\$ 11,739$ at age 24 , rising to $\$ 14,269$ at age 28 . College attendance rates are $18-19 \%$ over the ages 19-21. Roughly $22 \%$ of the females give birth to a child as a teenager. On average, $63 \%$ of the sample files a tax return (form 1040) in any given year after they turn 24.

\section{Analysis and Results}

In our core analysis, we split the 7,340 children in our linked analysis sample into two groups: (1) children younger than adolescence (less than 13 years) at RA and (2) adolescent children (those 13 to 18 years old) at RA. ${ }^{13}$ The children in the younger group were 8.2 years old at RA on average,

\footnotetext{
${ }^{13}$ MTO moves typically occurred within six months of RA, so a child's age at RA is essentially the child's age at the time of the move.
} 
while those in the older group were 15.1 years old on average (Table 1). This split at age 13 yields approximately the same number of observations for the younger and older groups for analyses of outcomes such as earnings in early adulthood. We report estimates with different age cutoffs and use linear interaction models to evaluate the robustness of the results in Section III.G.

Within each of these two groups, we estimate "intent-to-treat" (ITT) effects of the MTO treatments, which are essentially differences between treatment and control group means. Following the standard approach used in prior evaluations of MTO (e.g., Kling et al. 2007), we estimate ITT effects on an outcome $(y)$ using OLS regression specifications of the form:

$$
y_{i}=\alpha+\beta_{E}^{I T T} \operatorname{Exp}_{i}+\beta_{S}^{I T T} S 8_{i}+\gamma X_{i}+s_{i} \delta+\epsilon_{i}
$$

where Exp and S8 are indicator variables for being randomly assigned to the experimental and Section 8 groups respectively, $X$ is a vector of baseline covariates, and $s$ is a set of indicators for randomization site. All of our regressions are weighted to adjust for differences in sampling probabilities (randomization rates into the different treatment groups) across sites and over time. We cluster the standard errors by family (allowing for common error components across siblings) because randomization occurred at the family level.

In our baseline specifications, we include randomization site dummies $s$ (since randomization occurred within sites) but no additional covariates $X$, as the choice of which covariates to include is somewhat arbitrary. In supplemental specifications, we evaluate the sensitivity of our estimates to the inclusion of the 52 baseline covariates shown in Appendix Table 1a. Including these additional covariates affects the point estimates modestly and has little impact on the qualitative conclusions, as expected given that the covariates are balanced across the treatment groups. ${ }^{14}$

The estimates of $\beta_{E}^{I T T}$ and $\beta_{S}^{I T T}$ in (1) identify the causal impact of being offered a voucher to move through MTO. Since not all the families offered vouchers actually took them up, these ITT estimates understate the causal effect of actually moving to a different neighborhood. Following Kling et al. (2007), we estimate the impacts of moving through MTO - the impact of "treatment on the treated" (TOT) - by instrumenting for MTO voucher takeup with the treatment assignment indicators. Formally, we estimate specifications of the form

$$
y_{i}=\alpha_{T}+\beta_{E}^{T O T} \text { TakeExp }_{i}+\beta_{S}^{T O T} \text { TakeS } 8_{i}+\gamma_{T} X_{i}+s_{i} \delta_{T}+\epsilon_{i}^{T}
$$

\footnotetext{
${ }^{14}$ Replicating the covariate balance tests discussed in Section II.C on the estimation sub-samples (e.g., the subset of children for whom we observe earnings at age 24) yields very similar results to those reported in Appendix Table 1a.
} 
where TakeExp and TakeS8 are indicators for taking up the experimental and Section 8 vouchers, respectively. Since TakeExp and TakeS8 are endogenous variables, we instrument for them using the randomly-assigned MTO treatment group indicators (Exp and S8) and estimate (2) using twostage least squares. Under the assumption that MTO voucher offers only affect outcomes through the actual use of the voucher to lease a new residence, $\beta_{E}^{T O T}$ and $\beta_{S}^{T O T}$ can be interpreted as the causal effect of taking up the experimental and Section 8 vouchers and moving to a lower-poverty neighborhood (Angrist et al. 1996). ${ }^{15}$

This section reports estimates of (1) and (2) for various outcomes $y_{i}$. We begin by analyzing the "first-stage" effects of the MTO experiment on the characteristics of the neighborhoods where children grew up. We then turn to impacts on children's outcomes in adulthood, such as earnings and college attendance rates.

\section{A. Voucher Takeup and Neighborhood Characteristics during Childhood}

Table 2 shows the effects of the MTO treatments on voucher takeup rates and poverty rates in the neighborhoods where children were raised. Panel A considers younger children (below 13 at RA), while Panel B considers older children (between ages 13-18 at RA). The estimates in Table 2 include no controls other that randomization site indicators; Appendix Table 2 replicates Table 2 controlling for the baseline covariates listed in Appendix Table 1a and shows that the estimates are similar.

Column 1 of Table 2 reports estimates of the specification in (1) with an indicator for taking up a housing voucher as the dependent variable $y_{i}$. The control group mean is 0 for this outcome because those in the control group were not offered vouchers. Among younger children, $48 \%$ who were assigned to the experimental group took up the voucher they were offered. $66 \%$ of those in the Section 8 group took up the less restrictive voucher that they were offered. The corresponding takeup (or "compliance") rates were slightly lower among families with older children, at $40 \%$ and $55 \%$. Families in the treatment groups who chose to take up the vouchers were also more likely to have been dissatisfied with their current apartment and indicate they would be very likely to be able to find a new apartment (Kling et al. 2007). ${ }^{16}$

\footnotetext{
${ }^{15}$ The ITT estimates rely only on the assumption of random assignment, which is guaranteed by the experimental design. The TOT estimates rely on the additional (untestable) assumption that being offered an MTO voucher had no effect on those who did not take it up.

${ }^{16}$ One might be concerned that when MTO household heads (parents) moved, their children may have stayed behind in the old neighborhood with relatives or friends. In practice, virtually all children moved along with their parents. Approximately $95 \%$ of both younger and older children were still living with their parents one year after RA in the control group. The fraction living with their parents is, if anything, slightly higher in the treatment groups
} 
Families who took up the MTO housing vouchers moved to a variety of different neighborhoods. Appendix Table 1c lists the most common destinations in each of the five sites. For example, many MTO participants in New York were living in the Martin Luther King (MLK) Towers, a housing development in Harlem, at the point of RA. Many families who took up experimental vouchers moved to Wakefield in the North Bronx (near the Westchester County border), about 10 miles north of the MLK Towers. Several families who took up Section 8 vouchers moved to Soundview in the Central Bronx, about 6 miles north of the MLK Towers.

We characterize the neighborhoods to which MTO families moved more systematically by measuring the impacts of the MTO treatments on neighborhood poverty rates. Column 2 reports ITT estimates of impacts on poverty rates in the census tract where the child lived one year after random assignment using the specification in (1). The mean control group family was living in a very distressed census tract one year after RA, with a $50 \%$ poverty rate -2.92 standard deviations (SD) above the national average in the 2000 census national tract-poverty distribution. The MTO treatments led to large reductions in neighborhood poverty for both younger and older children. For younger children, the MTO voucher offers reduced the census-tract poverty rates in the experimental and Section 8 groups by 17 and 15 percentage points (pp). The ITT estimates of reductions in poverty rates are slightly smaller for the older children, at 14 and 12 pp respectively. This is because the voucher takeup rate was slightly lower among families with older children, as shown in Column 1.

Column 3 of Table 2 reports TOT estimates on poverty rates - i.e., the change in poverty rates for families that actually took up the voucher - using the specification in (2). The estimates in this column are essentially the ITT estimates reported in Column 2 divided by the impacts on voucher takeup reported in Column 1, which is the first stage of the 2SLS regression used to estimate (2). ${ }^{17}$ Among younger children, those who moved using the experimental voucher live in neighborhoods with a $36 \mathrm{pp}$ lower poverty rate than those in the control group one year after random assignment. Those who moved with the Section 8 voucher live in neighborhoods with a 23 pp lower poverty rate. The TOT impacts are very similar for older children.

We focus on the effects of the MTO treatments on poverty rates because the experimental vouchers were targeted based on poverty rates and poverty rates are the most common measure of neighborhood quality in the literature on neighborhood effects (Sampson et al. 2002). Prior MTO one year post-RA.

${ }^{17}$ The correspondence is not exact because the sample used in Column 1 differs slightly from that in Column 3 , as post-RA locations are not available for all families. 
research (Kling et al. 2007, Ludwig et al. 2012) has shown that the mean neighborhood poverty rate experienced post-RA provides a reliable linear summary index of neighborhood quality (treatment dosage) for explaining variation in MTO treatment impacts by site and treatment group for both MTO adults and children. However, it is important to note that the MTO treatments changed neighborhood characteristics in several other dimensions as well. The MTO treatment groups lived in neighborhoods with more-educated residents and a lower share of single parent households. MTO treatment group households - especially those in the experimental group - experienced large and persistent increases in neighborhood safety, neighborhood satisfaction, and housing quality relative to control group families (Sanbonmatsu et al. 2011). The MTO treatments also modestly improved post-random assignment school quality, but these improvements were substantially smaller than the improvements in residential neighborhood quality (Fryer and Katz 2013). The MTO treatments had more modest impacts in reducing neighborhood racial segregation (percent minority) than neighborhood economic segregation (Ludwig et al. 2013). The treatment effects we report in this paper should thus be interpreted as the effect of changing a bundle of neighborhood attributes rather than any one feature of neighborhood environments. ${ }^{18}$

The effects of the MTO treatments on neighborhood conditions attenuate over time because many control families moved out of high-poverty public housing projects and some families in the MTO treatment groups moved back to higher-poverty areas. Nevertheless, children in the treatment groups experienced substantially different neighborhood environments on average during their childhood. Column 4 of Table 2 shows that on average from the point of RA until age 18, children in the experimental voucher group lived in areas with approximately 10 pp lower poverty rates than those in the control group. Children in the Section 8 group lived in areas with approximately 8 pp lower poverty rates than those in the control group. The corresponding TOT effects, shown in Column 5, are a 22-25 pp reduction in mean poverty rates for those who took up the experimental voucher and a $12-15$ pp reduction in mean poverty rates for those who took up the Section 8 voucher. Thus, the impacts of MTO-induced moves on the average neighborhood poverty experienced during childhood are about twice as large for the experimental group as for the Section 8 group.

Columns 6 and 7 of Table 2 show ITT and TOT impacts on mean ZIP-code level poverty rates

\footnotetext{
${ }^{18}$ Because all of these neighborhood characteristics are highly correlated with each other, it is difficult to disentangle which attributes of neighborhoods are most predictive of children's success in the MTO data. The quasi-experimental estimates of neighborhood effects reported in Chetty and Hendren (2015) are better suited to studying this question because they are more precise and cover all areas of the United States.
} 
from RA until age 18 (rather than tract-level poverty rates). The impacts on ZIP-code poverty are about half as large as impacts on census-tract poverty because ZIP codes provide a more aggregated measure of neighborhoods than census tracts. These ZIP code measures are a useful benchmark because we can construct analogous ZIP-code level measures (but not tract-level measures) in the tax data to analyze the effects of the MTO treatments on where children live in adulthood.

The key implication of Table 2 for our analysis of exposure effects is that the younger MTO children received a much larger dosage of exposure to improved neighborhood environments than the older MTO children. The TOT effects on post-RA neighborhood poverty rates are similar for the younger and older MTO children. That is, families who took up vouchers moved to similar neighborhoods irrespective of their children's age. However, the younger children got the improvements in neighborhoods starting at younger ages. On average the younger group got 9.8 years of childhood exposure to better neighborhoods up to age 18, because they were 8.2 years old on average at RA. In contrast, those in the older group received only 2.9 years of childhood exposure to better neighborhoods on average, because they were 15.1 years old on average at RA. Our next task is to examine how this exposure to different neighborhood environments affected the long-run economic, educational, and family outcomes of the MTO children.

\section{B. Income in Adulthood}

Table 3 presents estimates of MTO treatment effects on children's income and employment rates in adulthood. As in Table 2, we divide children into two groups: younger children (less than 13 years at RA) and older children (13 to 18 years at RA).

We begin in Column 1 of Table 3 by estimating ITT effects of the MTO treatments on annual W-2 wage earnings between 2008-12. This regression is estimated with one observation per year per child and includes no controls other than randomization site indicators. To avoid measuring earnings when children are still in college, we only include observations in which a child is 24 or older. The standard errors, which are clustered by family, adjust for the repeated observations for each child. ${ }^{19}$

For children below age 13 at RA, mean W-2 earnings in the control group is $\$ 9,549$. Children assigned to the experimental voucher group have annual W-2 earnings that are $\$ 1,340(14 \%)$ higher on average than those in the control group. This estimate is significantly different from 0 with $p<0.05$. The estimated ITT effect of the Section 8 voucher is about half as large as the ITT

\footnotetext{
${ }^{19}$ In our baseline analysis, we do not trim the income measures. Top-coding income at $\$ 100,000$ yields similar estimates of mean treatment effects (Appendix Table 3c, Columns 9 and 10).
} 
effect of the experimental voucher. For children aged 13-18 at RA, the estimated effects of both the experimental and Section 8 vouchers are negative, although they are not statistically significant.

W-2 earnings do not include self-employment income, tips, or earnings from jobs that paid less than $\$ 1,800$ a year, all of which may be important income sources for individuals in the MTO sample. We therefore turn in Column 2 to a broader measure, which we call "individual earnings," that sums W-2 earnings and non-W-2 earnings using data from 1040 tax forms (see Section II.B for further details). For younger children, the ITT effect of the experimental voucher on individual earnings is $\$ 1,624$ - again a $14 \%$ increase relative to the control group mean, which is $\$ 11,270$. The ITT effect of the Section 8 voucher is $\$ 1,109$ and is marginally significant, with $p=0.101$. Once again, the estimated effects on the older children are negative but statistically insignificant.

The larger treatment effects on individual earnings than on W-2 earnings could potentially be driven by endogenous tax filing responses, as non-W-2 earnings are observed only for individuals who file tax returns. ${ }^{20}$ We do find that the experimental voucher treatment increased federal tax filing rates $5.7 \mathrm{pp}$ for younger children (see Table 12 below). However, mean non-W-2 earnings for tax filers in the control group - which is a plausible upper bound for non-filers - is only $\$ 1,721$. Hence, the $5.7 \mathrm{pp}$ filing increase accounts for at most $0.057 \times \$ 1,721=\$ 98$ of the increase in non$\mathrm{W}-2$ earnings for younger children, a small portion of the observed increase in non-W-2 earnings of $\$ 284$ (Appendix Table 3c, Column 2). Hence, the majority of the increase in non-W-2 earnings appears to be driven by real changes in earnings behavior, consistent with the fact that both nonW-2 and W-2 earnings rise by $14 \%$ in the experimental voucher group relative to the control group. We therefore use the broader "individual earnings" measure as our preferred measure of earnings in what follows.

Column 3 of Table 2 replicates the specification in Column 2 including the baseline covariates used in the MTO final impacts evaluation (Sanbonmatsu et al. 2011), listed in Appendix Table 1a. For younger children, the inclusion of these covariates reduces the point estimates by about $20 \%$, approximately one-third to one-half of a standard error of the baseline estimates. ${ }^{21}$ If one includes different subsets of the covariates, one can obtain point estimates that are slightly larger or smaller than the baseline estimates without controls. Importantly, the estimated coefficients generally fluctuate by less than half a standard error when we include different sets of covariates

\footnotetext{
${ }^{20}$ In contrast, W-2 earnings are observed for all individuals, irrespective of whether they file tax returns or not. Hence, the estimate in Column 1 of Table 3 is unaffected by concerns about endogenous reporting.

${ }^{21}$ The changes in the coefficients are due to differences in the characteristics of the treatment and control groups that arise from sampling error. For example, the drop in the experimental treatment effect is driven primarily by the fact that the experimental group has slightly more educated parents (Appendix Table 1a).
} 
and thus are not statistically significant from each other, consistent with random assignment and balance across the treatment arms.

For completeness, we report estimates with the full set of baseline controls for all the other specifications in Table 3 in Appendix Table 3a. The inclusion of controls tends to yield slightly smaller estimated MTO treatment effects relative to the specifications without controls, but the differences are not statistically indistinguishable from each other and do not alter the qualitative conclusions. In particular, the experimental voucher treatment has a large, statistically significant positive effect on earnings of younger children, the Section 8 voucher has smaller positive, marginally significant effects on younger children, and the effects of both treatments on older children are negative and statistically insignificant. ${ }^{22}$ We also consistently find significant treatment effects $(p<0.05)$ for the younger children, both with and without controls, when we pool the Section 8 and experimental groups into a single treatment group (Appendix Table 11, Columns 7-8).

Column 4 of Table 3 reports TOT estimates on individual earnings using the specification in (2). These TOT estimates correspond to the ITT estimates reported in Column 2; we report TOT estimates corresponding to all the other ITT specifications in Table 3 in Appendix Table 3b. The estimates in Column 4 show that children whose families took up the experimental voucher and moved when they were young (below age 13, age 8.2 on average) experience an increase in annual individual earnings in early adulthood of $\$ 3,477$. This is a $31 \%$ increase relative to the control group mean earnings of $\$ 11,270$ and a $34 \%$ increase relative to the "control complier mean" (CCM) of $\$ 10,165$ (Appendix Table 3b, Column 4). ${ }^{23}$

Section 8 moves lead to a TOT increase in individual earnings of $\$ 1,723$ per year $(15 \%$ of the control group mean and $16 \%$ of the Section 8 CCM) for younger children. The Section 8 TOT effect on earnings is roughly half as large as the TOT effect of the experimental voucher. This mirrors the fact that the Section 8 TOT effect of -12 pp on mean tract-level poverty rates from RA until age 18 was also roughly half as large as the experimental voucher TOT effect of -22 pp on poverty rates (Table 2, Column 5). Dividing the TOT effects on earnings by the TOT effects on poverty rates, we infer that growing up in a census tract with a 10 pp lower poverty rate starting

\footnotetext{
${ }^{22}$ For a few outcomes, such as W-2 earnings, the inclusion of controls attenuates the estimates to the point where the estimates are no longer significant with $p<0.05$. For example, Column 1 of Appendix Table 3a shows the ITT impact on W-2 earnings for the younger children in the Experimental group is $\$ 1,016.8$ with a standard error of $\$ 640$ $(p=0.11)$. However, the point estimate of $\$ 1,016.8$ is not statistically distinguishable from the baseline estimate without controls $(\$ 1,339.8)$.

${ }^{23}$ The CCM is an estimate of mean earnings for those in the control group who would have taken up the experimental voucher had they been assigned to the experimental group. The experimental CCM is calculated as mean earnings among compliers (i.e., those who took up the voucher) in the experimental group minus the TOT estimate of the experimental treatment effect, as in Kling et al. (2007).
} 
at a young age (age 8.2 on average) increases earnings in adulthood by about $13-15 \%$.

The TOT estimates for older children are around $-\$ 2,000$ for both treatments but are not statistically distinguishable from 0 . However, we can reject the hypothesis that the effects of the experimental voucher for the older children are the same as those for the younger children with $p=0.02$ (see Section IV.C).

In our baseline specifications, we measure earnings for younger children at an earlier age than for older children. In Column 5, we replicate the specification in Column 2 measuring earnings at age 26 for all children. ${ }^{24}$ This specification yields roughly similar estimates, showing that the age differences are not responsible for the larger effects observed for younger children. In Column 6, we measure earnings using data from the most recent available year (2012) for all children to evaluate whether differences in the calendar year when income is measured affect the results. Again, this specification yields similar estimates, with significant gains for younger children and negative point estimates for the older children.

In Column 7, we estimate the ITT effects of the MTO treatments on employment rates. This specification replicates Column 2 using an indicator for having any W-2 earnings in a calendar year as the dependent variable. MTO treatments have small, statistically insignificant impacts on the extensive margin of employment. The ITT for employment of the young experimental children is $1.8 \mathrm{pp}$, a $3 \%$ increase relative to the control group mean of $61.8 \%$. Thus, MTO's impacts on increasing earnings for younger children appear to be driven primary by higher wage rates and/or greater hours worked in a year rather than by changes in whether or not individuals work at all over the course of a year.

Household Income. In Column 8, we estimate ITT effects on household income. Household income expands upon our individual earnings measure by including spouse's income (for married tax filers), unemployment insurance income, and social security and disability (SSDI) income (see Section II.B for details). For younger children, the experimental ITT effect on household income is $\$ 2,231, \$ 607$ larger than the ITT on individual earnings reported in Column 2. The experimental ITT on household income is significantly different from 0 with $p<0.01$. The Section 8 ITT effect on household income is $\$ 1,452$ and is significantly different from 0 with $p<0.05$. The effects of the treatments on the household income of older children remain negative and statistically insignificant.

We investigate why the MTO treatments have larger effects on household income than on

\footnotetext{
${ }^{24}$ Earnings comparisons at age 26 limit the sample of younger MTO children to those who were 8 to 12 years old at RA with a mean of 10.7 years as compared to a mean age at RA for the older MTO children of 15.1 years.
} 
individual earnings for younger children in Appendix Table 3c, which shows ITT effects on the components of income that contribute to household income. The additional $\$ 607$ impact of the experimental voucher on household income relative to individual earnings is predominantly driven by spousal income, which is $\$ 521$ higher in the experimental group for younger children. ${ }^{25}$ This increase in spousal income can be entirely accounted for by the effect of the experimental voucher treatment on marriage rates (rather than an increase in a given spouse's level of earnings), as we show in Table 5 below. ${ }^{26}$ The experimental voucher treatment also increases unemployment benefits by $\$ 167$ per year, possibly because higher labor force participation rates increase eligibility for unemployment benefits. It reduces social security and disability benefits by $\$ 98$ per year, consistent with increases in labor supply and earnings.

Earnings Trajectories. Earnings rise steeply in the mid-late 20's as children complete education and enter the labor force (Haider and Solon 2006). Thus, one might expect the treatment effects of MTO to grow as we measure children's earnings at later ages. Figure 1 plots estimates of the ITT effect of the experimental voucher treatment on individual earnings, varying the age at which earnings are measured from 20 to 28 . These effects are estimated using specifications analogous to that in Column 5 of Table 3. The MTO experimental impact does in fact rise sharply with age of income measurement for the younger children. The null hypothesis that the experimental impacts do not vary with the age at which income is measured is rejected with $p<0.01 .^{27}$ In contrast, the treatment effects fall significantly with the age at which income is measured for the older children, implying that they not only have lower earnings but also have less earnings growth in their early career relative to those in the control group. A similar pattern of rising treatment effects with age of income measurement for younger children and declining effects with age of income measurement for older children is observed for the Section 8 group, although the estimates are noisier and attenuated (Appendix Figure 1).

\footnotetext{
${ }^{25}$ Part of the observed effect on spousal income could be driven by endogenous tax filing, as spousal income is only observed for individuals who file tax returns. However, calculations analogous to those above imply that at most $0.057 \times \$ 802.1=\$ 46$ of the $\$ 521$ experimental impact on spousal income can be accounted for by a filing response, assuming that the mean spousal income of married non-filers is no larger than the mean spousal income of $\$ 802$ for tax filers in the control group.

${ }^{26}$ For younger children, the experimental voucher increases the fraction married by 1.9 percentage points (Table 5 , Column 1). The mean individual income of spouses in the control group for married individuals is $\$ 25,568$. If the marginal individuals marry individuals with average income, we would predict an increase in household income of $0.019 \times \$ 25,568=\$ 486$, similar to the observed increase of $\$ 521$.

${ }^{27}$ To estimate this p-value, we regress earnings on the treatment group indicators linearly interacted with the age of income measurement, controlling for age of income measurement fixed effects interacted with site fixed effects. The p-value is based on the coefficient for the interaction of age at income measurement with the experimental treatment indicator. We estimate this regression in a dataset with one observation per age of income measurement per child and cluster standard errors by family.
} 
Column 9 quantifies the effects of the MTO treatment on earnings growth over a five-year period. The dependent variable in this specification is the difference in individual earnings in year $t$ minus year $t-5$; as in the other specifications in Table 3 , we restrict the sample to observations in which the individual is 24 or older in year $t$. In the control group, the mean level of income growth over five years is $\$ 4,002$ for younger children. The ITT effect of the experimental voucher on five-year income growth is $\$ 1,309$ (a 33\% increase), while the ITT effect of the Section 8 voucher is $\$ 800$ (a $20 \%$ increase). These results suggest that our baseline estimates, which measure income starting at age 24, likely understate the total lifetime earnings impacts of the MTO experimental voucher on children who were young at the point of the move.

Summary. In sum, our analysis of children's income in adulthood yields three robust findings. First, the MTO experimental voucher treatment substantially increased the earnings of children who were young (below age 13) at the point of the move, with a TOT impact on individual earnings of approximately 35\%. Second, the Section 8 voucher increased individual earnings of young children about half as much as the experimental voucher, consistent with the fact that it reduced neighborhood poverty rates half as much. Third, the impacts of both treatments on older children are somewhat negative (although not statistically significant).

These three facts are consistent with a simple model that combines positive exposure effects from moving to lower-poverty neighborhoods with a negative disruption cost of moving to such a neighborhood. Such a model would generate our empirical results because the exposure effects outweigh the disruption cost for children who move when young, but not for children who move at

older ages. Note that because families in both the control and treatment groups moved frequently, the disruption cost must reflect the cost of moving to a different type of neighborhood (as induced by the MTO voucher treatments, especially the experimental voucher) rather than a fixed cost of moving houses within the same neighborhood or a similar nearby neighborhood (as typically occurred in the control group).

\section{C. College Attendance and Quality}

In Table 4, we examine MTO impacts on college attendance rates and college quality. Table 4 and the subsequent tables are structured in the same way as Table 3: Panel A reports estimates for younger children (below age 13 at RA), while Panel B reports estimates for older children (ages 13-18 at RA). We report ITT estimates using the specification in (1), with no additional controls other than randomization site indicators. For this and all subsequent outcomes, the corresponding 
Appendix Tables with the same number provide ITT estimates with the full set of controls and TOT estimates corresponding to the specifications in the main table.

We begin in Column 1 by analyzing treatment effects on college attendance rates between the ages of 18-20. College attendance is measured using 1098-T forms as discussed in Section II.B. This regression includes one observation per child at age 18, 19, and 20; the standard errors, which are clustered by family, adjust for the repeated observations for each child. For younger children (Panel A), the mean college attendance rate between the ages of 18-20 in the control group is 16.5\%. Children assigned to the experimental voucher group are 2.5 percentage points (pp) more likely to attend college between the ages of 18-20. The corresponding TOT effect for children whose families took up the experimental voucher is a $5.2 \mathrm{pp}$ increase in college attendance rates, a $32 \%$ increase relative to the control group mean and a $34 \%$ increase relative to the control complier mean (Appendix Table 4b, Column 1).

The Section 8 voucher also has a positive ITT effect of $1 \mathrm{pp}$, but it is not statistically significant. In contrast, for the older children, both MTO treatments have large and statistically significant negative effects. The experimental ITT is $-4.3 \mathrm{pp}$, while the Section 8 ITT is $-3 \mathrm{pp}$. These findings mirror the patterns observed for earnings, although the negative impacts on college attendance for older children are larger than on earnings.

Columns 2-5 present estimates of impacts on college attendance rates by age, from age 18 to 21. The MTO experimental treatment increased college going for younger children in the period immediately following high school, but had little effect beyond age 20. For younger children, the experimental ITT effects are approximately 2.5 pp from ages 18-20, but fall to 0.4 pp at age 21 . The Section 8 ITT estimates exhibit a similar pattern, with positive effects of around $1 \mathrm{pp}$ from ages 18-20 and a small negative estimated effect at age $21 .{ }^{28}$ Meanwhile, the ITT effects on older children are consistently negative at all ages for both treatments.

Next, we investigate whether the MTO treatments also changed the types of colleges that students attended. To do so, we use a simple earnings-based index of college "quality," defined as the mean earnings at age 31 of all U.S. residents enrolled in a given college at age 20 (see Section II.D for details). For those not enrolled in any college at age 20, the index equals the mean earnings at age 31 of all U.S. residents not enrolled in college at age 20. We define college quality at age $a$

\footnotetext{
${ }^{28}$ We find small, statistically insignificant estimates on college attendance at older ages (up to age 25), similar to those at age 21. Thus, the positive MTO experimental treatment effect on college attendance for younger children from ages 18 to 20 does not appear to be driven purely by retiming of college attendance. However, our sample size declines when looking at older ages, so we cannot rule out some degree of retiming.
} 
for each child in the MTO sample based on the college in which the child was enrolled at age $a$.

Column 6 of Table 4 replicates the specification in Column 1 using college quality, measured between the ages of 18-20, as the dependent variable. For younger children, the experimental voucher increases mean college quality between the ages of $18-20$ by $\$ 687$ - that is, expected earnings at age 31 are $\$ 687$ higher for the experimental voucher group relative to the control group given the colleges that children attend. ${ }^{29}$ This estimate is significantly different from 0 with $p<0.01$. This increase of $\$ 687$ reflects a combination of extensive-margin responses (higher college attendance rates) and intensive-margin responses (attending a better college conditional on attending). We derive an upper bound on the extensive margin effect by assuming that those who are induced to attend college attend a college of average quality, which is a plausible upper bound for the quality of the college attended by the marginal college student. The mean college quality conditional on attending college for younger children in the control group is $\$ 31,409$, while the quality for all those who do not attend college is $\$ 18,867$. This suggests that at most $(31,409-18,867) \times 0.025=\$ 314$ of the $\$ 687$ impact is due to the extensive margin response. Hence, the MTO experimental voucher appears to improve not just college attendance rates but also the quality of colleges that students attend. $^{30}$

The Section 8 voucher also has a large positive effect on college quality for younger children that is significant with $p<0.05$. The estimated effects on college quality for older children are negative and substantial in magnitude. The difference between the positive MTO experimental impact on college quality for younger children and the large negative effect for older children is highly statistically significant $(p=0.0006)$, as shown in Table 11 below. The treatment impacts on college quality by age, shown in Column 7-10 of Table 4, are similar to those for college attendance rates. The effects are larger between ages 18-20 and become smaller at age 21, suggesting that most of the marginal children induced to attend college do so immediately after high school.

Overall, the positive MTO treatment impacts on college outcomes for younger children and negative impacts for older children closely mirror the impacts on earnings in Table 3 . These results further support the view that moving to lower-poverty areas improve outcomes when one moves as

\footnotetext{
${ }^{29}$ The increase in actual individual earnings of $\$ 1,624$ (Table 3, Column 2) is larger than the $\$ 686$ impact on projected earnings at age 31 based on college attendance. This indicates that the MTO treatment effects on earnings go beyond what one would expect just from the labor market returns to increased college attainment. This is to be expected given the fact that even in the experimental voucher group, more than $80 \%$ of children do not attend college.

${ }^{30}$ The point estimates of the treatment effects on college attendance and quality are slightly smaller when we include controls (Appendix Table 4a). With controls, we estimate that the experimental treatment increased college attendance rates by $1.7 \mathrm{pp}$ from ages 18-20 (as compared to 2.5 pp without controls) and increased college quality by $\$ 536.2$ (as compared to $\$ 687$ without controls).
} 
a young child but not at older ages.

\section{D. Marriage and Fertility}

We next examine MTO treatment impacts on children's marriage and fertility outcomes in Table 5. Columns 1-3 present ITT effects of the MTO treatments on marriage rates, based on whether the individual files a tax return jointly with a spouse. We include one observation per child per year from 2008-12, limiting the sample to observations where children are 24 or older. In Column 1, we pool males and females. For younger children, the experimental treatment increased the fraction married in early adulthood by $1.9 \mathrm{pp}$, while the Section 8 treatment increases the fraction married by $2.8 \mathrm{pp}$. These changes are quite large relative to the fraction married in the control group, which is only $3.4 \%{ }^{31}$ The MTO treatment effects for the younger children are substantially larger for females, for whom the marriage rate nearly doubles, than for males, for whom the effects are small and not statistically significant (Columns 2 and 3 ). There are no detectable treatment effects on marriage for the older children.

In Columns 4-7, we study the fertility behavior of the female children in the MTO sample, which we infer from applications from social security numbers for children (see Section II.B). These specifications include one observation for each female child because the outcomes are time-invariant. Columns 4 and 5 show that the MTO treatments do not have statistically significant effects on overall birth rates or teenage birth rates for either the younger or older female children. However, the experimental voucher treatment does change the family circumstances of births substantially, in particular the presence of the father at the birth. We measure whether the father is present at the child's birth by whether his name and SSN are listed on the child's social security number application (which is typically submitted when the child is born). In Column 6, we restrict the sample to females who have a birth and use an indicator for having a father listed on the firstborn child's SSN application as the dependent variable. We find that the experimental voucher treatment increases the share of births in which the father is present by $6.8 \mathrm{pp}$ for younger children. This leads to a significant decline of $4.8 \mathrm{pp}$ in the fraction of females who have a birth with no

\footnotetext{
${ }^{31}$ Because we only observe marital status for those who file tax returns, part of the observed response could be due to the increase in tax filing rates that we document in Table 8 below, but this bias is likely to be very small. The experimental voucher treatment increased federal tax filing rates 5.7 percentage points for younger children. If the marginal filer had the same probability of being married as individuals in the control group (3.4\%), then endogenous filing accounts for at most $0.057 \times 0.034=0.2$ percentage points of the $1.9 \mathrm{pp}$ increase in marriage rates that we observe. The more plausible explanation is that the increase in marriage rates induced by the treatments led to the increase in tax filing rates documented in Table 8, as virtually all married working-age couples file tax returns (Cilke 1998).
} 
father present, as shown in Column 7. ${ }^{32}$ The TOT effect corresponding to this estimate is -10.0 pp, implying that girls whose families moved using the experimental voucher when they were young are $26 \%$ less likely to become single mothers (Appendix Table 5b, Column 7).

As with other outcomes, the Section 8 voucher has smaller effects on the father's presence at birth than the experimental voucher. And the older female children in the MTO experimental group are much less likely to have a father listed on the birth certificate when they have births relative to the control group. Hence, marriage and fertility behavior exhibit what is now a familiar pattern of effects, with significant increases in marriage rates and reductions in single parenthood for children who moved to lower-poverty neighborhoods when young, but no change or opposite-signed effects for children who made the same moves at an older age.

\section{E. Neighborhood Characteristics in Adulthood}

The MTO vouchers substantially reduced the degree of neighborhood poverty experienced by MTO children during their childhood (Table 2). Do these childhood improvements in neighborhood environments persist into adulthood, providing better neighborhoods for the next generation (the children of MTO children)? In Table 6, we answer this question using information drawn from tax records on the ZIP codes where MTO children live in adulthood. ${ }^{33}$

Among younger children (Panel A), both the experimental and Section 8 children live in better neighborhoods in adulthood relative to the control group children on a wide range of measures. In Column 1, we measure ITT effects on ZIP-code level poverty rates, with one observation per child per year from 2008-12 (only including observations where children are age 24 or older). The experimental ITT estimate is -1.6 percentage points, about one-third as large as the treatment effect on the average poverty rate in the ZIP code where the individual lived in childhood (Table 2, Column 6). Columns 2-4 examine impacts on other neighborhood characteristics using the same specification as in Column 1. They show that children assigned to the experimental group also live in areas with higher mean income, less racial segregation (lower share of black residents), and a lower share of female-headed households. All of these treatment effects are significantly different from 0 with $p<0.01$. In contrast, the MTO treatments on adult neighborhood quality are smaller and typically not statistically significant for the older MTO children, as seen in Panel B of Table 6.

\footnotetext{
${ }^{32}$ Unlike Column 6, where we focus on the endogenously selected sample of girls who have births, the specification in Column 7 is estimated on the full sample of all young girls in the MTO data, using an indicator for having a birth with no father present as the dependent variable.

${ }^{33} \mathrm{We}$ are unable to obtain ZIP codes for $20.4 \%$ of the children because we do not have tax returns or W-2 forms for them. The rate of missing ZIP code data does not vary across the treatment and control groups.
} 
Together, Tables 5 and 6 indicate that the improvements in neighborhood environments for the younger MTO children lead to better neighborhood and family environments for the next generation, the grandchildren of the original MTO parents. Relative to the grandchildren in the control group, the grandchildren in the experimental group are more likely to be raised in lowerpoverty neighborhoods by two parents who have a higher level of household income and are more likely to have attended college. In short, subsidized housing vouchers produce durable benefits that persist into subsequent generations for children who moved to lower-poverty neighborhoods at young ages.

\section{F. Heterogeneity of Treatment Effects}

Prior work has found that the MTO treatments had more positive effects on female children than on male children in terms of mental health, physical health, risky behaviors, and educational outcomes during adolescence (Kling et al. 2007, Sanbonmatsu et al. 2011, Ludwig et al. 2013). In Table 7, we re-examine the heterogeneity of MTO treatment effects by child gender, but look at outcomes in adulthood.

In contrast to the substantially more favorable MTO treatment impacts for female than male children when they were teenagers, we find roughly similar impacts by gender when observing the MTO children as adults. Table 7 shows ITT estimates by gender for individual earnings, college quality, and ZIP-code level poverty rates in adulthood. Columns 1 and 2 show experimental ITT estimates by gender, while columns 3 and 4 show Section 8 ITT estimates by gender. We show the mean value of the dependent variable for the control group in the relevant estimation sample in square brackets to facilitate interpretation of magnitudes. ${ }^{34}$

For younger children (Panel A), the experimental ITT effect on individual earnings in adulthood (age 24 and above) for boys is $\$ 1,679$, an estimate that is significantly different from 0 with $p=$ 0.085. The comparable estimate for girls is a very similar $\$ 1,439(p=0.104)$. The Section 8 ITT effects are slightly smaller for both boys and girls, at approximately $\$ 1,100$. The experimental and Section 8 treatments also improve college quality (at ages 18-20) and neighborhood quality (at age 24 and above) for both boys and girls. Conversely, we find adverse long-term treatment effects for both boys and girls who were above age 13 at RA (Panel B).

The positive effects of the MTO treatments on adult outcomes for the younger boys point

\footnotetext{
${ }^{34} \mathrm{An}$ interesting feature of the data presented in Table 7 is that female MTO children have substantially higher adult earnings on average than male MTO children for both the younger and older groups - a striking reversal of the usual gender earnings gap favoring men. The difference arises from much higher employment rates for female than male MTO children, likely reflecting changes in labor market outcomes by gender in U.S. disadvantaged populations.
} 
to an intriguing dynamic pattern of neighborhood effects when combined with results from prior work. Previous work found positive initial impacts of MTO moves on young boys (at 1 to 3.5 years after random assignment), who had a significantly lower incidence of problem behaviors (Katz et al. 2001). But boys who moved to lower-poverty areas at young ages in the experimental group were doing moderately worse than those in the control group as teens in terms of risky behaviors and education (Sanbonmatsu et al. 2011). This pattern has now turned around to a strongly positive one in terms of labor market and educational outcomes in early adulthood. One speculative explanation for these patterns is that teenage misdeeds may have smaller adverse consequences and second chances may be more available for youth in middle-class neighborhoods than in more-distressed neighborhoods. The positive MTO experimental impacts in adulthood for the younger female youth are less surprising, as previous work found significant positive impacts for the younger females in the experimental group both as teens in the interim evaluation and continued modestly positive effects as older teens in the final evaluation.

We also explored heterogeneity of the MTO treatment effects by race and ethnicity (Appendix Table 7a) and across the five randomization sites (Appendix Table 7b). The MTO experimental voucher increased individual earnings in adulthood and college quality for children below age at 13 at RA in every racial group (Black, Hispanic, and White) and in all five sites (Baltimore, Boston, Chicago, New York, and Los Angeles). ${ }^{35}$ The treatment effects on earnings and college quality are larger in the sites where the treatments led to larger reductions in neighborhood poverty rates. In contrast, the estimated effects for the older children (ages 13-18 at RA) are negative in virtually all the subgroups for each of the outcomes.

In summary, the main lesson of the heterogeneity analysis is that the long-term benefits of childhood exposure to lower-poverty neighborhoods are highly robust across genders, racial groups, and geographic locations.

\section{G. Age Pattern of Exposure Effects}

Thus far, we have split the MTO children into "younger" vs. "older" children using a cutoff of age 13 at RA. In this section, we assess the sensitivity of our results to the choice of this cutoff and evaluate how the effects of the MTO treatments vary with a child's age at move more generally.

As a first step, we replicate the baseline specifications in Tables 3-6, varying the cutoff used to split the sample. We find very similar estimates if we define "young" children as those below age

\footnotetext{
${ }^{35}$ Note that the subgroup-specific estimates are naturally much less precise because of the smaller sample sizes, and hence are not statistically significant in many cases.
} 
12 at RA or those below age 14 at RA (Appendix Table 11). In particular, the estimated effects of the experimental voucher on individual earnings, college quality, neighborhood poverty share, and fraction married are all significantly different from 0 at conventional significance levels, with point estimates similar to the baseline estimates. The Section 8 voucher also has positive effects in all cases, most of which are smaller than the experimental voucher impacts but still significantly different from 0 .

Linear Exposure Models. A different way to assess how the MTO treatment effects vary with children's age at move is to estimate models that interact age at move linearly with the treatment indicators instead of splitting children into two groups. Pooling all children, we regress outcomes $(y)$ on the MTO treatment group indicators (Exp and S8) and interactions of these treatment group indicators with the age at random assignment (AgeRA):

$$
y_{i}=\alpha+\beta_{E 0} \operatorname{Exp}_{i}+\beta_{S 0} S 8_{i}+\beta_{E A} \operatorname{Exp}_{i} \cdot \operatorname{AgeR}_{i}+\beta_{S A} S 8 \cdot \operatorname{AgeR}_{i}+s_{i} \gamma+\epsilon_{i},
$$

controlling for randomization site indicators $\left(s_{i}\right)$. The coefficients on the main effects for treatment group assignment $\left(\beta_{E 0}\right.$ and $\left.\beta_{S 0}\right)$ can be interpreted as the ITT impact of being offered a voucher to move to a better neighborhood at birth. The coefficients on the interaction terms with age at RA $\left(\beta_{E A}\right.$ and $\left.\beta_{S A}\right)$ can be interpreted as the average reduction in the ITT effects per year of reduced exposure to the new area. Note that we observe college outcomes only for children who were 4 or older at RA and earnings only for those who were 6 or older at RA. Hence, the estimates of impacts at birth rely on out-of-sample extrapolations based on the linear functional form.

Table 8 presents estimates of (3) for individual earnings (Column 1), household income (Columns 2 and 3), college quality (Column 4), marriage rates (Column 5) and the ZIP-code poverty share in adulthood (Column 6). Column 7 reports effects on total taxes paid - an outcome that we return to in Section $\mathrm{V}$ below. Appendix Table 8 a replicates the ITT estimates in Table 8 including the baseline controls. Appendix Table 8b presents TOT estimates, estimated using a 2SLS specification where we instrument for voucher takeup (and the interactions) using treatment assignment indicators.

The estimates in Table 8 indicate large and statistically significant beneficial impacts of the experimental treatment for all the outcomes, with the gains declining rapidly with age at RA. In other words, the benefits of being offered an MTO experimental voucher increase with potential years of childhood exposure to better neighborhoods. For example, the experimental ITT estimates for individual earnings in Column 1 imply an increase in annual adult earnings of $\beta_{E 0}=\$ 4,823$ 
for those offered an experimental voucher at birth. The estimated effect on earnings falls by $\beta_{E A}=-\$ 364$ per year, so the predicted effect reaches zero for children who are 13.25 years at RA and becomes negative for children who move as teenagers. This pattern is consistent with positive childhood exposure effects on earnings coupled with a disruption cost of moving to a very different social environment (e.g., moving from a high-poverty to a low-poverty neighborhood or moving a substantial geographic distance) that outweighs the exposure benefits if children move after age 13.

The Section 8 voucher has a similar pattern of effects with attenuated magnitudes. The TOT estimates of both the treatment effects at birth and the interactions with age at RA are about half as large for the Section 8 group as for the experimental group for most outcomes (Appendix Table $8 \mathrm{~b}$ ). This mirrors the fact that the Section 8 treatment reduced neighborhood poverty rates in childhood half as much as the experimental treatment (Table 2).

Note that one cannot necessarily interpret the interaction effects $\left(\beta_{E A}\right.$ and $\left.\beta_{S A}\right)$ as the causal effects of an additional year of childhood exposure to lower-poverty areas. The differences in estimated effects by age at RA could be driven by heterogeneity in the types of families who sign up for MTO or comply with MTO treatments by age of children. Conceptually, our ability to identify causal exposure effects is limited by the fact that the MTO experiment only randomized voucher offers; it did not randomize the age at which children moved, which could be correlated with other unobservable factors. Nevertheless, the linear interaction models in Table 8 do provide further evidence supporting our main result that the MTO treatments had significant positive effects on children who were young at the point of random assignment.

Non-Parametric Estimates by Age at Move. In Figure 2, we evaluate how the effects of the MTO treatments vary with children's ages at move using a non-parametric approach. These figures plot ITT estimates of being assigned to the experimental voucher group by a child's age at RA, grouping children into two-year age bins. Given the small sample sizes in each age group, we focus on the two outcomes for which we have the greatest precision: household income and college quality. In Panel A, we regress household income on the treatment group indicators using a specification analogous to Column 8 of Table 3. In Panel B, we regress college quality on these indicators using the specification in Column 6 of Table 4. In each panel, we estimate separate regressions using the data within each age bin and plot the experimental ITT estimates along with a $95 \%$ confidence interval (shown by the dashed lines).

Panel A shows that the experimental voucher increased household income in adulthood by approximately $\$ 2,000$ for children who were offered the experimental voucher at or before age 10 . 
This effect declines steadily with age at RA and becomes negative around age 13. Similarly, Panel B shows significant positive effects on college quality for children who move at young ages, which then become negative for children moving in adolescence. ${ }^{36}$ In both cases, we cannot reject the hypothesis that the relationship between age at move and the treatment effects is linear, although the age-specific estimates are not very precise because of the small sample sizes. There is little evidence of a "critical age" below which children must move to benefit from a better neighborhood. The roughly linear pattern of exposure effects in the MTO data matches the quasi-experimental findings of Chetty and Hendren (2015), who document a much more precisely estimated pattern of linear childhood exposure effects using a sample of five million families that moved across counties. ${ }^{37}$

\section{Reconciling the Findings with Previous MTO Research}

In this section, we reconcile our new findings with prior research on MTO's impacts on the economic outcomes of adults and children. We first show that, consistent with prior work, exposure to better neighborhoods does not appear to improve adults' outcomes. We then explain why our findings of exposure effects for children were not detected in prior research. Finally, we evaluate whether our findings on the heterogeneous effects of the MTO treatments by age at move may be an artifact of multiple hypothesis testing given that prior research on MTO has tested for heterogeneity in several other dimensions as well.

\section{A. MTO Impacts on Adults' Economic Outcomes}

Previous research has found that the MTO treatments had little impact on adults' income and employment rates (Kling et al. 2007, Sanbonmatsu et al. 2011). These prior studies used data from state unemployment insurance (UI) records through 2008 and survey data collected in 2008-9. In Table 9, we re-examine the effects of MTO on adults' economic outcomes using the tax data. The tax data allow us to follow the MTO adults through 2012 and track individuals who move across state lines, who are missing from the state UI data of the original randomization sites.

\footnotetext{
${ }^{36}$ Appendix Figure 2 plots the corresponding ITT estimates for the Section 8 voucher by age bin. We find qualitatively similar declining patterns for the impacts of the Section 8 voucher, although the estimates are attenuated in magnitude, consistent with our earlier findings.

${ }^{37}$ Chetty and Hendren's quasi-experimental estimates of exposure effects are identified on a sample consisting entirely of families who moved across counties, comparing the outcomes of children who move to different areas at different ages. Since everyone in Chetty and Hendren's sample moves a significant distance, their estimates net out any fixed disruption costs of moving across social environments. In contrast, here we compare families who move to a low-poverty area (who face disruption costs of relocating to a very different area) to families who largely remain in higher-poverty areas (who do not pay such disruption costs). Our estimates therefore include the disruption cost of moving to a different environment. This difference may explain why we find negative effects for children who move at older ages in the MTO data, whereas Chetty and Hendren estimate positive exposure effects at all ages.
} 
Table 9 presents ITT estimates of MTO treatment impacts on the individual earnings, household income, and employment rates of MTO adults. ${ }^{38}$ The specifications in Columns 1-2 and 4-5 use one observation per year from 2008-12 for each of the 4,215 adults in the linked MTO-Tax data, while Column 3 uses data only from 2012.

Consistent with prior work, we find no effects of MTO treatments on any of the adults' economic outcomes. The point estimates tend to be slightly negative for the experimental group and slightly positive for the Section 8 group, but all of the estimates are small and are not significantly different from 0. For example, the experimental voucher ITT on mean individual earnings from 2008-2012 is $-\$ 354$ (2.4\% of the control group mean), with a standard error of $\$ 622$. The corresponding TOT estimate on individual earnings is $-\$ 734,5.1 \%$ of the control group mean and $4.7 \%$ of the control complier mean (Appendix Table 9b, Column 1). The upper bound of the $95 \%$ confidence interval for the TOT estimate is $\$ 1,795,12 \%$ of the control group mean. This is far below the $31 \%$ increase in individual earnings for young children.

Exposure Effect Estimates. Clampet-Lundquist and Massey (2008) show that the number of years an adult spends in a low-poverty area is correlated with their earnings and other economic outcomes. Their findings raise the possibility of time of exposure impacts for adults similar to what we documented above for children. ${ }^{39}$ We test for such exposure effects in Figure 3 by estimating the effects of the MTO treatments on individual earnings by the number of years since random assignment. We group the data into two-year bins based on the number of years elapsed since RA and estimate ITT regression specifications using the data within each bin.

We first verify that the total time of exposure to low-poverty environments increases with time since RA for adults who were assigned to the experimental voucher group relative to the control group. Prior studies have observed that some MTO participants in the experimental group moved back to higher-poverty areas over time, while some families in the control group moved to lowerpoverty areas over time (e.g., Clampet-Lundquist and Massey 2008). We assess the impacts of such subsequent moves in Panel A of Figure 3. We regress the cumulative number of years that the adult lived in a census tract with a poverty rate below $20 \%$ since RA on the MTO treatment indicators. The figure plots the ITT effects of the experimental voucher on cumulative exposure to low-poverty areas vs. the number of years since RA. It is clear that the total amount of exposure

\footnotetext{
${ }^{38}$ As in prior work, the "adult" whom we follow in the MTO data and link to the tax data is the household head at the point of RA, with preference given to the mother or other adult female guardian if present.

${ }^{39}$ Clampet-Lundquist and Massey's analysis does not directly identify causal exposure effects because it exploits cross-sectional variation across individuals (which may be confounded by omitted variables) rather than the experimental variation generated by the randomly assigned treatments.
} 
to low-poverty areas rises substantially over time in the experimental group relative to the control group despite the fact that some families moved again in subsequent years.

Panel B of Figure 3 shows ITT effects of the experimental voucher on adults' individual earnings by years since RA, estimated using regressions analogous to that in Column 1 of Table 9. The estimated impact on adult earnings is consistently close to zero when measuring earnings in the 1-10 years after RA, with no evidence of the increasing pattern that one would expect if time of exposure in adulthood has a causal effect. The results are very similar for the Section 8 treatment (Appendix Figure 3). We conclude that exposure to improved neighborhood environments - at least for the range of moves generated by the MTO experiment - has little impact on adults' economic outcomes. ${ }^{40}$

Together with our findings in Section III, the results in Figure 3 show that it is the amount of exposure to better neighborhoods during childhood (rather than total lifetime exposure) that matters for long-term economic success. Moreover, these findings imply that the MTO treatment effects on children's outcomes do not arise from improvements in family income. Instead, they are likely to be driven by direct effects of neighborhood environments on the children or to be mediated by parental health and stress, which were improved by the MTO treatments (Ludwig et al. 2011, Ludwig et al. 2012).

\section{B. MTO Impacts on Children's Economic Outcomes}

The MTO final impacts evaluation (Sanbonmatsu et al. 2011) found no treatment effects on children's economic outcomes using data from state UI records in 2008 and survey data from 2008-9. In Table 10, we reconcile our findings with these earlier results. As a reference, we begin in Column 1 of Table 10 by replicating the specification in Column 2 of Table 3, which shows that the MTO treatments had substantial positive effects on the individual earnings of younger children (those under 13 at RA). The remaining columns present variants of this specification that highlight three reasons why our findings differ from prior results.

First, if we had followed earlier MTO work in pooling younger and older MTO children, we also would have found no mean effects on earnings in adulthood, as shown in Column 2 of Table 10.

\footnotetext{
${ }^{40}$ Quigley and Raphael (2008) argue that the moves induced by MTO did not change neighborhood environments by enough to offset the spatial disadvantages faced by low-skilled minority female household heads. Although larger neighborhood changes could have different effects, we note that MTO moves did change neighborhood environments quite substantially. TOT estimates show that adults who moved using an experimental voucher lived in lower-poverty areas for approximately 5 more years on average (as implied by Figure 3) and experienced an 18 percentage point reduction in neighborhood poverty (1.5 standard deviations in the U.S. census tract poverty distribution) up to the point of the MTO final impacts evaluation, 10-15 years after RA (Ludwig et al. 2013).
} 
Such pooled estimates hide the positive MTO effects on younger children and negative effects on older children.

Second, we measure the earnings of children who were 24 years or older in 2012 in our data. If instead we had conducted our analysis in 2008 - the time of the MTO final impacts evaluation we would have found positive but very imprecisely estimated effects on earnings for children who were below age 13 at RA, as shown in Column 3. This is because one would have had only 552 observations on earnings for children who were less than 13 at RA in 2008. If one had attempted to expand the sample by including all children in the analysis, as in Column 4, one would have again obtained a point estimate close to 0 .

Finally, partly because of these data limitations, prior analyses measured earnings at very early ages, between the ages of 16-21. Columns 5 and 6 show that we find no effects on earnings at these early ages in our data even when we focus on children who were less than 13 at RA. The earnings impacts of MTO emerge only after children complete education and begin to enter the labor market, as shown in Figure 1.

In sum, there is no inconsistency between our empirical findings and prior MTO evaluations. The childhood exposure effects we document here were not apparent in prior studies because they did not have adequate long-term data to observe the emergence of MTO's impacts on earnings and other outcomes in adulthood for children who moved at young ages. ${ }^{41}$

\section{C. Multiple Comparisons}

Previous research has searched for impacts of MTO in a wide range of subgroups: across the five treatment sites, for different races, and for each gender. Given the extensive subgroup analysis that has been conducted in the MTO data, one may be concerned that our findings of significant effects in certain age subgroups are an artifact of multiple hypothesis testing. Of course, examining many subgroups can generate p-values that appear to be individually statistically significant purely by chance.

To address this concern, we implement a set of parametric $\mathrm{F}$ tests for the null hypothesis that there are no subgroup-specific treatment effects in the pooled data. These F tests adjust for the

\footnotetext{
${ }^{41}$ The MTO final impacts evaluation (Sanbonmatsu et al. 2011) found no significant effects of the MTO treatments on educational outcomes or risky behaviors for children who moved at young ages when they were observed as adolescents. The positive treatment effects for younger children show up only when we look at their outcomes in adulthood. Hence, our findings differ from the conclusions of prior research on MTO both because we focus children who moved at young ages and because we analyze long-term impacts rather than intermediate outcomes. We discuss our findings in the context of prior research on MTO in greater detail in the conclusion.
} 
over-rejection rate when analyzing any one subgroup separately by using a single joint test across all subgroups in the pooled sample. In Panel A of Table 11, we test the hypothesis that there is no treatment effect for either young children (under 13) or older children (13-18). We regress a subset of the outcomes analyzed in Tables 3-6 above on the MTO treatment indicators (Exp and S8) interacted with an indicator for being below age 13 at RA (Below13), including site dummies as controls. We then test the hypothesis that the Exp and Exp-Below13 interaction effect are both 0 (row 1), the S8 and S8-Below13 interaction effect are both 0 (row 2), and both sets of treatment effect estimates are 0 (row 3 ).

We reject the null of 0 treatment effects in both age subgroups with $p<0.05$ in most cases, especially for the experimental voucher group. For example, we reject the null hypothesis that the experimental voucher has no effect on individual earnings in either age subgroup with $p=0.020$. For college quality, we reject the hypothesis that the experimental voucher has no effect in either subgroup with $p=0.0006$ and reject the hypothesis that the experimental and Section 8 treatments have zero effects in all subgroups with $p=0.0020$.

The tests in Panel A consider the age-specific subgroups we focus on in this study, but not the other subgroups that have been analyzed in the broader literature. In Panel B, we test the hypothesis that there is no treatment effect in any of the primary subgroups that have been studied to date in the MTO data: randomization sites, racial groups, gender, and age at RA. As in Panel A, we regress outcomes on the MTO treatment indicators interacted with all of these subgroup indicators. We then test the hypothesis that the experimental indicator and all of its subgroup interactions are 0 (row 1), the Section 8 indicator and all of its interactions are 0 (row 2), and both sets of treatment effects are 0 (row 3 ).

The tests in Panel B have less power than those in Panel A because they consider many more subgroups. Nevertheless, when we focus on the outcomes for which we have the most precise estimates in our baseline analysis - e.g., the college outcomes and household income - we reject the null of 0 treatment effects in all subgroups with $p<0.05$ both for the experimental vs. control comparison in row 1 and the pooled comparison in row 3.

As an alternative to the parametric $\mathrm{F}$ test, we implement a nonparametric permutation test for subgroup heterogeneity using the p-values from our OLS regressions as critical values, as in Ding et al. (2015). We generate 5,000 "placebo" samples in which we randomly re-assign treatment status to families within randomization sites. In each placebo sample, we estimate the experimental and Section 8 treatment effects for our five core outcomes (individual earnings, college attendance, 
college quality, marriage, and poverty share in ZIP) for the twelve primary subgroups analyzed to date (age above/below 13, male/female, five sites, and three racial groups). Finally, we calculate the fraction of placebo simulations in which there is a subgroup where the p-values for all five outcomes (for either the experimental or Section 8 group) fall below the corresponding true p-values for the experimental treatment estimates in the below-age-13 subgroup. Intuitively, this approach asks, "if one were to loop over the twelve subgroups and estimate treatment effects on the five outcomes, what is the chance that one would obtain a set of p-values below the actual estimates purely by chance in one of the subgroups?"

We find that fewer than one percent of the placebo replications produce a subgroup where the p-values for the five outcomes lie below the values we estimate. Hence, the permutation test yields an adjusted p-value for the null hypothesis that there is no treatment effect on any of the five outcomes of $p<0.01$. The permutation test and parametric $\mathrm{F}$ tests thus both indicate that the significant treatment effects we detect are unlikely to be an artifact of making multiple comparisons.

Finally, it is important to note that we did not re-explore the MTO data arbitrarily searching for subgroups that exhibit significant effects. Rather, motivated by the quasi-experimental evidence in Chetty and Hendren (2015), we returned to the MTO data with a specific hypothesis that we would find larger effects for younger children. The fact that the results align closely with this hypothesis further reduces the likelihood that they reflect statistical noise driven by multiple hypothesis testing.

\section{Cost-Benefit Analysis and Policy Implications}

In this section, we compare the costs and benefits of the MTO interventions and discuss the implications of our results for the design of affordable housing policies, on which the U.S. federal government currently spends $\$ 46$ billion per year (Collinson et al. 2015). We focus on two policy questions. First, what are the costs and benefits of an MTO-type experimental voucher program that moves families with young children out of traditional project-based public housing into lowerpoverty neighborhoods? Second, what are the benefits of expanding the existing Section 8 housing voucher program? We begin by calculating the benefits of the MTO experimental vouchers, focusing on the increased earnings for children who move when young. We then quantify the fiscal costs of the program and discuss the policy implications of these calculations. We caution that all of the calculations reported in this section should be treated as rough estimates because they rely on several strong assumptions, starting with the basic premise that the treatment effects estimated from the MTO experiment can be extrapolated to evaluate current policy interventions. 
Earnings Benefits. The MTO experimental treatment increased individual earnings in early adulthood for children whose families moved before they were age 13 by $\$ 3,477,30.8 \%$ of the control group mean (Table 3, Column 4). We translate this estimate into a predicted lifetime earnings impact by assuming that (1) this $30.8 \%$ increase in individual earnings remains constant over the lifecycle, (2) the lifecycle profile of earnings for MTO participants follows the U.S. population average, and (3) the real wage growth rate is $0.5 \%$, approximately the rate of wage growth in the U.S. over the past decade, and the discount rate is $3 \%$, approximately the current 30 -year Treasury bond rate. ${ }^{42}$

Under these assumptions, moving to a lower-poverty area when young (at age 8 on average) using the experimental voucher increases total pre-tax lifetime earnings by $\$ 302,000 .{ }^{43}$ The present value of this increase in lifetime earnings is $\$ 99,000$ at age 8 . For a family with two young children at the point of the move, the MTO experimental treatment therefore has an estimated present value of approximately $\$ 198,000$ in terms of increased children's earnings.

Fiscal Costs. Next, we turn to the fiscal cost of the MTO experimental intervention. In calculating this cost, it is important to recognize that the higher earnings of children who moved to low-poverty areas at young ages increases tax revenue, reducing the cost of the program to the government. We therefore begin by estimating the effects of the MTO treatments on income tax revenue, a fiscal externality that is also a key input for normative analysis (Hendren 2013).

We examine MTO treatment impacts on tax filing rates and federal tax payments in adulthood in Table 12. Column 1 shows ITT effects on tax filing rates when children are 24 or older. Among younger children (Panel A), the experimental voucher treatment increases the fraction who file tax returns in their mid-late twenties by $5.7 \mathrm{pp}$, while the Section 8 treatment increases the filing rate by 4.8 pp. Column 2 reports ITT estimates on income taxes paid. The experimental ITT is $\$ 184$, while the Section 8 ITT is $\$ 109$. The corresponding TOT estimates, reported in Column 3 , show that children whose families moved using the experimental voucher when they were young pay an additional $\$ 394$ in income taxes per year in their mid-twenties. ${ }^{44}$ Conversely, the MTO treatments

\footnotetext{
${ }^{42}$ As shown in Figure 1, the assumption of a constant $30.8 \%$ effect is conservative, as the estimated treatment effects increase steadily over the ages where we measure earnings.

${ }^{43}$ We estimate the average lifecycle earnings profile by tabulating mean earnings by age for a random sample of the U.S. population in 2012 from ages 26-65. We then apply a $0.5 \%$ wage growth rate and a $3 \%$ annual discount rate to this profile to obtain an undiscounted sum of lifetime earnings for the average American of $\$ 1.74$ million and a PDV at age 8 of $\$ 570,000$. The younger children in the MTO control group earn $56 \%$ of the mean individual earnings in the U.S. population at age 26. Therefore, the estimated impact on undiscounted lifetime earnings is $0.308 \times 0.56 \times \$ 1.74 m=\$ 302,000$.

${ }^{44}$ Our measure of taxes paid does not include tax credits received. We find no significant treatment effects on Earned Income or Child Tax Credit amounts. This is consistent with the fact that most of the earnings increases
} 
reduce tax filing rates and tax payments by the older children, as expected given the negative effects of the treatments on older children's earnings.

We use the estimates in Table 12 to predict the total tax revenue impacts of the MTO experimental intervention on families with young children. The experimental ITT on tax payments of $\$ 184$ equals $1.63 \%$ of mean control group individual earnings. Under the same assumptions used to calculate the lifetime earnings gains above, this translates to an increase in lifetime tax revenue of $\$ 5,200$ in PDV at age 8 . The TOT estimate of $\$ 394$ implies a PDV increase in tax payments of $\$ 11,200$ per child who moves to a lower-poverty area at a young age. If there are two young (below age 13) children per family on average, the increased federal tax payments would be worth $\$ 22,400$ in PDV per family moved.

Olsen (2009) estimates that the direct fiscal costs of housing voucher programs are similar to or slightly lower than the costs of project-based public housing. ${ }^{45}$ Olsen's estimates imply that the main incremental cost of moving families out of public housing using an MTO-type voucher program would be the funding of counselors to help low-income families relocate. The mean MTO counseling costs were $\$ 1,789$ per family counseled (in 2012 dollars) or $\$ 3,783$ per family who took up a voucher (Goering et al. 1999, Table 4). This counseling cost of $\$ 3,783$ is far smaller than the tax revenue gain of $\$ 22,400$ for each family with two young children that is moved. Thus, an MTO-type experimental voucher policy that moves low-income families with young children out of high-poverty housing projects will most likely save the government money.

Policy Implications. We now return to the policy questions posed at the beginning of this section. On the narrower question of comparing MTO-type experimental vouchers to project-based public housing, the data strongly suggest that vouchers targeted at families with young children are likely to yield net gains. Indeed, such a policy is likely to reduce government expenditure while increasing children's future earnings substantially. However, it is critical to target such vouchers effectively to obtain these benefits. First, targeting the vouchers so that families are required to move to low-poverty areas is important. The MTO experimental vouchers - which restricted families to move to low-poverty census tracts - improve children's outcomes much more than existing Section 8 vouchers that give families more flexibility in choosing where to live. ${ }^{46}$ Second,

induced by the treatments are on the intensive rather than extensive margin (Table 3), and many people move into the phase-out region for these credits as they earn more.

${ }^{45}$ The costs of public housing are debated because of disagreements about how one should account for the depreciation of housing projects.

${ }^{46} \mathrm{An}$ interesting question is why giving families greater choice in where to live appears to reduce long-term benefits for children. One possibility is that the neighborhoods chosen by families with unrestricted Section 8 vouchers have other amenities that families value more than their children's long-term outcomes. However, the Section 8 voucher did 
it is critical to target the vouchers to families with young children. As shown above, moving families with older children out of existing public housing projects not only has smaller benefits, but actually appears to be detrimental. The common practice of putting families on waitlists to receive a housing voucher may be particularly inefficient, as this effectively allows many families to move to better neighborhoods only when their children grow older.

We next consider the broader issue of offering Section 8 housing vouchers to more low-income families. The MTO experiment shows that moving families who started out in high-poverty public housing projects to lower-poverty areas has substantial long-term benefits for children. However, the marginal Section 8 voucher may not induce such a move; instead, recent evidence suggests that Section 8 housing vouchers are frequently used to rent better housing within the same neighborhood rather than move to better neighborhoods (Jacob et al. 2015). Consistent with the lack of impact of neighborhood environments, Jacob et al. (2015) find that obtaining a Section 8 voucher through a lottery in Chicago has little impact on children's long-term outcomes for families living in unsubsidized private housing. These results again suggest that one may need to carefully target housing voucher subsidies to have an impact on children's outcomes. Providing more Section 8 vouchers (or equivalent cash benefits) may have little effect on children's outcomes, but providing MTO-type restricted vouchers that require families to move to better (e.g., low-poverty) neighborhoods may be quite valuable.

Our simple calculations neglect many important factors that should be considered in a more comprehensive cost-benefit evaluation. First, our calculations do not account for reductions in transfer payments or gains from better outcomes in future generations. As discussed above, the MTO treatments reduce dependence on long-term transfer programs such as disability insurance (Appendix Table 3c, Column 4) and are likely to have persistent effects on subsequent generations (Section III.E). Second, our calculations focus exclusively on the benefits in terms of children's earnings and thereby neglect other benefits, such as improved subjective well-being and health of adults (Ludwig et al. 2012) and reduced rates of crime (Kling et al. 2005).

Finally, our calculations ignore any spillover effects on prior residents of the neighborhoods where the MTO families moved. Although the MTO experiment itself yields no evidence on the magnitude of these spillovers, Chetty and Hendren's (2015) quasi-experimental estimates show that

not yield significantly greater benefits than the experimental voucher in terms of adults' earnings or their subjective well-being (Ludwig et al. 2012). Another possibility is that families make suboptimal neighborhood choices because of behavioral biases, so that restrictions in the choice set and nudges to encourage families to move to lower-poverty areas improve their own private welfare. See Chetty (2015) for further discussion of optimal policy and welfare analysis of neighborhood choice in behavioral models. 
mixed-income areas produce better outcomes for children in low-income families while generating, if anything, slightly better outcomes for children in higher-income families as well. This finding suggests that policies which reduce concentrated poverty may not have detrimental spillover effects on higher-income households, but further work that directly estimates these spillover effects is required to measure the social benefits of MTO-type policies.

\section{Discussion and Conclusion}

This paper has presented a new analysis of the impacts of the Moving to Opportunity experiment on children's long-term outcomes. We find robust evidence that children who moved to lower-poverty areas when they were young (below age 13) are more likely to attend college and have substantially higher incomes as adults. These children also live in better neighborhoods themselves as adults and are less likely to become single parents themselves, suggesting that some of the benefits of the initial MTO voucher treatment will persist into the following generation (the grandchildren of the parents who received the MTO vouchers). In contrast with the large gains for young children, moving to lower-poverty areas had negative effects on older youth. Finally, we replicate earlier findings that the moves induced by MTO had little impact on adults' economic outcomes.

Our findings show that a simple model featuring linear childhood exposure effects coupled with a fixed disruption cost of moving to a distinctly different social environment can reconcile some of the key findings and debates in the literature on neighborhood effects. First, our results suggest that a substantial fraction of the systematic variation in economic outcomes across areas documented in observational studies that attempt to control for selection effects (e.g., Brooks-Gunn et al. 1993, Cutler and Glaeser 1997, Ellen and Turner 1997, Sampson et al. 2002) can indeed be explained by causal effects of neighborhoods. Since many low-income individuals observed in a given area have grown up in that area since an early age, childhood exposure effects of the type documented here would generate significant differences in mean outcomes across areas in observational data. The fact that MTO had no impact on adults' outcomes (irrespective of exposure time to lower-poverty areas in adulthood) implies that neighborhood effects operate primarily through "developmental" effects during childhood (Sampson 2008) rather than contextual effects arising from spatial mismatch or other forces (Kain 1968, Wilson 1996).

Our results also are consistent with recent studies that document the importance of childhood exposure effects by studying immigrant assimilation (e.g., Bleakley and Chin 2004, Basu 2010, van den Berg et al. 2014) and families that move across counties within the U.S. (Chetty and 
Hendren 2015). In particular, the decline in MTO's treatment effects for children with age at RA coupled with the lack of an impact for adults matches Chetty and Hendren's (2015) finding that the gains from moving to better areas fall linearly with a child's age at move.

Our findings also complement studies in the child development literature that have documented robust correlations between years of exposure to high-poverty family environments and later outcomes (e.g., Duncan et al. 1994). Some studies in this literature argue that environmental conditions in the earliest years of childhood (e.g., before age five) have much larger long-term impacts than conditions in later years (e.g., Brooks-Gunn and Duncan 1997, Phillips et al. 2000, Heckman 2006). Because we only observe long-term outcomes for children who were four or older at random assignment, our results demonstrate that improvements in neighborhood environments continue to have large effects on children's long-term outcomes even after early childhood. Whether the impacts would be even larger at younger ages remains to be explored.

Although our findings help reconcile some key findings on neighborhood effects on outcomes in adulthood, other pieces of evidence remain to be explained. Most notably, MTO's treatment effects on children's short-term and medium-term outcomes are not fully aligned with the longterm impacts documented here (especially for boys) in three respects. First, the MTO treatments improved young children's short-term outcomes (e.g., reducing behavioral problems) in the years immediately following random assignment, but these gains largely faded away over the next decade (e.g., as measured by achievement on standardized tests). ${ }^{47}$ Yet the positive effects of the MTO treatments re-emerge in adulthood, as measured by earnings and college attainment. ${ }^{48}$ Second, MTO had more positive effects for girls than for boys for medium-term outcomes (Kling et al. 2007, Ludwig et al. 2013), but we find no significant gender differences in MTO's effects on children's outcomes in adulthood. Third, we find somewhat negative long-run impacts on older youth (ages 13 to 18 at RA), but earlier work showed positive initial impacts in terms of lower crime and problem behaviors for these children in the first three years after RA.

Although further work remains in synthesizing the evidence that has been collected from the MTO experiment, the results of this study demonstrate that offering low-income families housing

\footnotetext{
${ }^{47}$ See Katz et al. (2001), Sanbonmatsu et al. (2006), Sanbonmatsu et al. (2011), and Sciandra et al. (2013). Jacob (2004) also finds a similar lack of impacts on school outcomes for moves out of public housing in Chicago triggered by the quasi-random timing of the demolition of housing projects.

${ }^{48}$ This pattern echoes the results of other studies of early childhood and school interventions such as Perry PreSchool (Heckman et al. 2010), Head Start (Deming 2009), Project STAR (Chetty et al. 2011), and changes in teacher quality (Chetty et al. 2014), all of which find a pattern of fade-out on intermediate outcomes and re-emergence in adulthood. However, an important difference between the MTO intervention and the other interventions is that the improvement in neighborhoods induced by MTO was an on-going treatment throughout childhood rather than a one-time treatment whose impacts might later fade away.
} 
vouchers and assistance in moving to lower-poverty neighborhoods has substantial benefits for the families themselves and for taxpayers. It appears important to target such housing vouchers to families with young children - perhaps even at birth - to maximize the benefits. Our results provide less support for policies that seek to improve the economic outcomes of adults through residential relocation. More broadly, our findings suggest that efforts to integrate disadvantaged families into mixed-income communities are likely to reduce the persistence of poverty across generations. 


\section{References}

Angrist, Joshua D., Guido W. Imbens, and Donald B. Rubin. 1996. "Identification of Causal Effects Using Instrumental Variables." Journal of the American Statistical Association, 91 (434): 444-455.

Basu, Sukanya. 2010. "Age of Entry Effects on the Education of Immigrant Children: A Sibling Study." Vassar College, Working Paper.

Bleakley, Hoyt and Aimee Chin. 2004. "Language Skills and Earnings: Evidence from Childhood Immigrants." Review of Economics and Statistics, 86 (2): 481-96.

Brooks-Gunn, Jeanne and Greg J Duncan. 1997. "The Effects of Poverty on Children." The Future of Children, 7 (2): 55-71.

Brooks-Gunn, Jeanne, Greg J. Duncan, Pamela K. Klebanov, and Naomi Sealand. 1993. "Do Neighborhoods Influence Child and Adolescent Development?" American Journal of Sociology, 99 (2): 353-95.

Chetty, Raj. 2015. "Behavioral Economics and Public Policy: A Pragmatic Perspective." American Economic Review Papers and Proceedings, Forthcoming.

Chetty, Raj and Nathan Hendren. 2015. "The Impacts of Neighborhoods on Intergenerational Mobility: Childhood Exposure Effects and County-Level Estimates" Harvard Univ. mimeo.

Chetty, Raj, John Friedman, Nathaniel Hilger, Emmanuel Saez, Diane Whitmore Schanzenbach, and Danny Yagan. 2011. "How Does Your Kindergarten Classroom Affect Your Earnings? Evidence from Project STAR." Quarterly Journal of Economics, 126 (4): 15931660.

Chetty, Raj, John N. Friedman, and Jonah E. Rockoff. 2014. "Measuring the Impacts of Teachers II: Teacher Value-Added and Student Outcomes in Adulthood." American Economic Review, 104 (9): 2633-79.

Cilke, James. 1998. "A Profile of Non-Filers." U.S. Department of the Treasury, Office of Tax Analysis Working Paper No. 78. 
Clampet-Lundquist, Susan and Douglas S Massey. 2008. "Neighborhood Effects on Economic Self-Sufficiency: A Reconsideration of the Moving to Opportunity Experiment1." American Journal of Sociology, 114 (1): 107-143.

Coleman, James S. 1988. "Social Capital in the Creation of Human Capital." American Journal of Sociology, 94, 95-120.

Collinson, Robert, Ingrid Gould Ellen, and Jens Ludwig. 2015. "Low-Income Housing Policy." NBER Working Paper No. 21071.

Crowder, Kyle and Scott J South. 2011. "Spatial and Temporal Dimensions of Neighborhood Effects on High School Graduation." Social Science Research, 40 (1): 87-106.

Cutler, David M. and Edward L. Glaeser. 1997. "Are Ghettos Good or Bad?" Quarterly Journal of Economics, 112 (3): 827-72.

Deming, David. 2009. "Early Childhood Intervention and Life-cycle Skill Development: Evidence from Head Start." American Economic Journal: Applied Economics, 1 (3): 111-134.

Ding, Peng, Avi Feller, and Luke Miratrix. 2015. "Randomization Inference for Treatment Effect Variation." Journal of the Royal Statistical Society, Series B, Forthcoming.

Duncan, Greg J, Jeanne Brooks-Gunn, and Pamela Kato Klebanov. 1994. "Economic Deprivation and Early Childhood Development." Child Development, 65 (2): 296-318.

Ellen, Ingrid G. and Margery A. Turner. 1997. "Does Neighborhood Matter?" Housing Policy Debate, 8 (4): 833-66.

Fryer, Roland G. and Lawrence F. Katz. 2013. "Achieving Escape Velocity: Neighborhood and School Interventions to Reduce Persistent Poverty." American Economic Review Papers and Proceedings, 103 (3): 232-37.

Goering, John, Joan Kraft, Judith Feins, Debra McInnis, Mary Joel Hoelin, and Huda Elhassan. 1999. "Moving to Opportunity for Fair Housing Demonstration Program: Current Status and Initial Findings." U.S. Department of Housing and Urban Development.

Haider, Steven and Gary Solon. 2006. "Life-Cycle Variation in the Association between Current and Lifetime Earnings." American Economic Review, 96 (4): 1308-1320. 
Heckman, James J. 2006. "Skill Formation and the Economics of Investing in Disadvantaged Children." Science, 312 (5782): 1900-1902.

Heckman, James, Seong Hyeok Moon, Rodrigo Pinto, Peter Savelyev, and Adam Yavitz. 2010. "Analyzing Social Experiments as Implemented: A Reexamination of the Evidence from the HighScope Perry Preschool Program." Quantitative Economics, 1 (1): 1-46.

Hendren, Nathaniel. 2013. "The Policy Elasticity." NBER Working Paper No. 19177.

Jacob, Brian A. 2004. "Public Housing, Housing Vouchers, and Student Achievement: Evidence from Public Housing Demolitions in Chicago." American Economic Review, 94 (1): 233-258.

Jacob, Brian A., Max Kapustin, and Jens Ludwig. 2015. "The Impact of Housing Assistance on Child Outcomes: Evidence from a Randomized Housing Lottery." Quarterly Journal of Economics, 130 (1): 465-506.

Jencks, Christopher and Susan E. Mayer. 1990. "The Social Consequences of Growing Up in a Poor Neighborhood." in L. Lynn and M. G. H. McGeary, eds., Inner City Poverty in the United States, Washington D.C.: National Academy Press, pp. 111-185.

Kain, John F. 1968. "Housing Segregation, Negro Employment, and Metropolitan Decentralization." Quarterly Journal of Economics, 82 (2): 175-197.

Katz, Lawrence F., Jeffrey B. Liebman, and Jeffrey R. Kling. 2001. "Moving to Opportunity in Boston: Early Results of a Randomized Mobility Experiment." Quarterly Journal of Economics, 116 (2): 607-54.

Kling, Jeffrey R., Jeffrey B. Liebman, and Lawrence F. Katz. 2007. "Experimental Analysis of Neighborhood Effects." Econometrica, 75 (1): 83-119.

Kling, Jeffrey R, Jens Ludwig, and Lawrence F Katz. 2005. "Neighborhood Effects on Crime for Female and Male Youth: Evidence from a Randomized Housing Voucher Experiment." Quarterly Journal of Economics, 120 (1): 87-130.

Leventhal, Tama and Jeanne Brooks-Gunn. 2000. "The Neighborhoods they Live In: The Effects of Neighborhood Residence on Child and Adolescent Outcomes." Psychological Bulletin, 126 (2): 309-337. 
Ludwig, Jens, Greg J. Duncan, Lisa A. Gennetian, Lawrence F. Katz, Ronald C. Kessler, Jeffrey R. Kling, and Lisa Sanbonmatsu. 2012. "Neighborhood Effects on the Long-Term Well-Being of Low-Income Adults." Science, 337 (6101): 1505-1510.

Ludwig, Jens, Greg J. Duncan, Lisa A. Gennetian, Lawrence F. Katz, Ronald C. Kessler, Jeffrey R. Kling, and Lisa Sanbonmatsu. 2013. "Long-Term Neighborhood Effects on Low-Income Families: Evidence from Moving to Opportunity." American Economic Review Papers and Proceedings, 103 (3): 226-31.

Ludwig, Jens, Lisa Sanbonmatsu, Lisa Gennetian, Emma Adam, Greg J Duncan, Lawrence F Katz, Ronald C Kessler, Jeffrey R Kling, Stacy Tessler Lindau, Robert C Whitaker et al. 2011. "Neighborhoods, Obesity, and Diabetes: A Randomized Social Experiment." New England Journal of Medicine, 365 (16): 1509-1519.

Olsen, Edgar O. 2009. "The Cost-Effectiveness of Alternative Methods of Delivering Housing Subsidies." University of Virginia, Working Paper No. 351.

Orr, Larry L, Judith D. Feins, Robin Jacob, Erik Beecroft, Lisa Sanbonmatsu, Lawrence F. Katz, Jeffrey B. Liebman, and Jeffrey R. Kling. 2003. Moving to Opportunity for Fair Housing Demonstration Program: Interim Impacts Evaluation, US Department of Housing and Urban Development, Office of Policy Development and Research.

Phillips, Deborah A, Jack P Shonkoff et al. 2000. From Neurons to Neighborhoods: The Science of Early Childhood Development, National Academies Press.

Quigley, John M and Steven Raphael. 2008. "Neighborhoods, Economic Self-Sufficiency, and the MTO Program." Brookings-Wharton Papers on Urban Affairs, 2008 (1): 1-46.

Sampson, Robert J. 2008. "Moving to Inequality: Neighborhood Effects and Experiments meet Social Structure." American Journal of Sociology, 114 (1): 189-231.

Sampson, Robert J., Jeffrey D. Morenoff, and Thomas Gannon-Rowley. 2002. "Assessing "Neighborhood Effects": Social Processes and New Directions in Research." Annual Review of Sociology, 28 (1): 443-478.

Sanbonmatsu, Lisa, Jeffrey R Kling, Greg J Duncan, and Jeanne Brooks-Gunn. 2006. "Neighborhoods and Academic Achievement: Results from the Moving to Opportunity Experiment." Journal of Human Resources, 41 (4): 649-691. 
Sanbonmatsu, Lisa, Jens Ludwig, Lawrence F. Katz, Lisa A. Gennetian, Greg J. Duncan, Ronald C. Kessler, Emma Adam, Thomas McDade, and Stacy Tessler Lindau. 2011. Moving to Opportunity for Fair Housing Demonstration Program: Final Impacts Evaluation, Washington, DC: U.S. Department of Housing and Urban Development, Office of Policy Development and Research.

Sciandra, Matthew, Lisa Sanbonmatsu, Greg J Duncan, Lisa A Gennetian, Lawrence F Katz, Ronald C Kessler, Jeffrey R Kling, and Jens Ludwig. 2013. "Long-term Effects of the Moving to Opportunity Residential Mobility Experiment on Crime and Delinquency." Journal of Experimental Criminology, 9 (4): 451-489.

South, Scott J., Dana L. Haynie, and Sunita Bose. 2007. "Student Mobility and School Dropout." Social Science Research, 36 (1): 67-94.

van den Berg, Gerard J., Petter Lundborg, Paul Nystedt, and Dan-Olof Rooth. 2014. "Critical Periods during Childhood and Adolescence." Journal of the European Economic Association, 12 (6): 1521-1557.

Wilson, William J. 1987. The Truly Disadvantaged: The Inner City, the Underclass, and Public Policy, Chicago: University of Chicago Press.

Wilson, William J. 1996. When Work Disappears: The World of the New Urban Poor, New York: Random House.

Wodtke, Geoffrey T, David J Harding, and Felix Elwert. 2011. "Neighborhood Effects in Temporal Perspective: The Impact of Long-term Exposure to Concentrated Disadvantage on High School Graduation." American Sociological Review, 76 (5): 713-736.

Wood, David, Neal Halfon, Debra Scarlata, Paul Newacheck, and Sharon Nessim. 1993. "Impact of Family Relocation on Children's Growth Development, School Function, and Behavior." Journal of the American Medical Association, 270 (11): 1334-1338. 


\section{FIGURE 1}

\section{Impacts of Experimental Voucher by Age of Earnings Measurement}

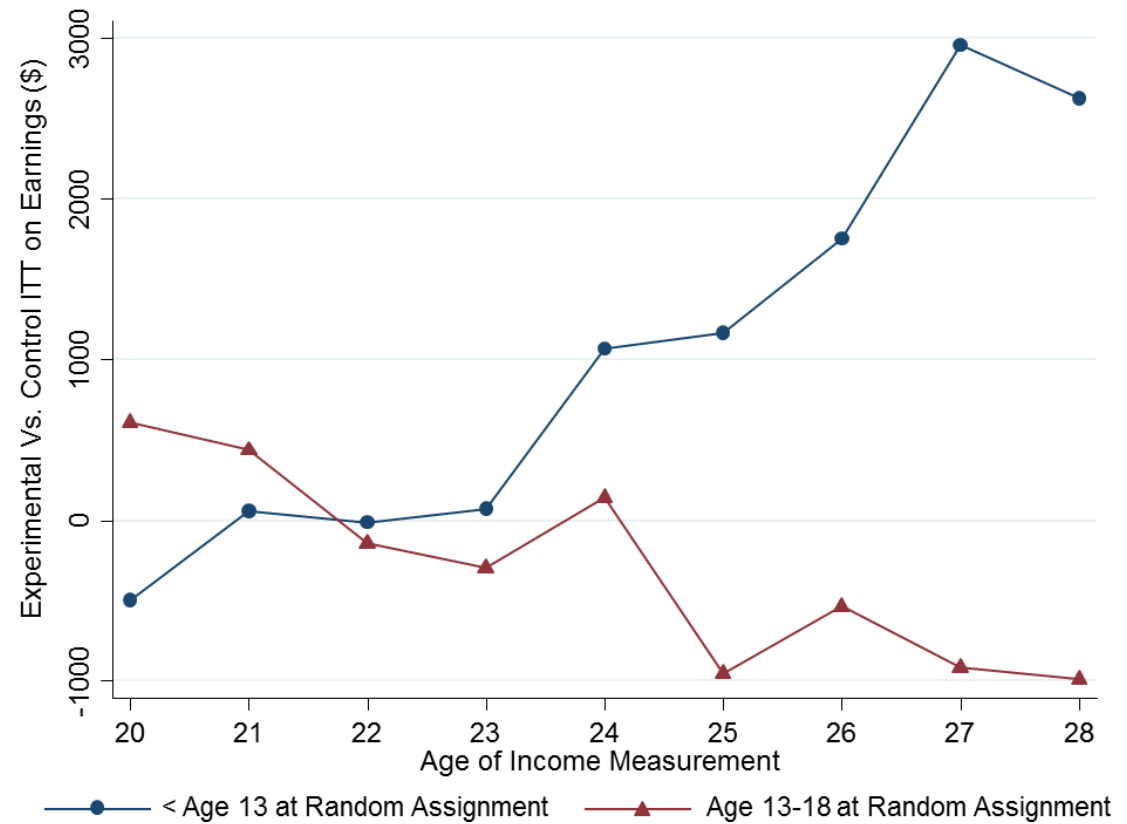

Notes: This figure presents intent-to-treat (ITT) estimates of the impact of being assigned to the experimental voucher group on individual earnings, varying the age at which earnings is measured from 20 to 28 . The estimate at each age is obtained from an OLS regression (weighted to adjust for differences in sampling probabilities across sites and over time) of individual earnings at that age on indicators for being assigned to the experimental voucher group and the section 8 voucher group as well as randomization site indicators. We plot the coefficient on the experimental voucher group indicator in this figure; the corresponding estimates for the Section 8 voucher group are shown in Appendix Figure 1. The series in circles restricts the sample to children below age 13 at random assignment; the series in triangles includes children between age 13 and 18 at random assignment. The estimates in the two series are obtained from separate regressions. The estimates at age 26 exactly match those reported in Column 5 of Table 3; the remaining estimates replicate that specification, varying the age at which earnings is measured. The null hypothesis that the experimental impacts do not vary with the age of income measurement is rejected with $p<0.01$ for the below 13 series and $p=0.06$ for the age 13-18 series. See notes to Table 3 for further details on specifications and variable definitions. 
FIGURE 2

\section{Impacts of Experimental Voucher by Children's Age at Random Assignment}

A. Household Income, Age $\geq 24(\$)$

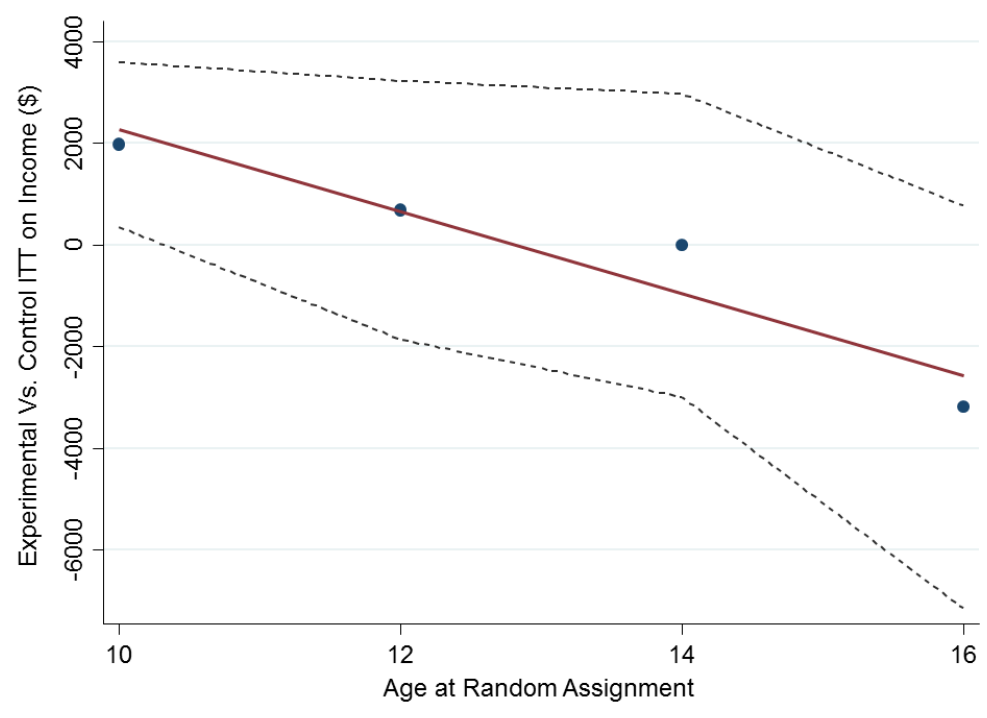

B. College Quality, Ages 18-20 (\$)

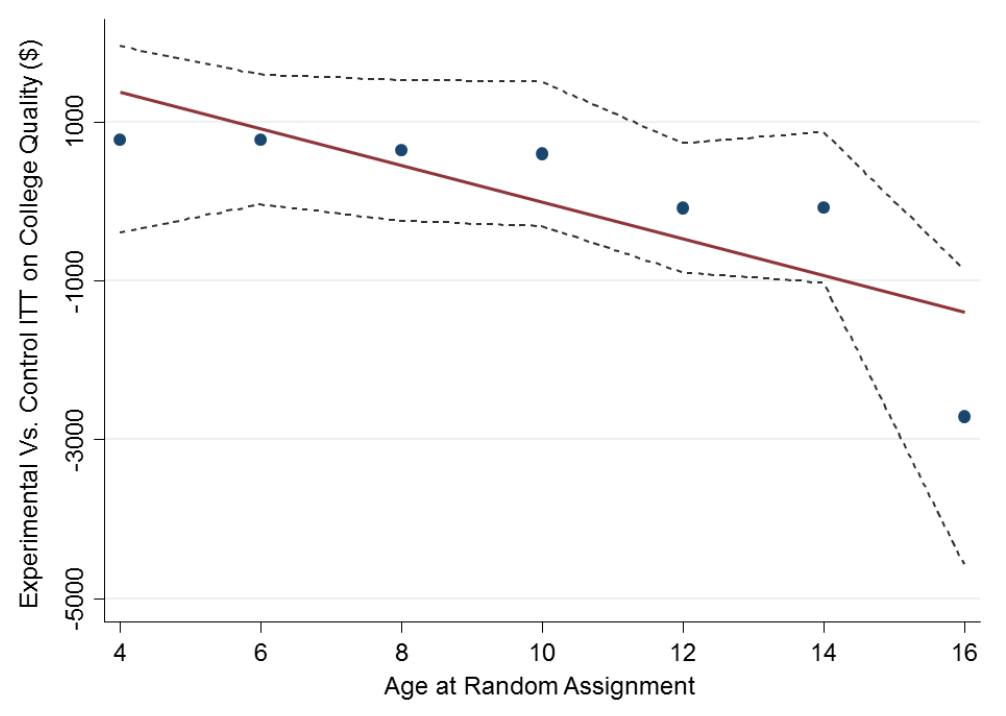

Notes: These figures plot intent-to-treat (ITT) estimates of the impact of being assigned to the experimental voucher group by a child's age at random assignment (RA). Panel A plots impacts on household income for those above age 24, while Panel $\mathrm{B}$ plots impacts on the earnings-based index of college quality between ages 18-20. To construct Panel A, we first divide children into two-year age groups based on their age at random assignment; for instance, children who were ages 12 or 13 at RA are placed in the "age 12" group in the figure. Since there are few children who are below age 10 at RA and whose income is observed at age 24, we include those below age 10 at RA in the age 10 bin; likewise, we include children who are 18 at RA in the age 16 bin. Using data within each age bin, we regress household income on indicators for being assigned to the experimental and section 8 voucher groups using the same specification as in Column 8 of Table 3, with one observation per individual per year from 2008-12 in which the individual is 24 or older. The solid line is a best fit line for the plotted estimates. The dashed lines show the $95 \%$ confidence interval for each of the estimates. Panel B replicates Panel A using college quality as the dependent variable. The regression specification used to estimate the coefficients plotted in Panel B is the same as that in Column 6 of Table 4, with one observation per year when the child is between the ages of 18-20. We plot the coefficients on the experimental voucher group indicator in this figure; the corresponding estimates for the Section 8 voucher group are shown in Appendix Figure 2. See notes to Tables 3 and 4 for definitions of household income and college quality. 


\section{FIGURE 3}

\section{Impacts of Experimental Voucher on Adults by Years Since Random Assignment}

\section{A. Cumulative Years of Exposure to Low-Poverty Neighborhoods}

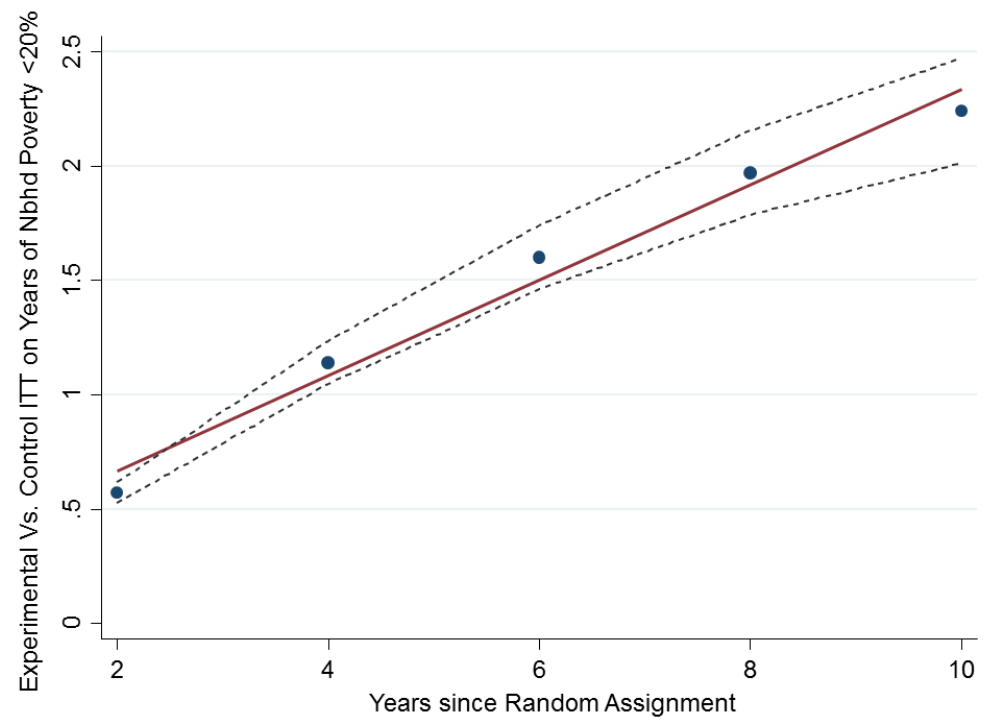

B. Individual Earnings (\$)

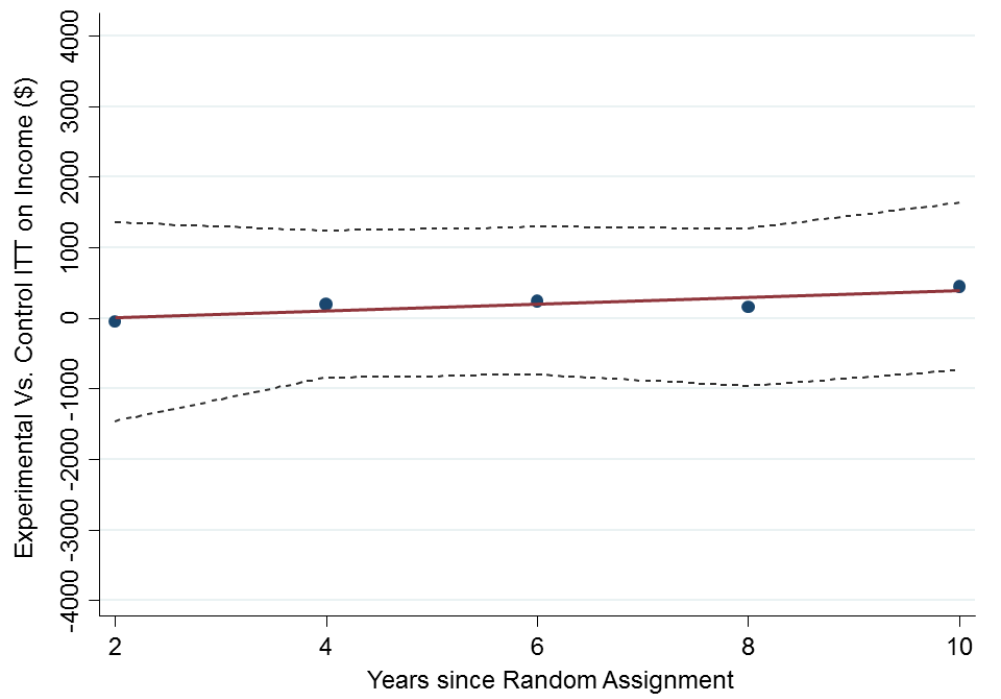

Notes: These figures plot intent-to-treat (ITT) estimates of the impact of being assigned to the experimental voucher group by the number of years since random assignment (RA) for adults. Panel A plots impacts on the total number of years the individual lived in a census tract with a poverty rate of less than $20 \%$ since RA. To construct Panel A, we first divide the data into two-year groups based on the number of years since RA (e.g., data in the first and second year after the calendar year of RA are assigned a value of 2). Using the data within each bin (with two observations per adult), we regress the total number of years in which the individual lived in a census tract with a poverty rate below $20 \%$ since RA on indicators for being assigned to the experimental and section 8 voucher groups as well as randomization site indicators, following the standard ITT specification used for other outcomes. The solid line is a best fit line for the plotted estimates. Tract poverty rates were linearly interpolated using data from the 1990 and 2000 decennial censuses as well as the 2005-09 American Community Survey. Panel B plots impacts on individual earnings, and is constructed using the same approach as in Panel A. The regression specification used to estimate the coefficients plotted in Panel B is analogous to that in Column 1 of Table 9, with one observation per adult at age 24 or above for the relevant years in each bin. We plot the coefficients on the experimental voucher group indicator in this figure; the corresponding estimates for the Section 8 voucher group are shown in Appendix Figure 3. See notes to Tables 9 for the definition of individual earnings. 


\section{APPENDIX FIGURE 1}

\section{Impacts of Section 8 Voucher by Age of Earnings Measurement}

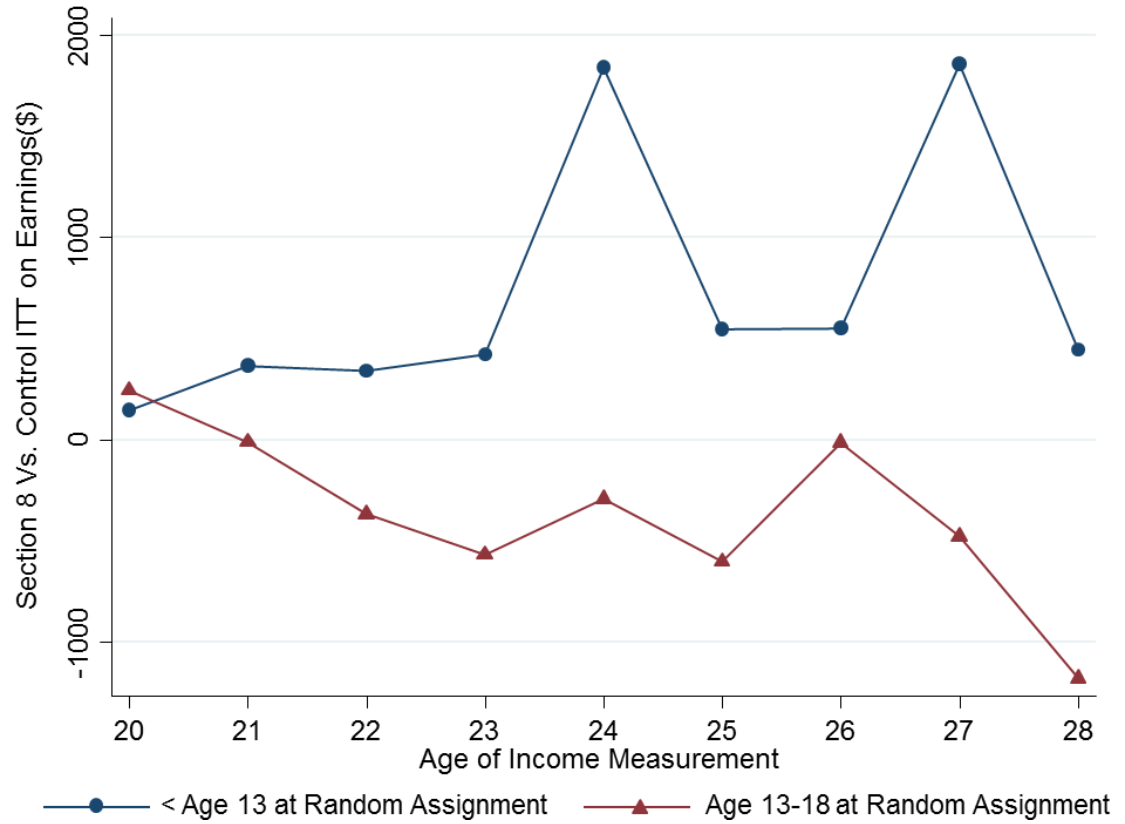

Notes: This figure replicates Figure 1 in the text, but plots the effects of being assigned to the Section 8 voucher group (relative to the control group). See notes to Figure 1 for details on variable definitions and specifications. 


\section{APPENDIX FIGURE 2}

Impacts of Section 8 Voucher by Age at Random Assignment

A. Household Income, Age $\geq 24(\$)$

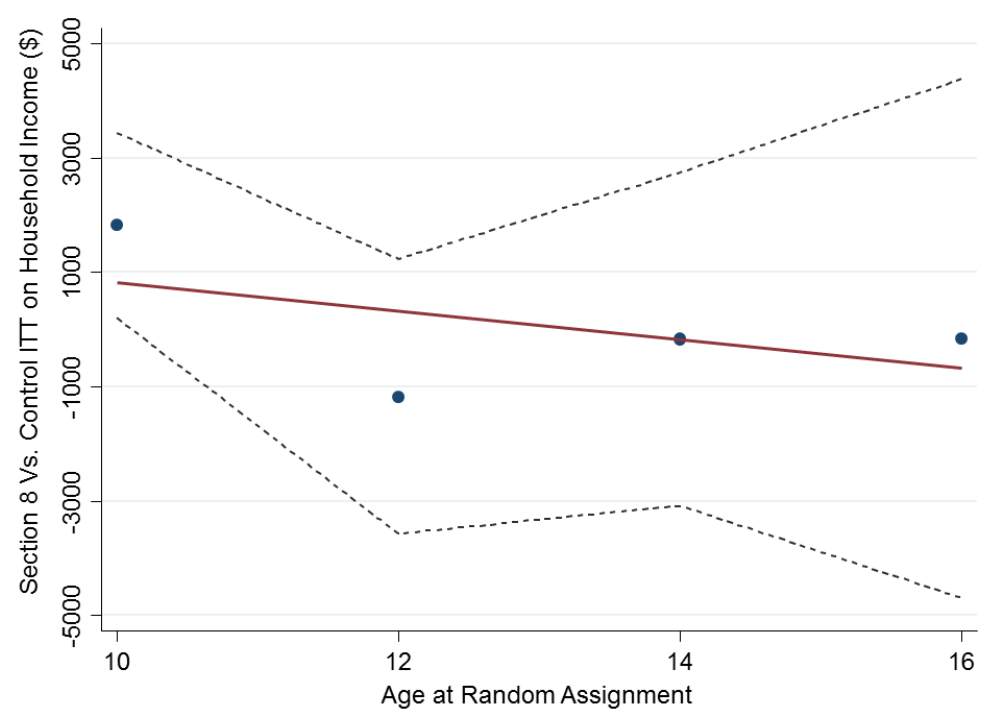

B. College Quality, Ages 18-20 (\$)

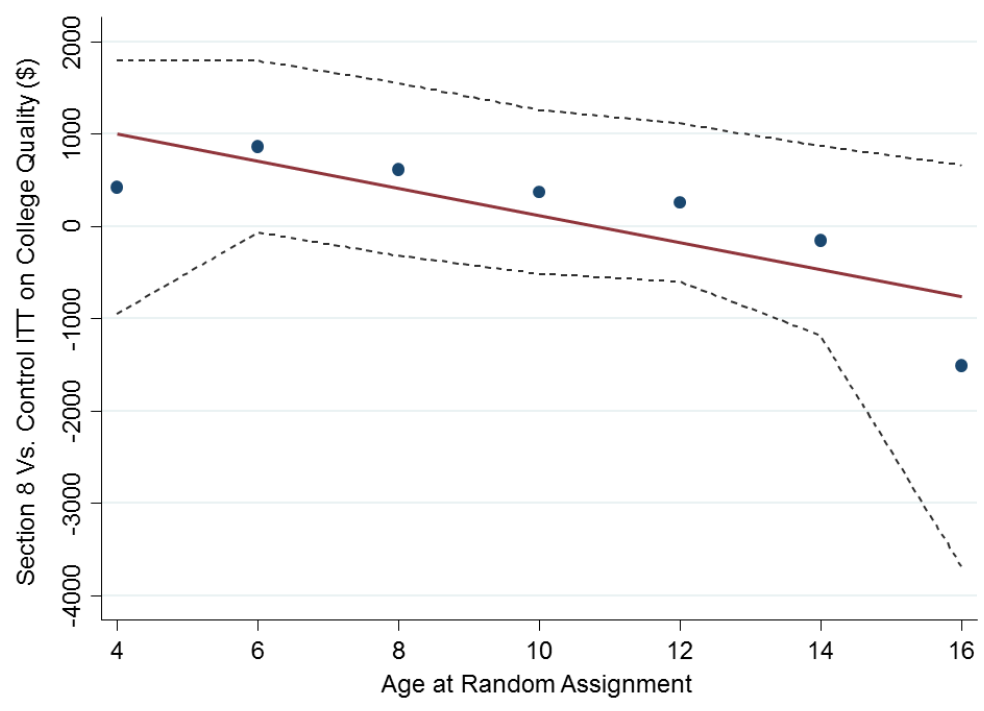

Notes: These figures replicate Figure 2 in the text, but plot the effects of being assigned to the Section 8 voucher group (relative to the control group). See notes to Figure 2 for details on variable definitions and specifications. 


\section{APPENDIX FIGURE 3}

Impacts of Section 8 Voucher on Adults by Years Since Random Assignment

A. Cumulative Years of Exposure to Low-Poverty Neighborhoods

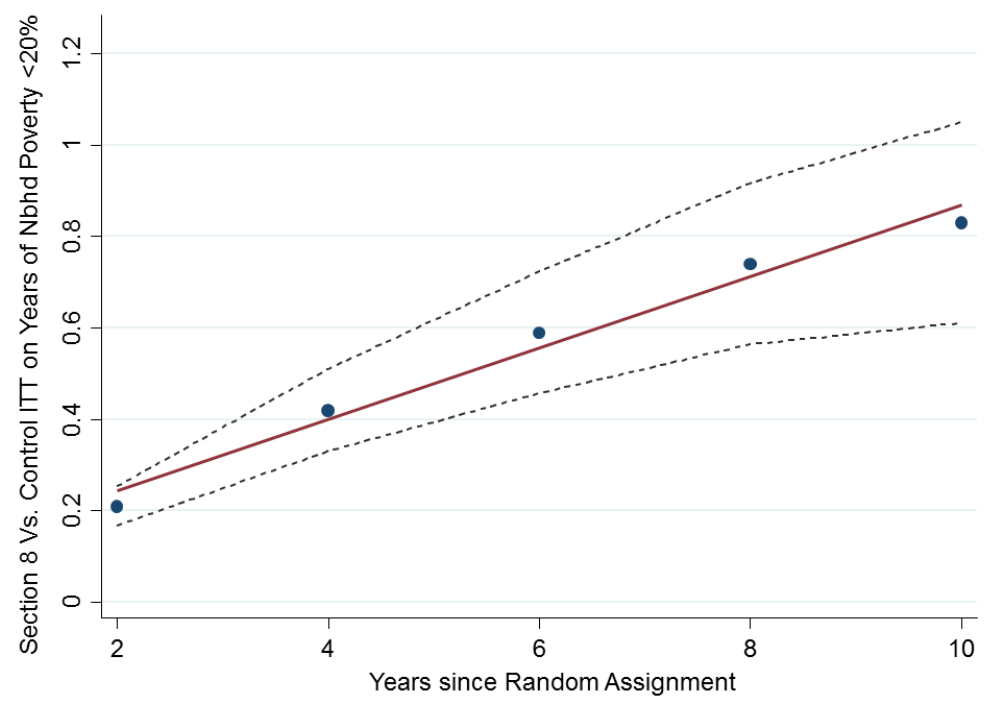

B. Individual Earnings (\$)

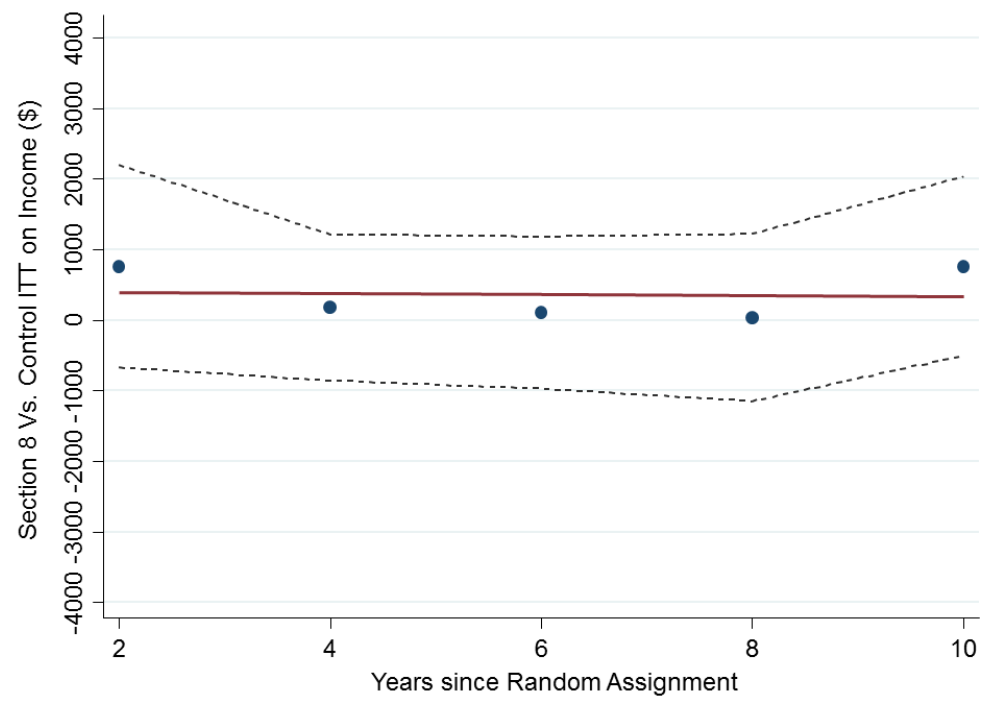

Notes: These figures replicate Figure 3 in the text, but plot the effects of being assigned to the Section 8 voucher group (relative to the control group). See notes to Figure 3 for details on variable definitions and specifications. 
TABLE 1

Summary Statistics and Balance Tests for Children in MTO-Tax Data Linked Sample

\begin{tabular}{|c|c|c|c|c|c|c|}
\hline & \multicolumn{3}{|c|}{$<$ Age 13 at Random Assignment } & \multicolumn{3}{|c|}{ Age 13-18 at Random Assignment } \\
\hline & $\begin{array}{c}\text { Control Grp. } \\
\text { Mean } \\
(1)\end{array}$ & $\begin{array}{c}\text { Exp. vs. } \\
\text { Control } \\
(2)\end{array}$ & $\begin{array}{c}\text { Sec 8. vs. } \\
\text { Control } \\
(3) \\
\end{array}$ & $\begin{array}{l}\text { Control Grp. } \\
\text { Mean } \\
(4) \\
\end{array}$ & $\begin{array}{c}\text { Exp. vs. } \\
\text { Control } \\
(5)\end{array}$ & $\begin{array}{c}\text { Sec 8. vs. } \\
\text { Control } \\
(6) \\
\end{array}$ \\
\hline Linked to tax data (\%) & 86.4 & $\begin{array}{l}-0.8 \\
(1.4)\end{array}$ & $\begin{array}{l}-0.4 \\
(1.5)\end{array}$ & 83.8 & $\begin{array}{c}1.5 \\
(2.0)\end{array}$ & $\begin{array}{l}-0.1 \\
(2.2)\end{array}$ \\
\hline Child's age at random assignment & 8.2 & $\begin{array}{l}-0.1 \\
(0.1)\end{array}$ & $\begin{array}{l}-0.0 \\
(0.1)\end{array}$ & 15.1 & $\begin{array}{c}0.1 \\
(0.1)\end{array}$ & $\begin{array}{l}-0.1 \\
(0.1)\end{array}$ \\
\hline $\begin{array}{l}\text { Household Head Completed High } \\
\text { School (\%) }\end{array}$ & 34.3 & $\begin{array}{l}4.2^{+} \\
(2.4)\end{array}$ & $\begin{array}{c}0.4 \\
(2.6)\end{array}$ & 29.5 & $\begin{array}{c}5.0 \\
(3.1)\end{array}$ & $\begin{array}{c}0.7 \\
(3.3)\end{array}$ \\
\hline Household Head Employed (\%) & 23.8 & $\begin{array}{c}1.0 \\
(2.1)\end{array}$ & $\begin{array}{l}-2.2 \\
(2.2)\end{array}$ & 25.3 & $\begin{array}{c}3.0 \\
(2.9)\end{array}$ & $\begin{array}{l}-0.4 \\
(3.0)\end{array}$ \\
\hline Household Head gets AFDC/TANF (\%) & 79.5 & $\begin{array}{c}0.6 \\
(1.9)\end{array}$ & $\begin{array}{c}1.8 \\
(2.0)\end{array}$ & 75.0 & $\begin{array}{l}-0.8 \\
(2.9)\end{array}$ & $\begin{array}{l}-1.0 \\
(3.0)\end{array}$ \\
\hline Household Head never married (\%) & 65.1 & $\begin{array}{l}-4.3^{+} \\
(2.3)\end{array}$ & $\begin{array}{l}-3.1 \\
(2.6)\end{array}$ & 53.0 & $\begin{array}{l}-3.1 \\
(3.2)\end{array}$ & $\begin{array}{l}-6.3^{+} \\
(3.4)\end{array}$ \\
\hline Household Head had teenage birth (\%) & 28.6 & $\begin{array}{l}-0.9 \\
(2.2)\end{array}$ & $\begin{array}{l}-0.3 \\
(2.5)\end{array}$ & 29.1 & $\begin{array}{l}-3.6 \\
(2.9)\end{array}$ & $\begin{array}{l}-2.5 \\
(3.2)\end{array}$ \\
\hline $\begin{array}{l}\text { Primary or secondary reason for move } \\
\text { is to get away from gangs or drugs (\%) }\end{array}$ & 78.1 & $\begin{array}{l}-1.8 \\
(2.1)\end{array}$ & $\begin{array}{l}-4.4^{+} \\
(2.4)\end{array}$ & 77.7 & $\begin{array}{c}3.1 \\
(2.6)\end{array}$ & $\begin{array}{l}-0.9 \\
(2.9)\end{array}$ \\
\hline $\begin{array}{l}\text { Household victims of crime in past } 5 \\
\text { years }(\%)\end{array}$ & 41.3 & $\begin{array}{c}2.5 \\
(2.4)\end{array}$ & $\begin{array}{c}0.9 \\
(2.7)\end{array}$ & 44.8 & $\begin{array}{c}1.3 \\
(3.3)\end{array}$ & $\begin{array}{l}-3.3 \\
(3.5)\end{array}$ \\
\hline Household Head African American (\%) & 66.9 & $\begin{array}{l}-0.4 \\
(2.0)\end{array}$ & $\begin{array}{l}-1.4 \\
(2.1)\end{array}$ & 63.9 & $\begin{array}{l}-1.9 \\
(2.7)\end{array}$ & $\begin{array}{l}-5.9^{*} \\
(2.8)\end{array}$ \\
\hline Household Head Hispanic (\%) & 29.4 & $\begin{array}{l}-0.3 \\
(2.0)\end{array}$ & $\begin{array}{l}-0.5 \\
(2.1)\end{array}$ & 31.1 & $\begin{array}{c}0.6 \\
(2.7)\end{array}$ & $\begin{array}{c}2.8 \\
(2.7)\end{array}$ \\
\hline Child susp./expelled in past 2 yrs. (\%) & 4.9 & $\begin{array}{c}0.7 \\
(0.8)\end{array}$ & $\begin{array}{c}0.4 \\
(0.9)\end{array}$ & 17.6 & $\begin{array}{l}1.0 \\
(2.0)\end{array}$ & $\begin{array}{c}0.4 \\
(2.2)\end{array}$ \\
\hline N. of Children in Linked MTO-Tax Data & 1613 & 1969 & 1427 & 686 & 959 & 686 \\
\hline
\end{tabular}

Notes: This table presents summary statistics and balance tests for match rates and a subset of variables collected prior to randomization; Appendix Table 1a replicates this table for all 52 control variables we use in our analysis. The estimates in the first row (fraction linked to tax data) are based on all children in the MTO data who were born in or before 1991. The estimates in the remaining rows use the subset of these observations successfully linked to the tax data. Columns 1-3 include children below age 13 at random assignment; Columns 46 include those above age 13 at random assignment. Columns 1 and 4 show the control group mean for each variable. Columns 2 and 5 report the difference between the experimental voucher and control group, which we estimate using an OLS regression (weighted to adjust for differences in sampling probabilities across sites and over time) of each variable on indicators for being assigned to the experimental voucher group, the section 8 voucher group, as well as indicators for randomization site. Columns 3 and 6 report the coefficient for being assigned to the section 8 group from the same regression. The estimates in Columns 2-3 and 5-6 are obtained from separate regressions. Standard errors, reported in parentheses, are clustered by family $\left({ }^{+}=p<0.10,{ }^{*}=\right.$ $p<0.05,{ }^{* *}=p<0.01$ ). The final row lists the number of individuals in the control, experimental, and section 8 groups in the linked MTO-Tax data sample. 
TABLE 2

First-Stage Impacts of MTO on Voucher Takeup and Neighborhood Poverty Rates

\begin{tabular}{|c|c|c|c|c|c|c|c|}
\hline \multirow[t]{2}{*}{ Dep. Var.: } & \multirow{2}{*}{$\begin{array}{c}\text { Housing } \\
\text { Voucher } \\
\text { Takeup (\%) } \\
(1) \\
\end{array}$} & \multicolumn{2}{|c|}{$\begin{array}{l}\text { Poverty Rate in } \\
\text { Tract one year } \\
\text { post RA (\%) }\end{array}$} & \multicolumn{2}{|c|}{$\begin{array}{c}\text { Mean Poverty Rate } \\
\text { in Tract post RA to } \\
\text { Age } 18(\%)\end{array}$} & \multicolumn{2}{|c|}{$\begin{array}{c}\text { Mean Poverty Rate } \\
\text { in ZIP post RA to } \\
\text { Age } 18(\%)\end{array}$} \\
\hline & & $\begin{array}{r}\text { ITT } \\
(2) \\
\end{array}$ & $\begin{array}{c}\text { TOT } \\
(3) \\
\end{array}$ & $\begin{array}{r}\text { ITT } \\
(4) \\
\end{array}$ & $\begin{array}{c}\text { TOT } \\
(5) \\
\end{array}$ & $\begin{array}{r}\text { ITT } \\
(6) \\
\end{array}$ & $\begin{array}{c}\text { TOT } \\
(7) \\
\end{array}$ \\
\hline \multicolumn{8}{|c|}{ Panel A: Children < Age 13 at Random Assignment } \\
\hline Exp. vs Control & $\begin{array}{l}47.66^{\star *} \\
(1.653)\end{array}$ & $\begin{array}{c}-17.05^{\star \star} \\
(0.853)\end{array}$ & $\begin{array}{c}-35.96^{\star *} \\
(1.392)\end{array}$ & $\begin{array}{c}-10.27^{* \star} \\
(0.650)\end{array}$ & $\begin{array}{c}-21.56^{\star *} \\
(1.118)\end{array}$ & $\begin{array}{l}-5.84^{\star *} \\
(0.425)\end{array}$ & $\begin{array}{c}-12.23^{\star *} \\
(0.752)\end{array}$ \\
\hline Sec 8. vs. Control & $\begin{array}{l}65.80^{* *} \\
(1.934)\end{array}$ & $\begin{array}{c}-14.88^{* *} \\
(0.802)\end{array}$ & $\begin{array}{c}-22.57^{* *} \\
(1.024)\end{array}$ & $\begin{array}{l}-7.97^{* *} \\
(0.615)\end{array}$ & $\begin{array}{c}-12.06^{* *} \\
(0.872)\end{array}$ & $\begin{array}{l}-3.43^{* *} \\
(0.423)\end{array}$ & $\begin{array}{l}-5.17^{* *} \\
(0.622)\end{array}$ \\
\hline Num of Obs. & 5044 & 4958 & 4958 & 5035 & 5035 & 5035 & 5035 \\
\hline Control Group Mean & 0 & 50.23 & 50.23 & 41.17 & 41.17 & 31.81 & 31.81 \\
\hline \multicolumn{8}{|c|}{ Panel B: Children Age 13-18 at Random Assignment } \\
\hline Exp. vs Control & $\begin{array}{l}40.15^{\star \star} \\
(2.157)\end{array}$ & $\begin{array}{c}-14.00^{\star *} \\
(1.136)\end{array}$ & $\begin{array}{c}-34.70^{* *} \\
(2.231)\end{array}$ & $\begin{array}{c}-10.04^{* *} \\
(0.948)\end{array}$ & $\begin{array}{c}-24.66^{\star *} \\
(1.967)\end{array}$ & $\begin{array}{l}-5.51^{* *} \\
(0.541)\end{array}$ & $\begin{array}{c}-13.52^{\star *} \\
(1.113)\end{array}$ \\
\hline Sec 8. vs. Control & $\begin{array}{l}55.04^{* *} \\
(2.537)\end{array}$ & $\begin{array}{c}-12.21^{* *} \\
(1.078)\end{array}$ & $\begin{array}{c}-22.03^{* *} \\
(1.738)\end{array}$ & $\begin{array}{l}-8.60^{* *} \\
(0.920)\end{array}$ & $\begin{array}{c}-15.40^{* *} \\
(1.530)\end{array}$ & $\begin{array}{l}-3.95^{\star *} \\
(0.528)\end{array}$ & $\begin{array}{l}-7.07^{\star *} \\
(0.921)\end{array}$ \\
\hline Num of Obs. & 2358 & 2302 & 2302 & 2293 & 2293 & 2292 & 2292 \\
\hline Control Group Mean & 0 & 49.14 & 49.14 & 47.90 & 47.90 & 35.17 & 35.17 \\
\hline
\end{tabular}

Notes: Columns 1, 2, 4 and 6 report intent-to-treat (ITT) estimates from OLS regressions (weighted to adjust for differences in sampling probabilities across sites and over time) of an outcome on indicators for being assigned to the experimental voucher group and the section 8 voucher group as well as randomization site indicators. Columns 3,5 and 7 report treatment-on-the-treated (TOT) estimates using a 2SLS specification, instrumenting for voucher takeup with the experimental and section 8 assignment indicators. Standard errors, reported in parentheses, are clustered by family $\left(^{+}=p<0.10,{ }^{*}=p<0.05,{ }^{* *}=p<0.01\right)$. Panel A restricts the sample to children below age 13 at random assignment; Panel $B$ includes children between age 13 and 18 at random assignment The estimates in Panels $A$ and $B$ are obtained from separate regressions. The dependent variable in Column 1 is an indicator for the family taking up an MTO voucher and moving. The dependent variable in Columns 2 and 3 is the census tract-level poverty rate one year after random assignment. The dependent variable in Columns 4-7 is the duration-weighted mean poverty rate in the Census tracts (columns 4 and 5) and ZIP codes (columns 6 and 7 ) where the child lived from random assignment till age 18. The sample in this table includes all children born before 1991 in the MTO data for whom an SSN was collected prior to RA because we were unable to link the MTO tract-level location information to the tax data. This sample is nearly identical our linked analysis sample because $99.1 \%$ of the children with non-missing SSN's are matched to the tax data. The duration-weighted poverty rate is constructed using information on the addresses where the youth lived from random assignment up to their 18th birthday, weighted by the amount of time spent at each address. Census tract poverty rates in each year are interpolated using data from the 1990 and 2000 decennial censuses as well as the 2005-09 American Community Survey, as in Sanbonmatsu et al. (2011); ZIP code poverty rates are from Census 2000 only and are not interpolated. 
TABLE 3

Impacts of MTO on Children's Income in Adulthood

\begin{tabular}{|c|c|c|c|c|c|c|c|c|c|}
\hline \multirow{2}{*}{ Dep. Var.: V } & \multirow{2}{*}{$\begin{array}{c}\text { W-2 Earnings (\$) } \\
\text { 2008-12 ITT } \\
(1)\end{array}$} & \multicolumn{3}{|c|}{ Indiv. Earnings 2008-12 (\$) } & \multirow{2}{*}{\multicolumn{2}{|c|}{$\frac{\text { Indiv. Earnings (\$) }}{\text { Age } 26 \text { ITT } 2012 \text { ITT }}$}} & \multirow{2}{*}{$\begin{array}{c}\text { Employed (\%) } \\
\text { 2008-12 ITT } \\
(7) \\
\end{array}$} & \multirow{2}{*}{$\begin{array}{c}\text { Hhold. Inc. (\$) } \\
\text { 2008-12 ITT } \\
(8) \\
\end{array}$} & \multirow{2}{*}{$\begin{array}{c}\text { Inc. Growth (\$) } \\
2008-12 \text { ITT } \\
(9) \\
\end{array}$} \\
\hline & & $\begin{array}{l}\text { ITT } \\
(2) \\
\end{array}$ & $\begin{array}{c}\text { ITT w/Cntrls. } \\
(3) \\
\end{array}$ & $\begin{array}{c}\text { TOT } \\
(4) \\
\end{array}$ & & $\begin{array}{c}2012 \text { ITT } \\
(6) \\
\end{array}$ & & & \\
\hline \multicolumn{10}{|c|}{ Panel A: Children < Age 13 at Random Assignment } \\
\hline Exp. vs. Control & $\begin{array}{l}1339.8^{*} \\
(671.3)\end{array}$ & $\begin{array}{l}1624.0^{*} \\
(662.4)\end{array}$ & $\begin{array}{l}1298.9^{*} \\
(636.9)\end{array}$ & $\begin{array}{l}3476.8^{*} \\
(1418.2)\end{array}$ & $\begin{array}{l}1751.4^{+} \\
(917.4)\end{array}$ & $\begin{array}{l}1443.8^{*} \\
(665.8)\end{array}$ & $\begin{array}{c}1.824 \\
(2.083)\end{array}$ & $\begin{array}{l}2231.1^{* \star} \\
(771.3)\end{array}$ & $\begin{array}{l}1309.4^{*} \\
(518.5)\end{array}$ \\
\hline Sec. 8 vs. Control & $\begin{array}{c}687.4 \\
(698.7)\end{array}$ & $\begin{array}{r}1109.3 \\
(676.1)\end{array}$ & $\begin{array}{c}908.6 \\
(655.8)\end{array}$ & $\begin{array}{c}1723.2 \\
(1051.5)\end{array}$ & $\begin{array}{c}551.5 \\
(888.1)\end{array}$ & $\begin{array}{l}1157.7^{+} \\
(690.1)\end{array}$ & $\begin{array}{c}1.352 \\
(2.294)\end{array}$ & $\begin{array}{l}1452.4^{*} \\
(735.5)\end{array}$ & $\begin{array}{c}800.2 \\
(517.0)\end{array}$ \\
\hline Num of Obs. & 8420 & 8420 & 8420 & 8420 & 1625 & 2922 & 8420 & 8420 & 8420 \\
\hline Control Group Mean & 9548.6 & 11270.3 & 11270.3 & 11270.3 & 11398.3 & 11302.9 & 61.8 & 12702.4 & 4002.2 \\
\hline \multicolumn{10}{|c|}{ Panel B: Children Age 13-18 at Random Assignment } \\
\hline Exp. vs. Control & $\begin{array}{l}-761.2 \\
(870.6)\end{array}$ & $\begin{array}{l}-966.9 \\
(854.3)\end{array}$ & $\begin{array}{l}-879.5 \\
(817.3)\end{array}$ & $\begin{array}{l}-2426.7 \\
(2154.4)\end{array}$ & $\begin{array}{l}-539.0 \\
(795.4)\end{array}$ & $\begin{array}{c}-969.2 \\
(1122.2)\end{array}$ & $\begin{array}{l}-2.173 \\
(2.140)\end{array}$ & $\begin{array}{l}-1519.8 \\
(1102.2)\end{array}$ & $\begin{array}{l}-693.6 \\
(571.6)\end{array}$ \\
\hline Sec. 8 vs. Control & $\begin{array}{l}-1048.9 \\
(932.5)\end{array}$ & $\begin{array}{c}-1132.8 \\
(922.3)\end{array}$ & $\begin{array}{l}-1136.9 \\
(866.6)\end{array}$ & $\begin{array}{l}-2051.1 \\
(1673.7)\end{array}$ & $\begin{array}{l}-15.11 \\
(845.9)\end{array}$ & $\begin{array}{c}-869.0 \\
(1213.3)\end{array}$ & $\begin{array}{l}-1.329 \\
(2.275)\end{array}$ & $\begin{array}{c}-936.7 \\
(1185.9)\end{array}$ & $\begin{array}{l}-885.3 \\
(625.2)\end{array}$ \\
\hline Num of Obs. & 11623 & 11623 & 11623 & 11623 & 2331 & 2331 & 11623 & 11623 & 11623 \\
\hline Control Group Mean & 13897.1 & 15881.5 & 15881.5 & 15881.5 & 13968.9 & 16602.0 & 63.6 & 19169.1 & 4128.1 \\
\hline
\end{tabular}

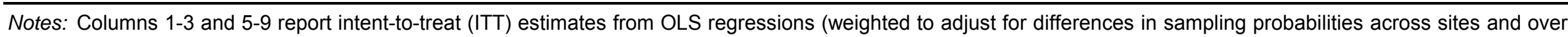

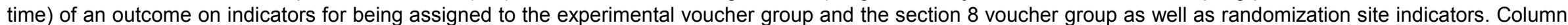

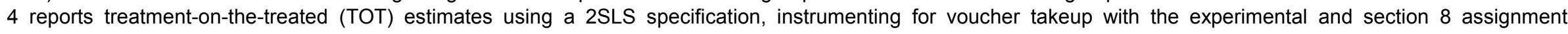

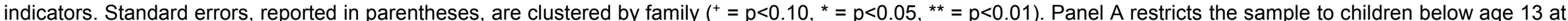

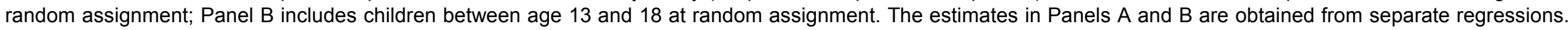

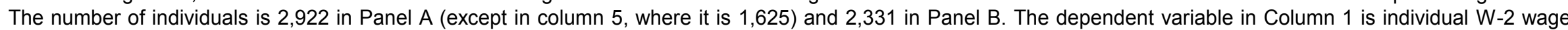

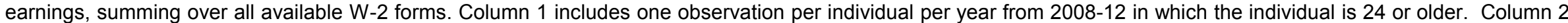

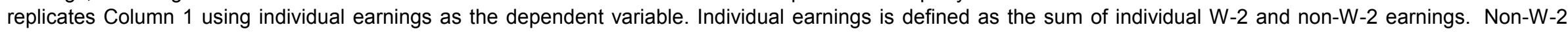

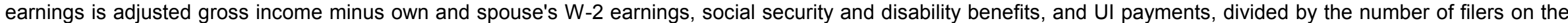

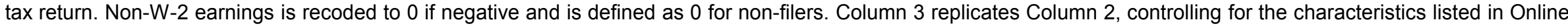

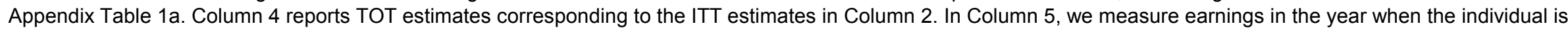

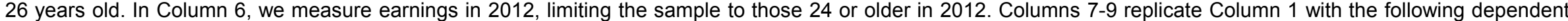

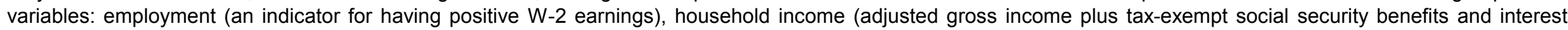

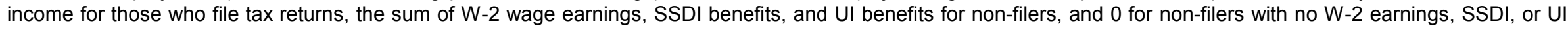
benefits), and individual earnings growth (the change in individual earnings between year $t-5$ and the current year $t$ ). 
TABLE 4

Impacts of MTO on Children's College Attendance Outcomes

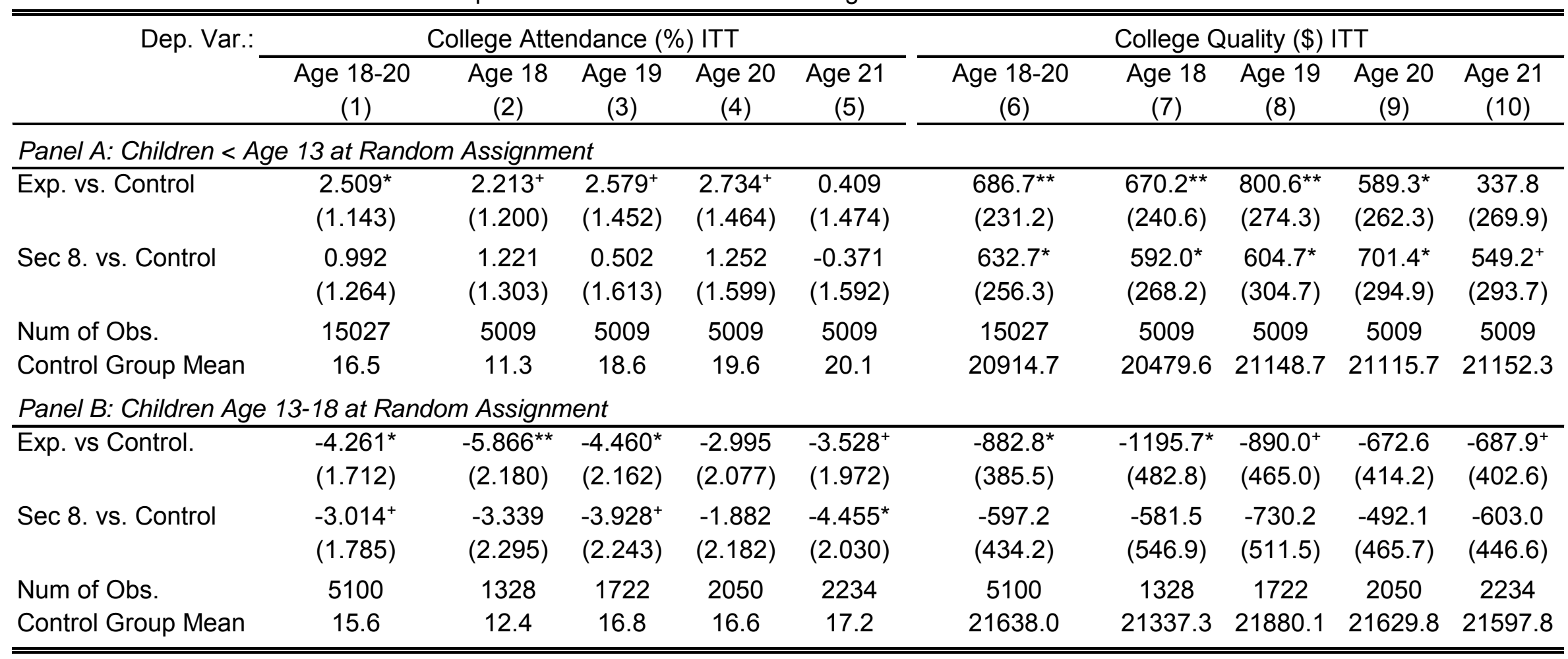

Notes: All columns report intent-to-treat (ITT) estimates from OLS regressions (weighted to adjust for differences in sampling probabilities across sites and over time) of an outcome on indicators for being assigned to the experimental voucher group and the section 8 voucher group as well as randomization site indicators. Standard errors, reported in parentheses, are clustered by family $\left({ }^{+}=p<0.10,{ }^{*}=p<0.05,{ }^{* *}=p<0.01\right)$. Panel A restricts the sample to children below age 13 at random assignment; Panel $B$ includes children between age 13 and 18 at random assignment. The estimates in Panels $A$ and $B$ are obtained from separate regressions. The dependent variable in Column 1 is an indicator for attending college in a given year (having one or more 1098-T tax forms filed on one's behalf), pooling data over the three years when the individual is ages 18-20 with one observation per year per individual. Years before 1999 are excluded because 1098-T data are available beginning only in 1999. Columns 2-5 replicate Column 1, using college attendance at each age between 18 and 21 as the dependent variable. The dependent variable in Column 6 is Chetty, Friedman, and Rockoff's (2014) earnings-based index of college quality, again pooling data from ages 18-20 starting in 1999. This index is constructed using U.S. population data as the mean earnings at age 31 of students enrolled in that college at age 20; children who do not attend college are assigned the mean earnings at age 31 of children who are not enrolled in any college at age 20 . Columns 7-10 replicate Column 2, using college quality at each age between 18 and 21 as the dependent variable. 
TABLE 5

Impacts of MTO on Marriage and Fertility

\begin{tabular}{|c|c|c|c|c|c|c|c|}
\hline \multirow{2}{*}{$\begin{array}{r}\text { Sample: } \\
\text { Dep. Var.: }\end{array}$} & \multirow{2}{*}{$\begin{array}{c}\text { All } \\
\text { Married } \\
(\%) \\
(1) \\
\end{array}$} & \multirow{2}{*}{$\begin{array}{c}\text { Males } \\
\text { Married } \\
(\%) \\
(2) \\
\end{array}$} & \multicolumn{5}{|c|}{ Females } \\
\hline & & & $\begin{array}{c}\text { Married } \\
(\%) \\
(3) \\
\end{array}$ & $\begin{array}{l}\text { Has } \\
\text { Birth } \\
(\%) \\
(4)\end{array}$ & $\begin{array}{c}\text { Teen } \\
\text { Birth } \\
(\%) \\
(5) \\
\end{array}$ & $\begin{array}{c}\text { Father on } \\
\text { Birth Cert. } \\
\begin{array}{c}(\%) \\
(6)\end{array} \\
\end{array}$ & $\begin{array}{c}\text { Birth with No } \\
\text { Father Present } \\
(\%) \\
(7) \\
\end{array}$ \\
\hline \multicolumn{8}{|c|}{ Panel A: Children < Age 13 at Random Assignment } \\
\hline Exp. vs. Control & $\begin{array}{c}1.934^{*} \\
(0.892)\end{array}$ & $\begin{array}{c}0.738 \\
(1.038)\end{array}$ & $\begin{array}{c}3.341^{*} \\
(1.476)\end{array}$ & $\begin{array}{l}-2.253 \\
(2.515)\end{array}$ & $\begin{array}{c}-0.670 \\
(2.117)\end{array}$ & $\begin{array}{l}6.849^{*} \\
(3.322)\end{array}$ & $\begin{array}{l}-4.807^{*} \\
(2.352)\end{array}$ \\
\hline Sec. 8 vs. Control & $\begin{array}{l}2.840^{* *} \\
(1.055)\end{array}$ & $\begin{array}{c}1.020 \\
(1.092)\end{array}$ & $\begin{array}{l}4.731^{* *} \\
(1.831)\end{array}$ & $\begin{array}{l}-0.285 \\
(2.679)\end{array}$ & $\begin{array}{c}2.409 \\
(2.375)\end{array}$ & $\begin{array}{c}2.671 \\
(3.523)\end{array}$ & $\begin{array}{l}-1.318 \\
(2.562)\end{array}$ \\
\hline Num of Obs. & 8420 & 4384 & 4036 & 2409 & 2379 & 1410 & 2409 \\
\hline Control Group Mean & 3.4 & 2.7 & 4.1 & 59.1 & 19.9 & 44.1 & 33.0 \\
\hline \multicolumn{8}{|c|}{ Panel B: Children Age 13-18 at Random Assignment } \\
\hline Exp. vs. Control & $\begin{array}{r}-0.0637 \\
(1.368)\end{array}$ & $\begin{array}{c}-1.441 \\
(1.848)\end{array}$ & $\begin{array}{c}1.173 \\
(1.988)\end{array}$ & $\begin{array}{l}-2.589 \\
(3.107)\end{array}$ & $\begin{array}{c}-2.404 \\
(3.172)\end{array}$ & $\begin{array}{l}-8.259^{*} \\
(4.153)\end{array}$ & $\begin{array}{c}4.253 \\
(3.626)\end{array}$ \\
\hline Sec. 8 vs. Control & $\begin{array}{c}0.654 \\
(1.465)\end{array}$ & $\begin{array}{l}-0.577 \\
(1.946)\end{array}$ & $\begin{array}{c}1.811 \\
(2.181)\end{array}$ & $\begin{array}{l}-0.547 \\
(3.304)\end{array}$ & $\begin{array}{l}-0.635 \\
(3.579)\end{array}$ & $\begin{array}{c}-0.182 \\
(4.409)\end{array}$ & $\begin{array}{c}-0.701 \\
(3.807)\end{array}$ \\
\hline Num of Obs. & 11623 & 5852 & 5771 & 1158 & 1141 & 888 & 1158 \\
\hline Control Group Mean & 9.3 & 9.3 & 9.2 & 77.8 & 24.7 & 46.7 & 41.4 \\
\hline
\end{tabular}

Notes: All columns report intent-to-treat (ITT) estimates from OLS regressions (weighted to adjust for differences in sampling probabilities across sites and over time) of an outcome on indicators for being assigned to the experimental voucher group and the section 8 voucher group as well as randomization site indicators. Standard errors, reported in parentheses, are clustered by family $\left({ }^{+}=p<0.10,{ }^{*}=p<0.05,{ }^{* *}=p<0.01\right)$. Panel A restricts the sample to children below age 13 at random assignment; Panel B includes children between age 13 and 18 at random assignment. The estimates in Panels $A$ and $B$ are obtained from separate regressions. Column 1 includes one observation per individual per year from 2008-12 in which the individual is 24 or older. The dependent variable in column 1 is an indicator for filing a tax return as a married individual in a given year. Columns 2 and 3 replicate Column 1 for males and females, respectively. Columns 4-7 restrict the sample to females and include one observation per individual. The dependent variable in Column 4 is an indicator for having a child before June 2014. In Column 5, it is an indicator for having a child before the age of 19. Column 6 restricts the sample to females who have a birth; the dependent variable in this column is an indicator for having a father listed on the first-born child's SSN application. In Column 7, the dependent variable is an indicator for having one or more births, with no father listed on the SSN application for the first birth. 
TABLE 6

Impacts of MTO on Children's Neighborhood Characteristics in Adulthood

\begin{tabular}{|c|c|c|c|c|}
\hline \multirow[t]{2}{*}{ Dep. Var.: } & $\begin{array}{l}\text { Poverty Share in } \\
\text { ZIP 2008-12 (\%) }\end{array}$ & $\begin{array}{l}\text { Mean Income in } \\
\text { ZIP 2008-12 (\$) }\end{array}$ & $\begin{array}{l}\text { Black Share in } \\
\text { ZIP 2008-12 (\%) }\end{array}$ & $\begin{array}{l}\text { Single Mother Share } \\
\text { in ZIP 2008-12 (\%) }\end{array}$ \\
\hline & $(1)$ & $(2)$ & $(3)$ & $(4)$ \\
\hline \multicolumn{5}{|c|}{ Panel A: Children < Age 13 at Random Assignment } \\
\hline Exp. vs. Control & $\begin{array}{c}-1.592^{* *} \\
(0.602)\end{array}$ & $\begin{array}{l}1345.9^{* *} \\
(489.5)\end{array}$ & $\begin{array}{l}-2.852^{*} \\
(1.417)\end{array}$ & $\begin{array}{l}-1.812^{*} \\
(0.862)\end{array}$ \\
\hline Sec. 8 vs. Control & $\begin{array}{l}-1.394^{*} \\
(0.699)\end{array}$ & $\begin{array}{l}1322.0^{*} \\
(558.6)\end{array}$ & $\begin{array}{l}-5.654^{* *} \\
(1.714)\end{array}$ & $\begin{array}{l}-3.087^{* *} \\
(1.001)\end{array}$ \\
\hline Num of Obs. & 6649 & 6649 & 6651 & 6648 \\
\hline Control Group Mean & 23.8 & 25014.3 & 43.0 & 42.0 \\
\hline \multicolumn{5}{|c|}{ Panel B: Children Age 13-18 at Random Assignment } \\
\hline Exp. vs. Control & $\begin{array}{l}-0.523 \\
(0.643)\end{array}$ & $\begin{array}{c}604.2 \\
(478.5)\end{array}$ & $\begin{array}{c}0.465 \\
(1.654)\end{array}$ & $\begin{array}{l}-0.294 \\
(0.940)\end{array}$ \\
\hline Sec. 8 vs. Control & $\begin{array}{l}-0.928 \\
(0.698)\end{array}$ & $\begin{array}{c}442.0 \\
(524.2)\end{array}$ & $\begin{array}{l}-2.631 \\
(1.715)\end{array}$ & $\begin{array}{l}-1.856^{+} \\
(0.976)\end{array}$ \\
\hline Num of Obs. & 9149 & 9149 & 9149 & 9148 \\
\hline Control Group Mean & 23.6 & 25170.5 & 39.6 & 40.1 \\
\hline
\end{tabular}

Notes: All columns report intent-to-treat (ITT) estimates from OLS regressions (weighted to adjust for differences in sampling probabilities across sites and over time) of an outcome on indicators for being assigned to the experimental voucher group and the section 8 voucher group as well as randomization site indicators. Standard errors, reported in parentheses, are clustered by family $\left({ }^{+}=p<0.10,{ }^{*}=p<0.05,{ }^{* *}=p<0.01\right)$. In this table, we only include observations where ZIP code information in the relevant year is available (based on 1040 tax returns, W2 's, or other information returns). In 2012 , ZIP code data are available for $79.56 \%$ of observations for children age 24 or older. Panel A restricts the sample to children below age 13 at random assignment; Panel B includes children between age 13 and 18 at random assignment. The estimates in Panels $A$ and $B$ are obtained from separate regressions. Outcome variables are defined using ZIP-code level data from the 2000 Census. All columns include one observation per individual per year from 2008-12 in which the individual is 24 or older and in which ZIP code information is available. The dependent variable in Columns 1 is the poverty share (share of households below the poverty line in the 2000 Census) in the individual's ZIP code. Columns 2-4 replicate Column 1 with the following dependent variables: mean income in the ZIP code (aggregate income divided by the number of individuals 16-64), black share (number of people who are black alone divided by total population in 2000) and single mother share (number of households with female heads and no husband present with own children present divided by the total number of households with own children present). 
TABLE 7

Heterogeneity of Treatment Effects by Gender

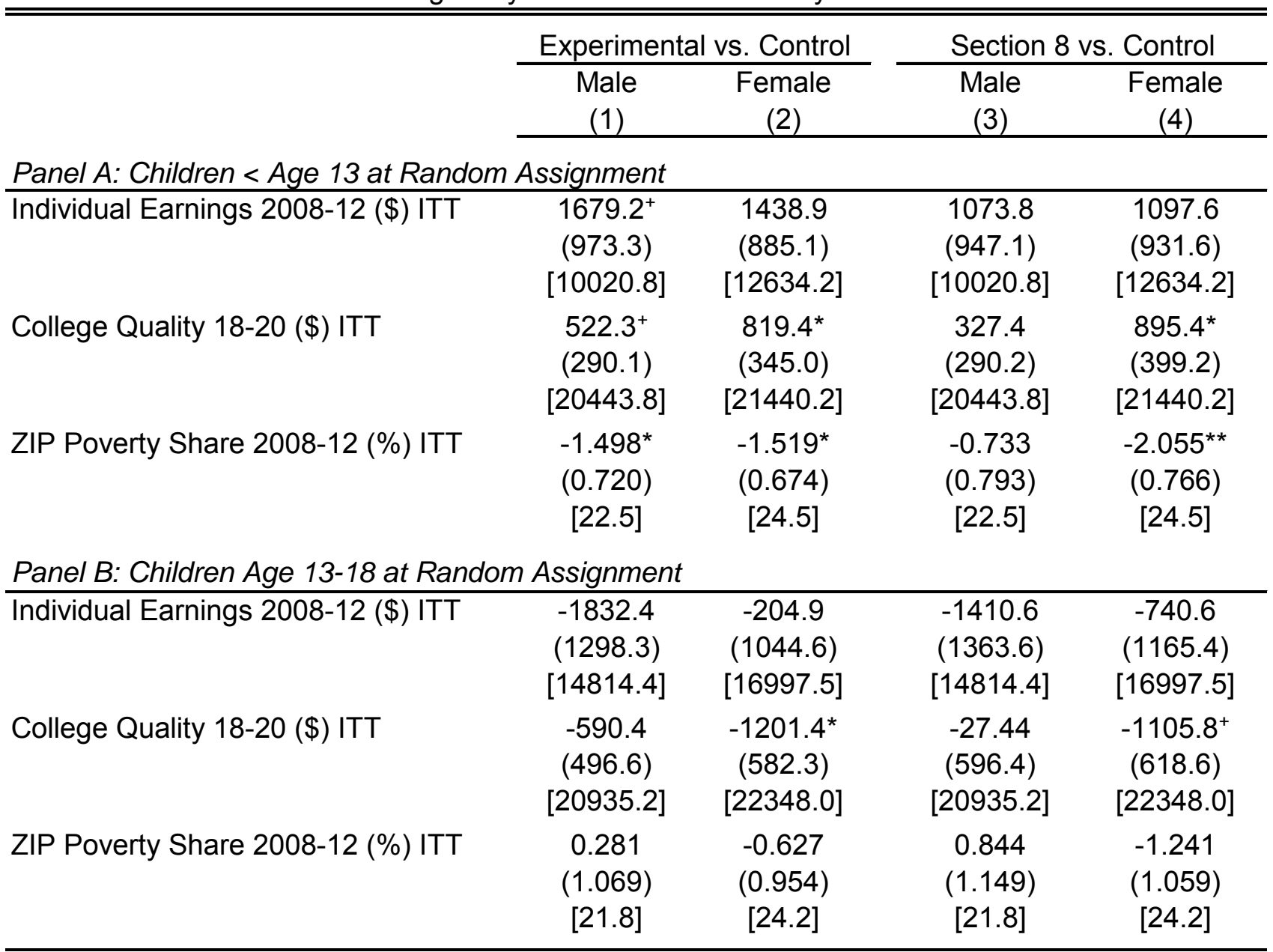

Notes: This table replicates the intent-to-treat (ITT) OLS regression specifications in Column 2 of Table 3 (individual earnings), Column 6 of Table 4 (college quality), and Column 1 of Table 6 (poverty share) separately for male and female children. Columns 1 and 2 report the coefficient on the indicator for being assigned to the experimental voucher group; columns 3 and 4 report the coefficient on the indicator for being assigned to the Section 8 voucher group. The estimates in Columns 1 and 3 are for males, and the two estimates in each row of these columns come from a single OLS regression analogous to that in Column 2 of Table 3. The estimates in Columns 2 and 4 for females are constructed analogously. Standard errors, reported in parentheses, are clustered by family $\left(^{+}=p<0.10,{ }^{*}=p<0.05,{ }^{* *}=p<0.01\right)$. Control group means for each estimation sample are reported in square brackets. Panel A restricts the sample to children below age 13 at random assignment; Panel $B$ includes children between age 13 and 18 at random assignment. See the notes to Tables 3, 4 and 6 for further details on specifications and variable definitions. 
TABLE 8

Linear Exposure Effect Estimates

\begin{tabular}{|c|c|c|c|c|c|c|c|}
\hline \multirow[t]{2}{*}{ Dep. Var.: } & \multirow{2}{*}{$\begin{array}{c}\text { Indiv. Earn. (\$) } \\
\text { 2008-2012 ITT } \\
(1)\end{array}$} & \multicolumn{2}{|c|}{ Household Income (\$) } & \multirow{2}{*}{$\begin{array}{l}\text { Coll. Qual. 18- } \\
20 \text { ITT (\$) } \\
(4)\end{array}$} & \multirow{2}{*}{$\begin{array}{c}\text { Married } \\
\text { ITT (\%) } \\
(5)\end{array}$} & \multirow{2}{*}{$\begin{array}{c}\text { ZIP Poverty } \\
\text { Share ITT }(\%) \\
(6)\end{array}$} & \multirow{2}{*}{$\begin{array}{c}\text { Taxes Paid } \\
\text { ITT (\$) } \\
(7)\end{array}$} \\
\hline & & $\begin{array}{c}2008-2012 \text { ITT } \\
(2) \\
\end{array}$ & $\begin{array}{c}\text { Age } 26 \text { ITT } \\
(3)\end{array}$ & & & & \\
\hline Experimental $\times$ Age at $\mathrm{RA}$ & $\begin{array}{l}-364.1^{+} \\
(199.5)\end{array}$ & $\begin{array}{c}-723.7^{\star *} \\
(255.5)\end{array}$ & $\begin{array}{l}-564.9^{*} \\
(282.8)\end{array}$ & $\begin{array}{c}-171.0^{\star *} \\
(55.16)\end{array}$ & $\begin{array}{l}-0.582^{*} \\
(0.290)\end{array}$ & $\begin{array}{l}0.261^{+} \\
(0.139)\end{array}$ & $\begin{array}{l}-65.81^{* *} \\
(23.88)\end{array}$ \\
\hline Section $8 \times$ Age at RA & $\begin{array}{l}-229.5 \\
(208.9)\end{array}$ & $\begin{array}{l}-338.0 \\
(266.4)\end{array}$ & $\begin{array}{c}157.2 \\
(302.0)\end{array}$ & $\begin{array}{l}-117.1^{+} \\
(63.95)\end{array}$ & $\begin{array}{l}-0.433 \\
(0.316)\end{array}$ & $\begin{array}{l}0.0109 \\
(0.156)\end{array}$ & $\begin{array}{l}-42.48^{+} \\
(24.85)\end{array}$ \\
\hline Experimental & $\begin{array}{l}4823.3^{*} \\
(2404.3)\end{array}$ & $\begin{array}{l}9441.1^{* *} \\
(3035.8)\end{array}$ & $\begin{array}{l}8057.1^{*} \\
(3760.9)\end{array}$ & $\begin{array}{c}1951.3^{* *} \\
(575.1)\end{array}$ & $\begin{array}{l}8.309^{*} \\
(3.445)\end{array}$ & $\begin{array}{l}-4.371^{*} \\
(1.770)\end{array}$ & $\begin{array}{l}831.2^{* *} \\
(279.4)\end{array}$ \\
\hline Section 8 & $\begin{array}{c}2759.9 \\
(2506.1)\end{array}$ & $\begin{array}{c}4447.7 \\
(3111.3)\end{array}$ & $\begin{array}{l}-1194.0 \\
(3868.2)\end{array}$ & $\begin{array}{l}1461.1^{*} \\
(673.6)\end{array}$ & $\begin{array}{c}7.193^{+} \\
(3.779)\end{array}$ & $\begin{array}{l}-1.237 \\
(2.021)\end{array}$ & $\begin{array}{l}521.7^{+} \\
(287.5)\end{array}$ \\
\hline Number of Observations & 20043 & 20043 & 3956 & 20127 & 20043 & 15798 & 20043 \\
\hline Control Group Mean & 13807.1 & 16259.9 & 14692.6 & 21085.1 & 6.6 & 23.7 & 627.8 \\
\hline
\end{tabular}

Notes: This table reports intent-to-treat (ITT) estimates from OLS regressions (weighted to adjust for differences in sampling probabilities across sites and over time) of an outcome on indicators for being assigned to the experimental voucher group and the section 8 voucher group, interactions between the experimental/section 8 indicators and age at random assignment (RA), and interactions between randomization site indicators and age at RA. All regressions are estimated using all children in the sample with available outcome data. Standard errors, reported in parentheses, are clustered by family $\left({ }^{+}=p<0.10,{ }^{*}=p<0.05,{ }^{* *}=p<0.01\right)$. The dependent variable is individual earnings in Column 1 and household income in Column 2 and 3. See notes to Table 3 for definitions of these variables. In Columns 4-7, we replicate Column 1 with the dependent variables used in Column 6 of Table 4, Column 1 of Table 5, Column 1 of Table 6, and Column 2 of Table 12. See notes to those tables for definitions of these variables. Columns 1, 2, and 5-7 include one observation per individual per year from 2008-12 in which the individual is 24 or older. Column 3 includes one observation per individual at age 26. Column 4 includes one observation per individual per year from ages 18-20, as in Table 4. The Experimental $x$ Age at RA coefficient can be interpreted as the change in the impact of being assigned to the experimental group for a child who is one year older at random assignment, and the Section $8 \times$ Age at RA coefficient can be interpreted analogously. 
TABLE 9

Impacts of MTO on Adults' Income

\begin{tabular}{lccccc}
\hline \hline \multirow{2}{*}{ Dep. Var.: } & \multicolumn{3}{c}{ Individual Earnings (\$) } & Employed (\%) & Hhold. Inc. (\$) \\
\cline { 2 - 4 } & $2008-12$ ITT & ITT w/Cntrls. & 2012 ITT & ITT & ITT \\
& $(1)$ & $(2)$ & $(3)$ & $(4)$ & $(5)$ \\
\hline Exp. vs. Control & -354.1 & -168.7 & -681.9 & -0.946 & -338.5 \\
& $(621.9)$ & $(558.2)$ & $(675.1)$ & $(1.704)$ & $(740.4)$ \\
Sec. 8 vs. Control & 249.5 & 468.1 & -99.67 & -0.702 & 516.7 \\
& $(675.2)$ & $(609.0)$ & $(758.4)$ & $(1.833)$ & $(829.4)$ \\
Num of Obs. & 21075 & 21075 & 4215 & 21075 & 21075 \\
Control Group Mean & 14381.0 & 14381.0 & 13700.6 & 54.9 & 17951.5 \\
\hline \hline
\end{tabular}

Notes: All columns report intent-to-treat (ITT) estimates from OLS regressions (weighted to adjust for differences in sampling probabilities across sites and over time) of an outcome on indicators for being assigned to the experimental voucher group and the section 8 voucher group as well as randomization site indicators. Standard errors, reported in parentheses, are clustered by family $\left(^{+}=p<0.10,{ }^{*}=p<0.05,{ }^{* *}=\right.$ $p<0.01)$. The sample consists of all individuals in the linked MTO-Tax dataset who were not classified as children at the point of random assignment. The number of individuals is 4,215 in all columns. The dependent variable in Columns 1-3 is individual earnings. Column 1 includes one observation per individual per year from 2008-12 in which the individual is 24 or older. Column 2 replicates Column 1, controlling for the predetermined characteristics listed in Appendix Table 1a. In Column 3 we replicate Column 1 using data from 2012 only. Columns 4 and 5 replicate Column 1 using employment and household income as the dependent variables. See notes to Table 3 for definitions of all dependent variables. 
TABLE 10

MTO Impacts on Children's Earnings: Comparison to MTO Final Impacts Evaluation

\begin{tabular}{|c|c|c|c|c|c|c|}
\hline \multirow{2}{*}{$\begin{array}{r}\text { Dep. Var.: } \\
\text { Sample: }\end{array}$} & \multicolumn{4}{|c|}{$\begin{array}{l}\text { Individual Earnings } \\
\text { Measured Age } \geq 24 \quad(\$)\end{array}$} & \multicolumn{2}{|c|}{$\begin{array}{c}\text { Individual Earnings } \\
\text { Measured Age 16-21 (\$) }\end{array}$} \\
\hline & $\begin{array}{c}<\text { Age } 13 \\
2008-12 \\
(1)\end{array}$ & $\begin{array}{c}\text { All Children } \\
2008-12 \\
(2) \\
\end{array}$ & $\begin{array}{c}<\text { Age } 13 \\
2008 \\
(3)\end{array}$ & $\begin{array}{c}\text { All Children } \\
2008 \\
(4) \\
\end{array}$ & $\begin{array}{c}<\text { Age } 13 \\
\text { Up to } 2012 \\
(5)\end{array}$ & $\begin{array}{c}\text { All Children } \\
2008 \\
(6) \\
\end{array}$ \\
\hline Exp. vs. Control & $\begin{array}{l}1624.0^{*} \\
(662.4)\end{array}$ & $\begin{array}{c}302.5 \\
(578.2)\end{array}$ & $\begin{array}{c}1840.9 \\
(1339.7)\end{array}$ & $\begin{array}{l}-236.6 \\
(757.0)\end{array}$ & $\begin{array}{l}-30.97 \\
(229.7)\end{array}$ & $\begin{array}{l}-286.3 \\
(410.8)\end{array}$ \\
\hline Sec. 8 vs. Control & $\begin{array}{l}1109.3 \\
(676.1)\end{array}$ & $\begin{array}{l}-44.06 \\
(621.5)\end{array}$ & $\begin{array}{l}2860.1^{+} \\
(1486.1)\end{array}$ & $\begin{array}{l}-213.7 \\
(799.9)\end{array}$ & $\begin{array}{c}197.4 \\
(176.6)\end{array}$ & $\begin{array}{c}190.0 \\
(351.8)\end{array}$ \\
\hline $\begin{array}{l}\text { Num of Obs. } \\
\text { Control Group Mean }\end{array}$ & $\begin{array}{c}8420 \\
11270.3\end{array}$ & $\begin{array}{c}20043 \\
13807.1\end{array}$ & $\begin{array}{c}552 \\
11615.0\end{array}$ & $\begin{array}{c}2851 \\
14531.5\end{array}$ & $\begin{array}{l}30011 \\
4033.3\end{array}$ & $\begin{array}{c}3384 \\
4923.0\end{array}$ \\
\hline
\end{tabular}

Notes: All columns report intent-to-treat (ITT) estimates from OLS regressions (weighted to adjust for differences in sampling probabilities across sites and over time) of an outcome on indicators for being assigned to the experimental voucher group and the section 8 voucher group as well as randomization site indicators. Standard errors, reported in parentheses, are clustered by family $\left(^{+}=p<0.10,{ }^{*}=\right.$ $\left.p<0.05,{ }^{* *}=p<0.01\right)$. The dependent variable is individual earnings in all columns, defined in the notes to Table 3. Column 1 replicates the specification in Column 2 of Table 3, Panel A, and includes children below age thirteen at age of random assignment. This specification includes one observation per individual per year from 2008-12 in which the individual is 24 or older. Column 2 replicates Column 1 , pooling all children (irrespective of age at random assignment) in the sample. Columns 3 and 4 replicate Columns 1 and 2, limiting the sample to data from the 2008 tax year, which was the last year of data available for the MTO final impacts evaluation (Sanbonmatsu et al. 2011). Columns 3 and 4 therefore only include children who were 24 or older in 2008. Column 5 replicates column 1, with one observation per year in which the child is between the ages of 16-21, using all years in which we observe individual earnings (1999-2012). Column 6 replicates Column 4, restricting the sample to children between the ages of 16 and 21 in 2008, as in the MTO final impacts evaluation. 
TABLE 11

Multiple Comparisons: F Tests for Subgroup Heterogeneity

\begin{tabular}{|c|c|c|c|c|c|c|}
\hline Dep. Var.: & $\begin{array}{c}\text { Indiv. Earnings } \\
2008-12(\$) \\
\text { (1) }\end{array}$ & $\begin{array}{l}\text { Hhold. Inc. } \\
\text { 2008-12 (\$) } \\
\text { (2) }\end{array}$ & $\begin{array}{c}\text { College } \\
\text { Attendance } \\
\text { 18-20 (\%) } \\
\text { (3) }\end{array}$ & $\begin{array}{c}\text { College } \\
\text { Quality } \\
18-20(\$) \\
(4)\end{array}$ & $\begin{array}{c}\text { Married } \\
(\%) \\
(5)\end{array}$ & $\begin{array}{c}\text { Poverty } \\
\text { Share in ZIP } \\
2008-12(\%) \\
\text { (6) }\end{array}$ \\
\hline \multicolumn{7}{|c|}{ Panel A: p-values for Comparisons by Age Group } \\
\hline Exp. vs. Control & 0.0203 & 0.0034 & 0.0035 & 0.0006 & 0.0814 & 0.0265 \\
\hline Sec. 8 vs. Control & 0.0864 & 0.0700 & 0.1517 & 0.0115 & 0.0197 & 0.0742 \\
\hline Exp \& Sec. 8 vs. Control & 0.0646 & 0.0161 & 0.0218 & 0.0020 & 0.0434 & 0.0627 \\
\hline \multicolumn{7}{|c|}{ Panel B: p-values for Comparisons by Age, Site, Gender, and Race Groups } \\
\hline Exp. vs. Control & 0.1121 & 0.0086 & 0.0167 & 0.0210 & 0.2788 & 0.0170 \\
\hline Sec. 8 vs. Control & 0.0718 & 0.1891 & 0.1995 & 0.0223 & 0.1329 & 0.0136 \\
\hline Exp \& Sec. 8 vs. Control & 0.1802 & 0.0446 & 0.0328 & 0.0202 & 0.1987 & 0.0016 \\
\hline
\end{tabular}

Notes: This table presents p-values for non-zero MTO treatment effects in subgroups for selected outcomes analyzed in Tables 3 to 6 . In Panel A, we regress the outcome on the MTO treatment indicators (Exp and S8) interacted with an indicator for being below age 13 at RA (Below13), including site dummies as controls, and clustering standard errors by family. We then run $F$ tests for the null hypothesis that the Exp and Exp-Below13 interaction effect are both 0 (row 1), the S8 and S8-Below13 interaction effect are both 0 (row 2), and both sets of treatment effect estimates are 0 (row 3). In Panel B, we regress the outcomes on the MTO treatment indicators interacted with the following subgroup indicators: the five randomization sites, racial groups (Black, Hispanic, and Other), gender, and age at RA below 13. As in Panel A, we then test the hypothesis that the experimental indicator and all of its subgroup interactions are 0 (row 1), the Section 8 indicator and all of its interactions are 0 (row 2), and both sets of treatment effects are 0 (row 3). See notes to Tables 3-6 for definitions of the outcome variables. 
TABLE 12

Impacts of MTO on Federal Income Tax Payments

\begin{tabular}{|c|c|c|c|}
\hline \multirow{2}{*}{\multicolumn{2}{|c|}{$\begin{array}{c}\text { Dep. Var.: Filing a Tax Return (\%) } \\
2008-12 \text { ITT } \\
(1) \\
\end{array}$}} & \multicolumn{2}{|c|}{ Total Income Taxes Paid (\$) } \\
\hline & & $\begin{array}{c}2008-12 \text { ITT } \\
(2) \\
\end{array}$ & $\begin{array}{c}2008-12 \text { TOT } \\
(3)\end{array}$ \\
\hline \multicolumn{4}{|c|}{ Panel A: Children < Age 13 at Random Assignment } \\
\hline Exp. vs. Control & $\begin{array}{l}5.748^{\star *} \\
(2.055)\end{array}$ & $\begin{array}{l}183.9^{\star *} \\
(62.80)\end{array}$ & $\begin{array}{l}393.6^{\star *} \\
(134.1)\end{array}$ \\
\hline Sec. 8 vs. Control & $\begin{array}{l}4.789^{*} \\
(2.237)\end{array}$ & $\begin{array}{l}109.0^{*} \\
(54.76)\end{array}$ & $\begin{array}{l}169.1^{*} \\
(85.48)\end{array}$ \\
\hline $\begin{array}{l}\text { Num of Obs. } \\
\text { Control Group Mean }\end{array}$ & $\begin{array}{l}8420 \\
59.3\end{array}$ & $\begin{array}{l}8420 \\
447.5\end{array}$ & $\begin{array}{l}8420 \\
447.5\end{array}$ \\
\hline \multicolumn{4}{|c|}{ Panel B: Children Age 13-18 at Random Assignment } \\
\hline Exp. vs. Control & $\begin{array}{l}-2.079 \\
(2.055)\end{array}$ & $\begin{array}{l}-175.9^{+} \\
(91.15)\end{array}$ & $\begin{array}{l}-441.6^{+} \\
(230.8)\end{array}$ \\
\hline Sec. 8 vs. Control & $\begin{array}{l}-2.248 \\
(2.249)\end{array}$ & $\begin{array}{l}-127.1 \\
(95.52)\end{array}$ & $\begin{array}{l}-230.1 \\
(173.2)\end{array}$ \\
\hline $\begin{array}{l}\text { Num of Obs. } \\
\text { Control Group Mean }\end{array}$ & $\begin{array}{l}11623 \\
65.6\end{array}$ & $\begin{array}{l}11623 \\
775.2\end{array}$ & $\begin{array}{l}11623 \\
775.2\end{array}$ \\
\hline
\end{tabular}

Notes: Columns 1 and 2 report intent-to-treat (ITT) estimates from OLS regressions (weighted to adjust for differences in sampling probabilities across sites and over time) of an outcome on indicators for being assigned to the experimental voucher group and the section 8 voucher group as well as randomization site indicators. Column 3 reports treatment-on-the-treated (TOT) estimates using a 2SLS specification, instrumenting for voucher takeup with the experimental and section 8 assignment indicators. Standard errors, reported in parentheses, are clustered by family $\left({ }^{+}=p<0.10,{ }^{*}=p<0.05,{ }^{* *}=p<0.01\right)$. Panel A restricts the sample to children below age 13 at random assignment; Panel $B$ includes children between age 13 and 18 at random assignment. The estimates in Panels $A$ and $B$ are obtained from separate regressions. The dependent variable in columns 1 is an indicator for filing a 1040 tax return. In Columns 2 and 3, the dependent variable is total taxes paid, defined as the total tax field from form 1040 for filers and total taxes withheld on $\mathrm{W}$ 2 forms for non-filers. Columns 1 and 2 include one observation per individual per year from 2008-12 in which the individual is 24 or older. Column 3 reports TOT estimates corresponding to the ITT estimates in column 3. 
APPENDIX TABLE 1a

Summary Statistics and Balance Tests for all Baseline Covariates for Children in MTO-Tax Data Linked Sample

\begin{tabular}{|c|c|c|c|c|c|c|}
\hline & \multicolumn{3}{|c|}{$<$ Age 13 at Random Assignment } & \multicolumn{3}{|c|}{ Age 13-18 at Random Assignment } \\
\hline & $\begin{array}{c}\text { Control } \\
\text { Grp. Mean } \\
(1)\end{array}$ & $\begin{array}{c}\text { Exp. vs. } \\
\text { Control } \\
(2)\end{array}$ & $\begin{array}{c}\text { Sec 8. vs. } \\
\text { Control } \\
(3)\end{array}$ & $\begin{array}{c}\text { Control } \\
\text { Grp. Mean } \\
(4)\end{array}$ & $\begin{array}{c}\text { Exp. vs. } \\
\text { Control } \\
(5)\end{array}$ & $\begin{array}{c}\text { Sec 8. vs. } \\
\text { Control } \\
(6)\end{array}$ \\
\hline \multicolumn{7}{|l|}{ Pre-Randomization Children's Characteristics } \\
\hline Age at Random Assignment & 8.2 & $\begin{array}{l}-0.1 \\
(0.1)\end{array}$ & $\begin{array}{l}-0.0 \\
(0.1)\end{array}$ & 15.1 & $\begin{array}{l}0.1 \\
(0.1)\end{array}$ & $\begin{array}{l}-0.1 \\
(0.1)\end{array}$ \\
\hline Male (\%) & 52.7 & $\begin{array}{l}-1.7 \\
(1.7)\end{array}$ & $\begin{array}{l}-1.9 \\
(1.9)\end{array}$ & 51.1 & $\begin{array}{l}-1.9 \\
(2.6)\end{array}$ & $\begin{array}{c}0.1 \\
(2.8)\end{array}$ \\
\hline $\begin{array}{l}\text { Problems that made it difficult to get to school } \\
\text { and/or to play active games }(\%)\end{array}$ & 6.2 & $\begin{array}{c}0.8 \\
(0.9)\end{array}$ & $\begin{array}{c}0.1 \\
(1.0)\end{array}$ & 6.8 & $\begin{array}{c}0.9 \\
(1.5)\end{array}$ & $\begin{array}{c}0.7 \\
(1.5)\end{array}$ \\
\hline $\begin{array}{l}\text { Missing: Problems that made it difficult to get } \\
\text { to school or to play active games }(\%)\end{array}$ & 5.7 & $\begin{array}{l}-0.0 \\
(1.0)\end{array}$ & $\begin{array}{c}0.2 \\
(1.1)\end{array}$ & 7.7 & $\begin{array}{c}0.1 \\
(1.5)\end{array}$ & $\begin{array}{l}-0.3 \\
(1.7)\end{array}$ \\
\hline $\begin{array}{l}\text { Problems that required special medicine } \\
\text { and/or equipment }(\%)\end{array}$ & 8.9 & $\begin{array}{c}0.1 \\
(1.0)\end{array}$ & $\begin{array}{l}-0.3 \\
(1.1)\end{array}$ & 7.0 & $\begin{array}{c}0.3 \\
(1.4)\end{array}$ & $\begin{array}{l}2.6^{+} \\
(1.5)\end{array}$ \\
\hline $\begin{array}{l}\text { Suspended or expelled from school in past } 2 \\
\text { years }(\%)\end{array}$ & 4.9 & $\begin{array}{c}0.7 \\
(0.8)\end{array}$ & $\begin{array}{c}0.4 \\
(0.9)\end{array}$ & 17.6 & $\begin{array}{c}1.0 \\
(2.0)\end{array}$ & $\begin{array}{c}0.4 \\
(2.2)\end{array}$ \\
\hline $\begin{array}{l}\text { Missing: Suspended or expelled from school in } \\
\text { past } 2 \text { years }(\%)\end{array}$ & 4.2 & $\begin{array}{l}-0.8 \\
(0.8)\end{array}$ & $\begin{array}{c}0.5 \\
(0.9)\end{array}$ & 5.9 & $\begin{array}{c}0.1 \\
(1.3)\end{array}$ & $\begin{array}{l}3.5^{\star} \\
(1.6)\end{array}$ \\
\hline $\begin{array}{l}\text { Special school, class, or help for behavioral } \\
\text { problems in past } 2 \text { years (\%) }\end{array}$ & 4.7 & $\begin{array}{c}0.3 \\
(0.8)\end{array}$ & $\begin{array}{c}1.2 \\
(0.9)\end{array}$ & 6.6 & $\begin{array}{c}2.1 \\
(1.4)\end{array}$ & $\begin{array}{l}2.5^{+} \\
(1.5)\end{array}$ \\
\hline $\begin{array}{l}\text { Missing: Special school, class, or help for } \\
\text { behavioral problems in past } 2 \text { years }(\%)\end{array}$ & 14.2 & $\begin{array}{l}-2.1 \\
(1.4)\end{array}$ & $\begin{array}{l}-1.0 \\
(1.5)\end{array}$ & 19.9 & $\begin{array}{c}2.1 \\
(2.4)\end{array}$ & $\begin{array}{c}1.3 \\
(2.5)\end{array}$ \\
\hline $\begin{array}{l}\text { Special class for gifted students or did } \\
\text { advanced work }(\%)\end{array}$ & 11.1 & $\begin{array}{l}-0.3 \\
(1.2)\end{array}$ & $\begin{array}{l}-0.6 \\
(1.2)\end{array}$ & 16.6 & $\begin{array}{l}-4.0^{*} \\
(2.1)\end{array}$ & $\begin{array}{c}0.3 \\
(2.4)\end{array}$ \\
\hline $\begin{array}{l}\text { Missing: Special class for gifted students or } \\
\text { did advanced work }(\%)\end{array}$ & 5.8 & $\begin{array}{l}-0.7 \\
(0.9)\end{array}$ & $\begin{array}{l}-0.1 \\
(1.0)\end{array}$ & 10.7 & $\begin{array}{l}-0.9 \\
(1.7)\end{array}$ & $\begin{array}{l}-0.0 \\
(1.8)\end{array}$ \\
\hline $\begin{array}{l}\text { Special school, class, or help for learning } \\
\text { problem in past } 2 \text { years (\%) }\end{array}$ & 12.9 & $\begin{array}{l}-1.4 \\
(1.2)\end{array}$ & $\begin{array}{l}-2.3^{+} \\
(1.2)\end{array}$ & 15.6 & $\begin{array}{l}3.5^{+} \\
(2.0)\end{array}$ & $\begin{array}{c}1.5 \\
(2.1)\end{array}$ \\
\hline $\begin{array}{l}\text { Missing: Special school, class, or help for } \\
\text { learning problem in past } 2 \text { years }(\%)\end{array}$ & 3.4 & $\begin{array}{c}0.1 \\
(0.7)\end{array}$ & $\begin{array}{c}0.9 \\
(0.8)\end{array}$ & 5.5 & $\begin{array}{c}0.4 \\
(1.2)\end{array}$ & $\begin{array}{l}2.6^{+} \\
(1.5)\end{array}$ \\
\hline $\begin{array}{l}\text { School asked to talk about problems child has } \\
\text { with schoolwork or behavior in past } 2 \text { yrs. (\%) }\end{array}$ & 17.9 & $\begin{array}{c}0.6 \\
(1.5)\end{array}$ & $\begin{array}{l}-0.4 \\
(1.6)\end{array}$ & 30.1 & $\begin{array}{c}1.0 \\
(2.6)\end{array}$ & $\begin{array}{l}-0.3 \\
(2.7)\end{array}$ \\
\hline $\begin{array}{l}\text { Child in hospital before } 1 \text { st birthday because } \\
\text { he/she was sick or injured (\%) }\end{array}$ & 4.4 & $\begin{array}{l}-0.4 \\
(0.7)\end{array}$ & $\begin{array}{l}-0.2 \\
(0.8)\end{array}$ & & & \\
\hline $\begin{array}{l}\text { Missing: Child in hospital before 1st birthday } \\
\text { because he/she was sick or injured (\%) }\end{array}$ & 1.9 & $\begin{array}{l}-0.4 \\
(0.5)\end{array}$ & $\begin{array}{l}-0.6 \\
(0.5)\end{array}$ & & & \\
\hline Child weight $<6$ pounds at birth (\%) & 3.0 & $\begin{array}{c}0.3 \\
(0.6)\end{array}$ & $\begin{array}{c}1.0 \\
(0.8)\end{array}$ & & & \\
\hline & 01 & t Page & & & & \\
\hline
\end{tabular}




\begin{tabular}{|c|c|c|c|c|c|c|}
\hline Missing: Child weight $<6$ pounds at birth $(\%)$ & 2.7 & $\begin{array}{l}-0.8 \\
(0.6)\end{array}$ & $\begin{array}{l}-0.2 \\
(0.7)\end{array}$ & & & \\
\hline $\begin{array}{l}\text { Someone in household usually read a book to } \\
\text { child more than once a day (\%) }\end{array}$ & 5.6 & $\begin{array}{l}-0.5 \\
(0.8)\end{array}$ & $\begin{array}{l}-1.6^{+} \\
(0.9)\end{array}$ & & & \\
\hline $\begin{array}{l}\text { Missing: Someone in household usually read a } \\
\text { book to child more than once a day }(\%)\end{array}$ & 2.3 & $\begin{array}{c}0.3 \\
(0.6)\end{array}$ & $\begin{array}{l}-0.4 \\
(0.6)\end{array}$ & & & \\
\hline Pre-Randomization Household Characteristics & & & & & & \\
\hline Adult receiving AFDC/TANF (\%) & 79.5 & $\begin{array}{c}0.6 \\
(1.9)\end{array}$ & $\begin{array}{c}1.8 \\
(2.0)\end{array}$ & 75.0 & $\begin{array}{l}-0.8 \\
(2.9)\end{array}$ & $\begin{array}{l}-1.0 \\
(3.0)\end{array}$ \\
\hline Adult owning a car (\%) & 15.5 & $\begin{array}{l}5.0^{* *} \\
(1.8)\end{array}$ & $\begin{array}{l}3.3^{+} \\
(1.9)\end{array}$ & 20.1 & $\begin{array}{l}-1.0 \\
(2.4)\end{array}$ & $\begin{array}{l}-1.0 \\
(2.6)\end{array}$ \\
\hline Disabed Person in Household (\%) & 16.1 & $\begin{array}{c}0.1 \\
(1.8)\end{array}$ & $\begin{array}{l}-3.3^{+} \\
(1.9)\end{array}$ & 15.3 & $\begin{array}{c}1.5 \\
(2.3)\end{array}$ & $\begin{array}{c}0.0 \\
(2.6)\end{array}$ \\
\hline No teen children in core household (\%) & 71.6 & $\begin{array}{l}-4.0^{+} \\
(2.2)\end{array}$ & $\begin{array}{l}-3.7 \\
(2.5)\end{array}$ & 6.1 & $\begin{array}{l}-0.6 \\
(1.2)\end{array}$ & $\begin{array}{r}1.0 \\
(1.5)\end{array}$ \\
\hline Core Household size is 2 or smaller (\%) & 8.0 & $\begin{array}{c}1.0 \\
(1.0)\end{array}$ & $\begin{array}{l}-0.2 \\
(1.1)\end{array}$ & 9.1 & $\begin{array}{l}-0.5 \\
(1.5)\end{array}$ & $\begin{array}{r}1.3 \\
(1.8)\end{array}$ \\
\hline Core Household size is 3 or smaller (\%) & 23.7 & $\begin{array}{l}-0.3 \\
(1.9)\end{array}$ & $\begin{array}{l}-2.1 \\
(2.0)\end{array}$ & 22.3 & $\begin{array}{l}-0.5 \\
(2.7)\end{array}$ & $\begin{array}{l}-2.1 \\
(2.8)\end{array}$ \\
\hline Core Household size is 4 or smaller (\%) & 25.4 & $\begin{array}{l}2.6 \\
(2.2)\end{array}$ & $\begin{array}{c}1.6 \\
(2.4)\end{array}$ & 24.0 & $\begin{array}{c}1.5 \\
(2.9)\end{array}$ & $\begin{array}{r}0.3 \\
(3.1)\end{array}$ \\
\hline Victims of Crime in the past 5 years (\%) & 41.3 & $\begin{array}{l}2.5 \\
(2.4)\end{array}$ & $\begin{array}{c}0.9 \\
(2.7)\end{array}$ & 44.8 & $\begin{array}{c}1.3 \\
(3.3)\end{array}$ & $\begin{array}{l}-3.3 \\
(3.5)\end{array}$ \\
\hline \multicolumn{7}{|l|}{ Pre-Randomization Neighborhood Characteristics } \\
\hline Living in same nbhd. for over 5 years (\%) & 58.9 & $\begin{array}{l}-2.5 \\
(2.4)\end{array}$ & $\begin{array}{c}0.6 \\
(2.7)\end{array}$ & 70.4 & $\begin{array}{l}-3.4 \\
(3.0)\end{array}$ & $\begin{array}{r}3.0 \\
(3.1)\end{array}$ \\
\hline Chat with neighbor at least once a week (\%) & 52.8 & $\begin{array}{l}-2.1 \\
(2.5)\end{array}$ & $\begin{array}{l}-1.2 \\
(2.8)\end{array}$ & 50.9 & $\begin{array}{l}-0.4 \\
(3.4)\end{array}$ & $\begin{array}{l}-5.7 \\
(3.6)\end{array}$ \\
\hline $\begin{array}{l}\text { Very likely to tell neighbor if he/she saw } \\
\text { neighbor's child getting into trouble (\%) }\end{array}$ & 59.2 & $\begin{array}{l}-3.7 \\
(2.5)\end{array}$ & $\begin{array}{l}-1.1 \\
(2.7)\end{array}$ & 59.6 & $\begin{array}{l}-2.9 \\
(3.2)\end{array}$ & $\begin{array}{l}-7.9^{*} \\
(3.5)\end{array}$ \\
\hline No family living in the neighborhood (\%) & 64.2 & $\begin{array}{c}0.4 \\
(2.3)\end{array}$ & $\begin{array}{l}-1.3 \\
(2.7)\end{array}$ & 67.0 & $\begin{array}{l}-4.0 \\
(3.1)\end{array}$ & $\begin{array}{l}-2.1 \\
(3.4)\end{array}$ \\
\hline No friends in the neighborhood (\%) & 41.3 & $\begin{array}{c}0.1 \\
(2.4)\end{array}$ & $\begin{array}{l}-2.5 \\
(2.7)\end{array}$ & 41.6 & $\begin{array}{c}1.1 \\
(3.3)\end{array}$ & $\begin{array}{l}-4.2 \\
(3.5)\end{array}$ \\
\hline Unsafe Streets at night (\%) & 50.5 & $\begin{array}{c}0.6 \\
(2.5)\end{array}$ & $\begin{array}{l}-0.5 \\
(2.8)\end{array}$ & 53.8 & $\begin{array}{l}-3.1 \\
(3.3)\end{array}$ & $\begin{array}{l}-6.5^{+} \\
(3.5)\end{array}$ \\
\hline Very Dissatisfied with neighborhood (\%) & 46.8 & $\begin{array}{c}1.0 \\
(2.4)\end{array}$ & $\begin{array}{c}1.7 \\
(2.7)\end{array}$ & 48.2 & $\begin{array}{l}-2.2 \\
(3.3)\end{array}$ & $\begin{array}{l}-6.0^{+} \\
(3.5)\end{array}$ \\
\hline \multicolumn{7}{|l|}{ Pre-Randomization Housing Characteristics } \\
\hline $\begin{array}{l}\text { Sure he/she would find an apartment in a } \\
\text { different area of the city }(\%)\end{array}$ & 46.6 & $\begin{array}{l}-0.7 \\
(2.5)\end{array}$ & $\begin{array}{c}4.5 \\
(2.8)\end{array}$ & 40.4 & $\begin{array}{l}7.9^{*} \\
(3.3)\end{array}$ & $\begin{array}{c}3.8 \\
(3.6)\end{array}$ \\
\hline
\end{tabular}




\begin{tabular}{|c|c|c|c|c|c|c|}
\hline More than 3 moves in last 5 years (\%) & 10.9 & $\begin{array}{l}-3.4^{*} \\
(1.4)\end{array}$ & $\begin{array}{l}-0.8 \\
(1.8)\end{array}$ & 8.6 & $\begin{array}{c}-0.7 \\
(1.9)\end{array}$ & $\begin{array}{l}-2.3 \\
(1.9)\end{array}$ \\
\hline $\begin{array}{l}\text { Primary or Secondary reason for move is to } \\
\text { get away from gangs or drugs (\%) }\end{array}$ & 78.1 & $\begin{array}{l}-1.8 \\
(2.1)\end{array}$ & $\begin{array}{l}-4.4^{+} \\
(2.4)\end{array}$ & 77.7 & $\begin{array}{l}3.1 \\
(2.6)\end{array}$ & $\begin{array}{l}-0.9 \\
(2.9)\end{array}$ \\
\hline $\begin{array}{l}\text { Primary or Secondary Reason for moving was } \\
\text { to have access to better schools (\%) }\end{array}$ & 51.0 & $\begin{array}{c}1.3 \\
(2.4)\end{array}$ & $\begin{array}{l}6.9^{* *} \\
(2.7)\end{array}$ & 47.0 & $\begin{array}{l}-0.3 \\
(3.3)\end{array}$ & $\begin{array}{l}6.2^{+} \\
(3.5)\end{array}$ \\
\hline $\begin{array}{l}\text { Had already previously applied for a Section } 8 \\
\text { voucher or certificate }(\%)\end{array}$ & 46.8 & $\begin{array}{l}-4.9^{*} \\
(2.4)\end{array}$ & $\begin{array}{l}-6.7^{*} \\
(2.6)\end{array}$ & 46.3 & $\begin{array}{c}3.9 \\
(3.3)\end{array}$ & $\begin{array}{l}-7.2^{*} \\
(3.5)\end{array}$ \\
\hline \multicolumn{7}{|l|}{ Pre-Randomization Hhold. Head Characteristics } \\
\hline Age as of $12 / 31 / 08$ & 44.8 & $\begin{array}{c}0.4 \\
(0.4)\end{array}$ & $\begin{array}{c}0.2 \\
(0.4)\end{array}$ & 50.9 & $\begin{array}{c}0.5 \\
(0.5)\end{array}$ & $\begin{array}{l}0.6 \\
(0.5)\end{array}$ \\
\hline Adult has a GED (\%) & 20.5 & $\begin{array}{l}-4.6^{*} \\
(2.0)\end{array}$ & $\begin{array}{l}-1.4 \\
(2.3)\end{array}$ & 19.2 & $\begin{array}{l}-2.0 \\
(2.6)\end{array}$ & $\begin{array}{l}-2.7 \\
(2.7)\end{array}$ \\
\hline High School Completion (\%) & 34.3 & $\begin{array}{l}4.2^{+} \\
(2.4)\end{array}$ & $\begin{array}{c}0.4 \\
(2.6)\end{array}$ & 29.5 & $\begin{array}{c}5.0 \\
(3.1)\end{array}$ & $\begin{array}{c}0.7 \\
(3.3)\end{array}$ \\
\hline Missing: High School Completion (\%) & 6.6 & $\begin{array}{l}-1.0 \\
(1.2)\end{array}$ & $\begin{array}{c}0.3 \\
(1.5)\end{array}$ & 7.6 & $\begin{array}{l}-0.8 \\
(1.6)\end{array}$ & $\begin{array}{c}2.4 \\
(2.1)\end{array}$ \\
\hline Enrolled in School (\%) & 16.6 & $\begin{array}{l}-1.2 \\
(1.8)\end{array}$ & $\begin{array}{c}2.0 \\
(2.2)\end{array}$ & 14.5 & $\begin{array}{l}-2.9 \\
(2.3)\end{array}$ & $\begin{array}{l}-0.8 \\
(2.4)\end{array}$ \\
\hline Hispanic (\%) & 29.4 & $\begin{array}{l}-0.3 \\
(2.0)\end{array}$ & $\begin{array}{l}-0.5 \\
(2.1)\end{array}$ & 31.1 & $\begin{array}{c}0.6 \\
(2.7)\end{array}$ & $\begin{array}{c}2.8 \\
(2.7)\end{array}$ \\
\hline Male head of household (\%) & 2.8 & $\begin{array}{l}-0.5 \\
(0.8)\end{array}$ & $\begin{array}{l}-1.6^{*} \\
(0.7)\end{array}$ & 2.6 & $\begin{array}{l}-0.6 \\
(1.0)\end{array}$ & $\begin{array}{c}1.9 \\
(1.4)\end{array}$ \\
\hline Never been married $(\%)$ & 65.1 & $\begin{array}{l}-4.3^{+} \\
(2.3)\end{array}$ & $\begin{array}{l}-3.1 \\
(2.6)\end{array}$ & 53.0 & $\begin{array}{l}-3.1 \\
(3.2)\end{array}$ & $\begin{array}{l}-6.3^{+} \\
(3.4)\end{array}$ \\
\hline Teenage Parents (\%) & 28.6 & $\begin{array}{l}-0.9 \\
(2.2)\end{array}$ & $\begin{array}{l}-0.3 \\
(2.5)\end{array}$ & 29.1 & $\begin{array}{l}-3.6 \\
(2.9)\end{array}$ & $\begin{array}{l}-2.5 \\
(3.2)\end{array}$ \\
\hline African-American (\%) & 66.9 & $\begin{array}{l}-0.4 \\
(2.0)\end{array}$ & $\begin{array}{l}-1.4 \\
(2.1)\end{array}$ & 63.9 & $\begin{array}{l}-1.9 \\
(2.7)\end{array}$ & $\begin{array}{l}-5.9^{\star} \\
(2.8)\end{array}$ \\
\hline $\begin{array}{l}\text { Racial group other than African-American or } \\
\text { white }(\%)\end{array}$ & 24.7 & $\begin{array}{c}1.8 \\
(1.9)\end{array}$ & $\begin{array}{c}1.3 \\
(2.0)\end{array}$ & 28.9 & $\begin{array}{c}1.3 \\
(2.7)\end{array}$ & $\begin{array}{l}2.8 \\
(2.8)\end{array}$ \\
\hline Employed (\%) & 23.8 & $\begin{array}{c}1.0 \\
(2.1)\end{array}$ & $\begin{array}{l}-2.2 \\
(2.2)\end{array}$ & 25.3 & $\begin{array}{l}3.0 \\
(2.9)\end{array}$ & $\begin{array}{l}-0.4 \\
(3.0)\end{array}$ \\
\hline Number of Children & 1,613 & 1,969 & 1,427 & 686 & 959 & 686 \\
\hline
\end{tabular}

Notes: This table replicates Table 1 in the text for all the pre-determined variables used in the regressions that include controls. Columns 1-3 restrict the sample to individuals below age 13 at random assignment; Columns 4-6 include individuals above age 13 at random assignment. Columns 1 and 4 show the control group mean for each variable. Columns 2 and 5 report the difference between the experimental voucher and control group, which we estimate using an OLS regression (weighted to adjust for differences in sampling probabilities across sites and over time) of an outcome on indicators for being assigned to the experimental voucher group, the section 8 voucher group, and randomization site. Columns 3 and 6 report the coefficient for being assigned to the section 8 voucher group from the same regression. The estimates in Columns 2-3 and 5-6 are obtained from separate regressions. Standard errors, reported in parentheses, are clustered by family $\left(^{+}=\right.$ $\left.p<0.10,{ }^{*}=p<0.05,{ }^{* *}=p<0.01\right)$. Out of the 196 differences in this table, there are 13 differences with $p<0.05$ and 2 with $p<0.01$. The final row lists the numbers of individuals in the control, experimental, and section 8 groups in the linked MTO-Tax Data. See Sanbonmatsu et al. (2011) for details on variable definitions. Note that certain variables (e.g., child weight at birth) were not collected for older youth and are therefore omitted from the age 13-18 group. 
APPENDIX TABLE $1 \mathrm{~b}$

Summary Statistics for Children's Outcomes in Linked MTO-Tax Data Sample

\begin{tabular}{|c|c|c|c|c|c|}
\hline & $\begin{array}{c}\text { Mean } \\
(1)\end{array}$ & $\begin{array}{c}\text { Std. Dev. } \\
\text { (2) }\end{array}$ & $\begin{array}{c}\text { Median } \\
(3)\end{array}$ & $\begin{array}{c}\text { Num. of } \\
\text { Obs. } \\
(4)\end{array}$ & $\begin{array}{c}\text { Num. of } \\
\text { Children } \\
\text { (5) }\end{array}$ \\
\hline \multicolumn{6}{|l|}{ Income } \\
\hline W-2 Wage Earnings at age $24(\$)$ & 10,146 & 14,178 & 3,900 & 5,253 & 5,253 \\
\hline W-2 Wage Earnings at age $25(\$)$ & 10,958 & 14,260 & 4,400 & 4,589 & 4,589 \\
\hline W-2 Wage Earnings at age $26(\$)$ & 11,391 & 14,995 & 4,400 & 3,956 & 3,956 \\
\hline W-2 Wage Earnings at age $27(\$)$ & 11,819 & 15,638 & 3,800 & 3,394 & 3,394 \\
\hline W-2 Wage Earnings at age $28(\$)$ & 12,505 & 16,530 & 4,100 & 2,851 & 2,851 \\
\hline Individual Earnings at age $24(\$)$ & 11,739 & 14,290 & 8,400 & 5,253 & 5,253 \\
\hline Individual Earnings at age $25(\$)$ & 12,456 & 14,257 & 8,700 & 4,589 & 4,589 \\
\hline Individual Earnings at age $26(\$)$ & 13,040 & 14,898 & 9,300 & 3,956 & 3,956 \\
\hline Individual Earnings at age $27(\$)$ & 13,597 & 15,725 & 9,300 & 3,394 & 3,394 \\
\hline Individual Earnings at age $28(\$)$ & 14,269 & 16,665 & 9,400 & 2,851 & 2,851 \\
\hline Household Income at age $24(\$)$ & 12,920 & 15,628 & 9,400 & 5,253 & 5,253 \\
\hline Household Income at age $25(\$)$ & 14,031 & 16,400 & 10,000 & 4,589 & 4,589 \\
\hline Household Income at age $26(\$)$ & 15,116 & 18,038 & 11,200 & 3,956 & 3,956 \\
\hline Household Income at age $27(\$)$ & 15,992 & 19,274 & 11,400 & 3,394 & 3,394 \\
\hline Household Income at age $28(\$)$ & 17,035 & 20,564 & 11,900 & 2,851 & 2,851 \\
\hline Employed at age $\geq 24$ & 62.3 & 48.5 & 100 & 20,043 & 5,253 \\
\hline 5-year Income Growth at age $\geq 24$ & 4,046 & 14,394 & 434 & 20,043 & 5,253 \\
\hline \multicolumn{6}{|l|}{$\underline{\text { College Attendance }}$} \\
\hline In College at age $18(\%)$ & 11.7 & 32.1 & 0 & 6,337 & 6,337 \\
\hline In College at age $19(\%)$ & 18.0 & 38.5 & 0 & 6,731 & 6,731 \\
\hline In College at age $20(\%)$ & 19.0 & 39.3 & 0 & 7,059 & 7,059 \\
\hline In College at age $21(\%)$ & 18.2 & 38.6 & 0 & 7,243 & 7,243 \\
\hline College Quality at age $18(\$)$ & 20,841 & 6,979 & 18,900 & 6,337 & 6,337 \\
\hline College Quality at age $19(\$)$ & 21,518 & 7,667 & 18,900 & 6,731 & 6,731 \\
\hline College Quality at age $20(\$)$ & 21,423 & 7,484 & 18,900 & 7,059 & 7,059 \\
\hline College Quality at age $21(\$)$ & 21,319 & 7,467 & 18,900 & 7,243 & 7,243 \\
\hline
\end{tabular}


Neighborhood Characteristics

$\begin{array}{lccccc}\text { Mean Hhold. Income in ZIP at age } \geq 24(\$) & 25,661 & 10,591 & 24,000 & 15,798 & 4,688 \\ \text { Poverty Share in ZIP at age } \geq 24(\%) & 23.0 & 12.2 & 21.5 & 15,798 & 4,688 \\ \text { Share Black in ZIP at age } \geq 24(\%) & 40.0 & 32.2 & 34.3 & 15,800 & 4,688 \\ \text { Single Mother Share in ZIP at age } \geq 24(\%) & 40.0 & 18.0 & 38.0 & 15,796 & 4,688\end{array}$

Fertility (females only) and Marriage

$\begin{array}{lccccc}\text { Married at age } \geq 24(\%) & 7.5 & 26.3 & 0 & 20,043 & 5,253 \\ \text { Has a Birth before June 2014 (\%) } & 64.4 & 47.9 & 100 & 3,567 & 3,567 \\ \text { Has a Birth while a Teenager (\%) } & 21.7 & 41.2 & 0 & 3,520 & 3,520 \\ \text { Father Listed on Birth Certificate (\%) } & 45.2 & 49.8 & 0 & 2,298 & 2,298 \\ \text { Birth with No Father Present (\%) } & 35.3 & 47.8 & 0 & 3,567 & 3,567\end{array}$

$\underline{\text { Tax Payments }}$

Filed a Tax Return at age $\geq 24(\%)$

63.4

48.2

100

20,043

5,253

Federal Income Tax Paid at age $\geq 24(\$)$

611

1,781

0

20,043

5,253

Notes: This table reports the mean, standard deviation, median, the number of observations, and the number of children for all outcome variables used in Tables 3-8 in the text. Median income statistics are rounded to the nearest $\$ 100$ to protect confidentiality. The sample consists of all children in the linked MTO-Tax dataset for whom the relevant variables are available between 1999-2012. Variables that pool ages (age $\geq 24$ ) are measured pooling data from years 2008-12; all other variables are measured at a single point for each individual. Fertility outcomes are for female children only. See notes to Tables 3-6 and 12 for variable definitions. 
APPENDIX TABLE 1C

Examples of MTO Residential Locations by Site

\begin{tabular}{|c|c|c|c|c|}
\hline $\begin{array}{c}\text { Baltimore } \\
(1) \\
\end{array}$ & $\begin{array}{c}\text { Boston } \\
(2) \\
\end{array}$ & $\begin{array}{c}\text { Chicago } \\
(3)\end{array}$ & $\begin{array}{c}\text { Los Angeles } \\
(4) \\
\end{array}$ & $\begin{array}{c}\text { New York City } \\
(5)\end{array}$ \\
\hline \multicolumn{5}{|l|}{ Baseline Housing Projects } \\
\hline $\begin{array}{l}\text { Flag House (Jonestown), } \\
\text { Lexington-Poe, } \\
\text { Murphy Homes (W. Baltimore) }\end{array}$ & $\begin{array}{l}\text { Maverick (East Boston), } \\
\text { Mission Hill, } \\
\text { Old Colony (South Boston) }\end{array}$ & $\begin{array}{l}\text { Ida B. Wells, } \\
\text { Robert Taylor Homes, } \\
\text { Stateway Gardens }\end{array}$ & $\begin{array}{l}\text { Imperial Courts (Watts), } \\
\text { Nickerson Gardens (Watts), } \\
\text { Pueblo del Rio (South LA) }\end{array}$ & $\begin{array}{l}\text { King Towers (Harlem), } \\
\text { University Ave Cons (Bronx), } \\
\text { Wagner Houses (East Harlem) }\end{array}$ \\
\hline \multicolumn{5}{|c|}{ Destination Neighborhoods for Families who Took Up Experimental Voucher } \\
\hline $\begin{array}{l}\text { Belair-Edison, } \\
\text { Columbia, } \\
\text { Lakeland }\end{array}$ & $\begin{array}{l}\text { Hyde Park, } \\
\text { Randolph, } \\
\text { Roslindale }\end{array}$ & $\begin{array}{l}\text { Calumet Heights, } \\
\text { Cottage Grove Heights, } \\
\text { Riverdale }\end{array}$ & $\begin{array}{l}\text { Baldwin Hills/Crenshaw, } \\
\text { Bellflower, } \\
\text { Downey }\end{array}$ & $\begin{array}{l}\text { Pelham Gardens (Bronx), } \\
\text { Wakefield (Bronx) }\end{array}$ \\
\hline \multicolumn{5}{|c|}{ Destination Neighborhoods for Families who Took Up Section 8 Voucher } \\
\hline $\begin{array}{l}\text { Armistead Gardens, } \\
\text { Dundalk, } \\
\text { Gwynn Oak (MD) }\end{array}$ & $\begin{array}{l}\text { Jamaica Plain, } \\
\text { Mattapan, } \\
\text { Roxbury }\end{array}$ & $\begin{array}{l}\text { Grand Crossing, } \\
\text { Oakland, } \\
\text { Washington Park }\end{array}$ & $\begin{array}{l}\text { Florence-Firestone, } \\
\text { Historic South-Central, } \\
\text { Westmont }\end{array}$ & $\begin{array}{l}\text { Pelham Parkways (Bronx), } \\
\text { Soundview (Bronx) }\end{array}$ \\
\hline
\end{tabular}

Notes: This table lists some of the most common locations where families who moved using an MTO voucher lived before and after they moved. The locations listed are not comprehensive and are for illustrative purposes only; MTO families moved to a variety of different neighborhoods beyond the small subset listed here. Panel A lists neighborhoods based on the most common housing projects where MTO families who moved using a Section 8 or experimental voucher lived at the point of random assignment. Panel B lists neighborhoods based on the most common ZIP codes for the first recorded move address for families who were assigned to the experimental voucher group and took up the voucher they were offered. Panel $C$ replicates Panel $B$ for the Section 8 group. The neighborhoods were identified by mapping the names of housing projects (Panel A) and ZIP codes (Panels B and C) to neighborhood names relying on information from web searches; since many of the housing projects have been torn down and ZIP codes do not uniquely identify neighborhoods, these locations may not correspond exactly to current neighborhood definitions and conditions. 


\section{APPENDIX TABLE 2}

Impacts of MTO on Voucher Takeup and Neighborhood Poverty Rates: Estimates with Controls

\begin{tabular}{|c|c|c|c|c|c|c|c|}
\hline \multirow[t]{2}{*}{ Dep. Var. } & \multirow[t]{2}{*}{$\begin{array}{c}\text { Housing } \\
\text { Voucher } \\
\text { Takeup (\%) }\end{array}$} & \multicolumn{2}{|c|}{$\begin{array}{c}\text { Poverty Rate in } \\
\text { Tract one year } \\
\text { post RA (\%) }\end{array}$} & \multicolumn{2}{|c|}{$\begin{array}{c}\text { Mean Poverty Rate } \\
\text { in Tract post RA to } \\
\text { Age } 18(\%)\end{array}$} & \multicolumn{2}{|c|}{$\begin{array}{c}\text { Mean Poverty Rate } \\
\text { in ZIP post RA to } \\
\text { Age } 18(\%)\end{array}$} \\
\hline & & $\begin{array}{l}\text { ITT } \\
(2)\end{array}$ & $\begin{array}{c}\text { TOT } \\
(3)\end{array}$ & $\begin{array}{l}\text { ITT } \\
(4)\end{array}$ & $\begin{array}{c}\text { TOT } \\
(5)\end{array}$ & $\begin{array}{l}\text { ITT } \\
(6)\end{array}$ & $\begin{array}{c}\text { TOT } \\
(7)\end{array}$ \\
\hline
\end{tabular}

Panel A: Children < Age 13 at Random Assignment

\begin{tabular}{lccccccc}
\hline Exp. vs Control. & $47.36^{* *}$ & $-16.89^{* *}$ & $-35.84^{* *}$ & $-10.14^{* *}$ & $-21.46^{* *}$ & $-5.71^{* *}$ & $-12.15^{* *}$ \\
& $(1.655)$ & $(0.852)$ & $(1.369)$ & $(0.642)$ & $(1.094)$ & $(0.419)$ & $(0.744)$ \\
Sec 8. vs. Control & $65.39^{* *}$ & $-14.81^{* *}$ & $-22.52^{* *}$ & $-7.88^{* *}$ & $-11.93^{* *}$ & $-3.25^{* *}$ & $-4.84^{* *}$ \\
& $(1.931)$ & $(0.797)$ & $(1.026)$ & $(0.607)$ & $(0.864)$ & $(0.416)$ & $(0.610)$ \\
Num of Obs. & 5044 & 4958 & 4958 & 5035 & 5035 & 5035 & 5035 \\
Control Group Mean & 0 & 50.23 & 50.23 & 41.17 & 41.17 & 31.81 & 31.81 \\
Panel B: Children Age 13-18 at Random Assignment & & & & \\
\hline Exp. vs Control. & $39.65^{* *}$ & $-13.86^{* *}$ & $-34.64^{* *}$ & $-9.81^{* *}$ & $-24.39^{* *}$ & $-5.44^{* *}$ & $-13.64^{* *}$ \\
& $(2.134)$ & $(1.127)$ & $(2.222)$ & $(0.933)$ & $(1.912)$ & $(0.536)$ & $(1.107)$ \\
Sec 8. vs. Control & $56.01^{* *}$ & $-12.33^{* *}$ & $-21.68^{* *}$ & $-8.33^{* *}$ & $-14.53^{* *}$ & $-3.72^{* *}$ & $-6.23^{* *}$ \\
& $(2.541)$ & $(1.081)$ & $(1.701)$ & $(0.923)$ & $(1.508)$ & $(0.533)$ & $(0.913)$ \\
Num of Obs. & 2358 & 2302 & 2302 & 2293 & 2293 & 2292 & 2292 \\
Control Group Mean & 0 & 49.14 & 49.14 & 47.90 & 47.90 & 35.17 & 35.17 \\
\hline \hline
\end{tabular}

Notes: This table replicates Table 2 in the text, including controls for the baseline covariates listed in Appendix Table 1a in every regression specification. Standard errors, reported in parentheses, are clustered by family $\left(^{+}=p<0.10,{ }^{*}=p<0.05,{ }^{* *}=p<0.01\right)$. See notes to Table 2 for details on variable definitions and specifications. 
APPENDIX TABLE 3a

Impacts of MTO on Children's Income in Adulthood: Estimates with Controls

Dep. Var.: W-2 Earnings (\$) Indiv. Earnings 2008-12 (\$) Indiv. Earnings (\$) Employed (\%) Hhold. Inc. (\$) Inc. Growth (\$) 2008-12 ITT ITT ITT w/Cntrls. TOT Age 26 ITT 2012 ITT 2008-12 ITT 2008-12 ITT $2008-12$ ITT

$(1)$

(2)

(3)

(4)

(5)

(6)

(8)

(9)

\begin{tabular}{|c|c|c|c|c|c|c|c|c|c|}
\hline Exp. vs. Control & $\begin{array}{c}1016.8 \\
(640.5)\end{array}$ & $\begin{array}{l}\text { 1298.9* } \\
(636.9)\end{array}$ & $\begin{array}{l}\text { 1298.9* } \\
(636.9)\end{array}$ & $\begin{array}{c}2798.5^{\star} \\
(1369.8)\end{array}$ & $\begin{array}{c}1378.6 \\
(887.0)\end{array}$ & $\begin{array}{l}1335.4^{*} \\
(643.0)\end{array}$ & $\begin{array}{c}0.920 \\
(1.958)\end{array}$ & $\begin{array}{l}1764.2^{*} \\
(716.3)\end{array}$ & $\begin{array}{l}1105.9^{*} \\
(510.7)\end{array}$ \\
\hline Sec. 8 vs. Control & $\begin{array}{c}492.4 \\
(677.3)\end{array}$ & $\begin{array}{c}908.6 \\
(655.8)\end{array}$ & $\begin{array}{c}908.6 \\
(655.8)\end{array}$ & $\begin{array}{c}1426.3 \\
(1023.5)\end{array}$ & $\begin{array}{c}219.4 \\
(895.7)\end{array}$ & $\begin{array}{c}1075.9 \\
(679.0)\end{array}$ & $\begin{array}{c}0.736 \\
(2.132)\end{array}$ & $\begin{array}{l}1140.1 \\
(702.2)\end{array}$ & $\begin{array}{c}638.2 \\
(517.1)\end{array}$ \\
\hline Num of Obs. & 8420 & 8420 & 8420 & 8420 & 1625 & 2922 & 8420 & 8420 & 8420 \\
\hline Control Group Mean & 9548.6 & 11270.3 & 11270.3 & 11270.3 & 11398.3 & 11302.9 & 61.8 & 12702.4 & 4002.2 \\
\hline \multicolumn{10}{|c|}{ Panel B: Children Age 13-18 at Random Assignment } \\
\hline Exp. vs. Control & $\begin{array}{l}-655.3 \\
(825.0)\end{array}$ & $\begin{array}{l}-879.5 \\
(817.3)\end{array}$ & $\begin{array}{l}-879.5 \\
(817.3)\end{array}$ & $\begin{array}{l}-2224.6 \\
(2069.7)\end{array}$ & $\begin{array}{l}-449.4 \\
(745.6)\end{array}$ & $\begin{array}{c}-911.5 \\
(1125.8)\end{array}$ & $\begin{array}{l}-1.655 \\
(1.988)\end{array}$ & $\begin{array}{l}-1396.0 \\
(1047.3)\end{array}$ & $\begin{array}{l}-641.5 \\
(576.1)\end{array}$ \\
\hline Sec. 8 vs. Control & $\begin{array}{r}-1134.7 \\
(870.5)\end{array}$ & $\begin{array}{c}-1136.9 \\
(866.6)\end{array}$ & $\begin{array}{r}-1136.9 \\
(866.6)\end{array}$ & $\begin{array}{l}-2022.8 \\
(1546.9)\end{array}$ & $\begin{array}{l}-15.53 \\
(797.7)\end{array}$ & $\begin{array}{c}-878.9 \\
(1166.1)\end{array}$ & $\begin{array}{l}-1.050 \\
(2.179)\end{array}$ & $\begin{array}{l}-1068.2 \\
(1101.6)\end{array}$ & $\begin{array}{l}-968.6 \\
(615.2)\end{array}$ \\
\hline Num of Obs. & 11623 & 11623 & 11623 & 11623 & 2331 & 2331 & 11623 & 11623 & 11623 \\
\hline Control Group Mean & 13897.1 & 15881.5 & 15881.5 & 15881.5 & 13968.9 & 16602.0 & 63.6 & 19169.1 & 4128.1 \\
\hline
\end{tabular}

Notes: This table replicates Table 3 in the text, including controls for the baseline covariates listed in Appendix Table 1a in every regression specification. Note that Columns 2 and 3 are identical to make the structure of this table match that of Table 3 in the text. Standard errors, reported in parentheses, are clustered by family $\left({ }^{+}=p<0.10,{ }^{*}=p<0.05,{ }^{* *}=p<0.01\right)$. See notes to Table 3 for details on variable definitions and specifications. 
APPENDIX TABLE 3b

Impacts of MTO on Children's Income in Adulthood: Treatment-on-Treated Estimates

Dep. Var.: W-2 Earnings (\$) Indiv. Earnings 2008-12 (\$) Indiv. Earnings (\$) Employed (\%) Hhold. Inc. (\$) Inc. Growth (\$) 2008-12 TOT TOT TOT w/Cntrls. TOT Age $26 \quad 2012$ 2008-12 TOT 2008-12 TOT 2008-12 TOT

(1)

(2)

(3)

$(4)$

(5)

(6)

$(7)$

(8)

(9)

\begin{tabular}{|c|c|c|c|c|c|c|c|c|c|}
\hline \multicolumn{10}{|c|}{ Panel A: Children < Age 13 at Random Assignment } \\
\hline Exp. vs. Control & $\begin{array}{l}2866.5^{\star} \\
(1436.3)\end{array}$ & $\begin{array}{c}3476.8^{*} \\
(1418.2)\end{array}$ & $\begin{array}{c}2798.5^{\star} \\
(1369.8)\end{array}$ & $\begin{array}{c}3476.8^{*} \\
(1418.2)\end{array}$ & $\begin{array}{c}3794.9^{+} \\
(1986.5)\end{array}$ & $\begin{array}{l}3036.2^{*} \\
(1398.8)\end{array}$ & $\begin{array}{c}3.907 \\
(4.454)\end{array}$ & $\begin{array}{l}4776.0^{* *} \\
(1662.8)\end{array}$ & $\begin{array}{l}2802.5^{*} \\
(1106.1)\end{array}$ \\
\hline Sec. 8 vs. Control & $\begin{array}{c}1065.8 \\
(1086.8)\end{array}$ & $\begin{array}{c}1723.2 \\
(1051.5)\end{array}$ & $\begin{array}{c}1426.3 \\
(1023.5)\end{array}$ & $\begin{array}{c}1723.2 \\
(1051.5)\end{array}$ & $\begin{array}{c}858.1 \\
(1389.3)\end{array}$ & $\begin{array}{c}1801.7^{+} \\
(1073.3)\end{array}$ & $\begin{array}{c}2.100 \\
(3.570)\end{array}$ & $\begin{array}{c}2255.6^{*} \\
(1144.5)\end{array}$ & $\begin{array}{l}1242.2 \\
(807.3)\end{array}$ \\
\hline Num of Obs. & 8420 & 8420 & 8420 & 8420 & 1625 & 2922 & 8420 & 8420 & 8420 \\
\hline CCM Exp. & 8901.1 & 10165.2 & 10843.5 & 10165.2 & 9431.3 & 10409.0 & 60.6 & 10803.5 & 3032.9 \\
\hline CCM Sec. 8 & 9025.2 & 10546.1 & 10843.0 & 10546.1 & 11459.8 & 10444.5 & 61.3 & 11798.1 & 3181.7 \\
\hline \multicolumn{10}{|c|}{ Panel B: Children Age 13-18 at Random Assignment } \\
\hline Exp. vs. Control & $\begin{array}{l}-1910.0 \\
(2192.9)\end{array}$ & $\begin{array}{l}-2426.7 \\
(2154.4)\end{array}$ & $\begin{array}{l}-2224.6 \\
(2069.7)\end{array}$ & $\begin{array}{l}-2426.7 \\
(2154.4)\end{array}$ & $\begin{array}{c}-1356.2 \\
(1999.8)\end{array}$ & $\begin{array}{c}-2436.1 \\
(2825.4)\end{array}$ & $\begin{array}{l}-5.458 \\
(5.383)\end{array}$ & $\begin{array}{c}-3817.0 \\
(2783.9)\end{array}$ & $\begin{array}{l}-1740.7 \\
(1442.6)\end{array}$ \\
\hline Sec. 8 vs. Control & $\begin{array}{l}-1899.1 \\
(1693.1)\end{array}$ & $\begin{array}{l}-2051.1 \\
(1673.7)\end{array}$ & $\begin{array}{l}-2022.8 \\
(1546.9)\end{array}$ & $\begin{array}{c}-2051.1 \\
(1673.7)\end{array}$ & $\begin{array}{c}-27.64 \\
(1527.4)\end{array}$ & $\begin{array}{l}-1571.9 \\
(2193.5)\end{array}$ & $\begin{array}{l}-2.407 \\
(4.123)\end{array}$ & $\begin{array}{l}-1696.5 \\
(2150.9)\end{array}$ & $\begin{array}{l}-1602.9 \\
(1130.1)\end{array}$ \\
\hline Num of Obs. & 11623 & 11623 & 11623 & 11623 & 2331 & 2331 & 11623 & 11623 & 11623 \\
\hline CCM Exp. & 15984.9 & 18334.6 & 18132.4 & 18334.6 & 15236.9 & 19426.5 & 67.0 & 22548.8 & 5665.7 \\
\hline CCM Sec. 8 & 15432.4 & 17374.2 & 17345.9 & 17374.2 & 14635.5 & 18062.8 & 66.0 & 20914.8 & 5431.8 \\
\hline
\end{tabular}

Notes: This table replicates Table 3 in the text, but reports treatment-on-the-treated (TOT) estimates instead of ITT estimates in all columns. The TOT coefficients are estimated using a 2SLS specification (weighted to adjust for differences in sampling probabilities across sites and over time and including randomization site fixed effects), instrumenting for voucher takeup with the experimental and section 8 assignment indicators. Standard errors, reported in parentheses, are clustered by family $\left({ }^{+}=p<0.10,{ }^{*}=p<0.05,{ }^{* *}=p<0.01\right)$. CCM Exp. denotes the control complier mean corresponding to the experimental voucher group. CCM Exp. is constructed as the mean value of the dependent variable in the estimation sample among compliers (i.e., those who took up the voucher) in the experimental group minus the TOT estimate of the experimental effect. CCM Sec. 8. denotes the control complier mean corresponding to the Section 8 group, constructed analogously. Note that Columns 2 and 4 are identical to make the structure of this table match that of Table 3 in the text. See notes to Table 3 for further details on variable definitions and specifications. 
APPENDIX TABLE 3c

Impacts of MTO on Children's Income in Adulthood: Decomposition of Income Responses

\begin{tabular}{|c|c|c|c|c|c|c|c|c|c|c|}
\hline Dep. Var.: & $\begin{array}{c}\text { W-2 } \\
\text { Earnings } \\
(\$) \\
(1) \\
\end{array}$ & $\begin{array}{c}\text { Non-W-2 } \\
\text { Earnings } \\
(\$) \\
(2) \\
\end{array}$ & $\begin{array}{c}\text { Indiv. } \\
\text { Earnings (\$) } \\
{[\text { Col. 1+2] }} \\
(3) \\
\end{array}$ & $\begin{array}{l}\text { Soc. Sec. } \\
\text { and DI Inc. } \\
\qquad \begin{array}{c}(\$) \\
(4)\end{array}\end{array}$ & $\begin{array}{c}\text { Unemp. } \\
\text { Benefits } \\
(\$) \\
(5) \\
\end{array}$ & $\begin{array}{c}\text { Indiv. } \\
\text { Income }(\$) \\
\text { [Col. } 3+4+5] \\
(6)\end{array}$ & $\begin{array}{c}\text { Spouse } \\
\text { Income } \\
(\$) \\
(7) \\
\end{array}$ & $\begin{array}{c}\text { Hhold. } \\
\text { Income (\$) } \\
{[\text { Col. 6+7] }} \\
(8)\end{array}$ & $\begin{array}{c}\text { Top-Coded } \\
\text { Ind. Earnings } \\
(\$) \\
(9) \\
\end{array}$ & $\begin{array}{c}\text { Top-Coded } \\
\text { Hhold Inc. } \\
(\$) \\
(10) \\
\end{array}$ \\
\hline \multicolumn{11}{|c|}{ Panel A: Children < Age 13 at Random Assignment } \\
\hline Exp. vs. Control & $\begin{array}{l}1339.8^{*} \\
(671.3)\end{array}$ & $\begin{array}{c}284.2 \\
(181.7)\end{array}$ & $\begin{array}{l}1624.0^{*} \\
(662.4)\end{array}$ & $\begin{array}{l}-97.70^{+} \\
(53.61)\end{array}$ & $\begin{array}{c}166.6^{+} \\
(99.31)\end{array}$ & $\begin{array}{l}\text { 1692.9* } \\
(669.4)\end{array}$ & $\begin{array}{c}520.9 \\
(353.5)\end{array}$ & $\begin{array}{c}2231.1^{\star *} \\
(771.3)\end{array}$ & $\begin{array}{l}1554.6^{*} \\
(650.8)\end{array}$ & $\begin{array}{c}2104.0^{* *} \\
(743.4)\end{array}$ \\
\hline Sec. 8 vs. Control & $\begin{array}{c}687.4 \\
(698.7)\end{array}$ & $\begin{array}{l}421.9^{*} \\
(214.0)\end{array}$ & $\begin{array}{c}1109.3 \\
(676.1)\end{array}$ & $\begin{array}{c}-28.91 \\
(72.12)\end{array}$ & $\begin{array}{c}193.4 \\
(118.6)\end{array}$ & $\begin{array}{l}1273.8^{+} \\
(690.5)\end{array}$ & $\begin{array}{c}207.9 \\
(282.9)\end{array}$ & $\begin{array}{l}1452.4^{*} \\
(735.5)\end{array}$ & $\begin{array}{r}1090.2 \\
(675.2)\end{array}$ & $\begin{array}{l}1455.8^{*} \\
(729.2)\end{array}$ \\
\hline Num of Obs. & 8420 & 8420 & 8420 & 8420 & 8420 & 8420 & 8420 & 8420 & 8420 & 8420 \\
\hline Control Group Mean & 9548.6 & 1721.7 & 11270.3 & 197.6 & 764.4 & 12232.3 & 802.1 & 12702.4 & 11270.3 & 12664.5 \\
\hline \multicolumn{11}{|c|}{ Panel B: Children Age 13-18 at Random Assignment } \\
\hline Exp. vs. Control & $\begin{array}{l}-761.2 \\
(870.6)\end{array}$ & $\begin{array}{l}-205.7 \\
(189.6)\end{array}$ & $\begin{array}{l}-966.9 \\
(854.3)\end{array}$ & $\begin{array}{c}57.46 \\
(48.57)\end{array}$ & $\begin{array}{c}0.344 \\
(100.4)\end{array}$ & $\begin{array}{c}-909.1 \\
(857.7)\end{array}$ & $\begin{array}{l}-498.5 \\
(608.6)\end{array}$ & $\begin{array}{c}-1519.8 \\
(1102.2)\end{array}$ & $\begin{array}{c}-847.9 \\
(828.5)\end{array}$ & $\begin{array}{r}-1178.5 \\
(988.8)\end{array}$ \\
\hline Sec. 8 vs. Control & $\begin{array}{r}-1048.9 \\
(932.5)\end{array}$ & $\begin{array}{l}-83.92 \\
(204.4)\end{array}$ & $\begin{array}{r}-1132.8 \\
(922.3)\end{array}$ & $\begin{array}{c}131.8^{*} \\
(65.91)\end{array}$ & $\begin{array}{c}65.40 \\
(120.9)\end{array}$ & $\begin{array}{l}-935.6 \\
(925.9)\end{array}$ & $\begin{array}{c}29.17 \\
(644.8)\end{array}$ & $\begin{array}{c}-936.7 \\
(1185.9)\end{array}$ & $\begin{array}{r}-1055.7 \\
(893.0)\end{array}$ & $\begin{array}{c}-625.4 \\
(1076.7)\end{array}$ \\
\hline Num of Obs. & 11623 & 11623 & 11623 & 11623 & 11623 & 11623 & 11623 & 11623 & 11623 & 11623 \\
\hline Control Group Mean & 13897.1 & 1984.4 & 15881.5 & 114.2 & 922.5 & 16918.2 & 2702.4 & 19169.1 & 15755.3 & 18555.3 \\
\hline
\end{tabular}

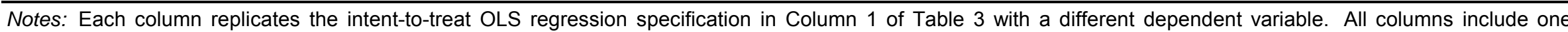

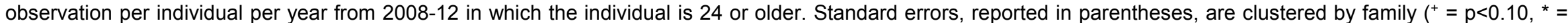

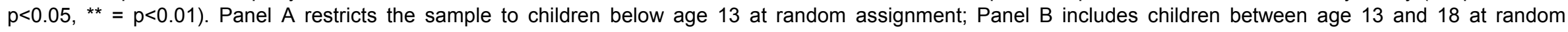

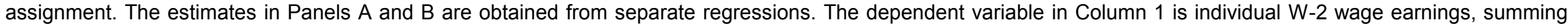

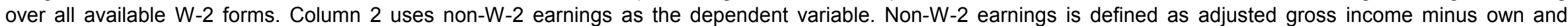

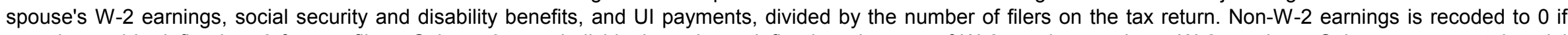

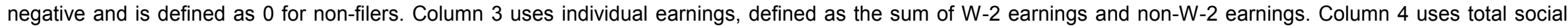

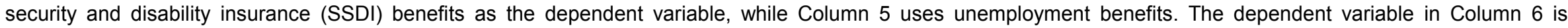

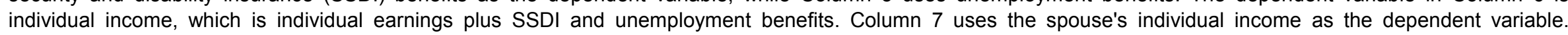

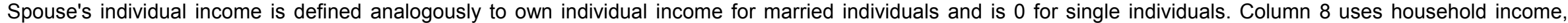

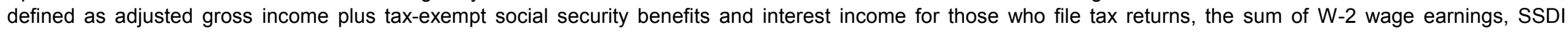

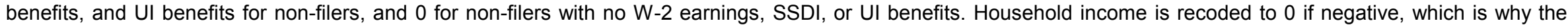

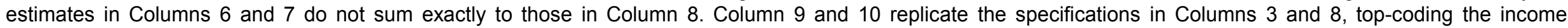
measures at $\$ 100,000$. 
APPENDIX TABLE 4a

Impacts of MTO on Children's College Attendance Outcomes: Estimates with Controls

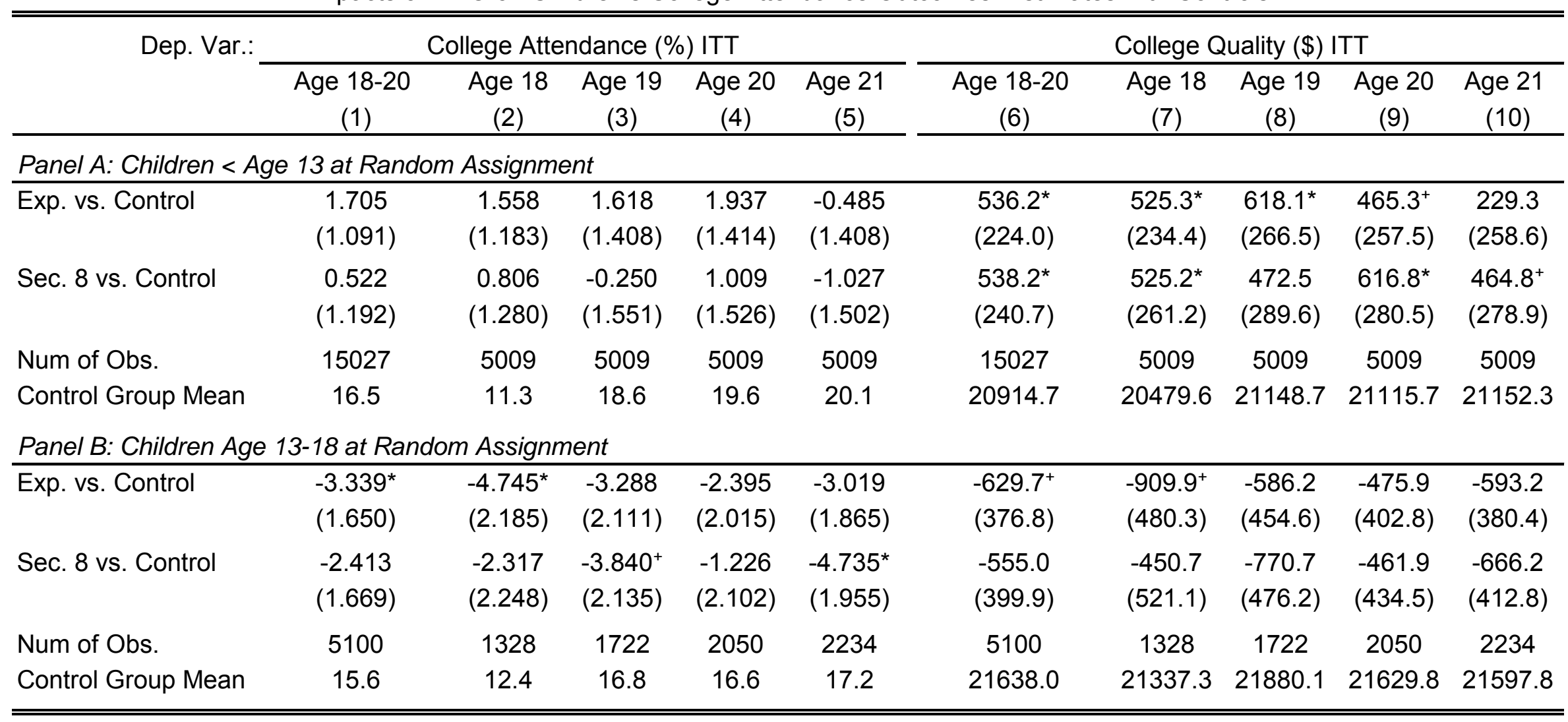

Notes: This table replicates Table 4 in the text, including controls for the baseline covariates listed in Appendix Table 1a in every regression specification. Standard errors, reported in parentheses, are clustered by family $\left({ }^{+}=p<0.10,{ }^{*}=p<0.05,{ }^{* *}=p<0.01\right)$. See notes to Table 4 for details on variable definitions and specifications. 
APPENDIX TABLE 4b

Impacts of MTO on Children's College Attendance Outcomes: Treatment-on-Treated Estimates

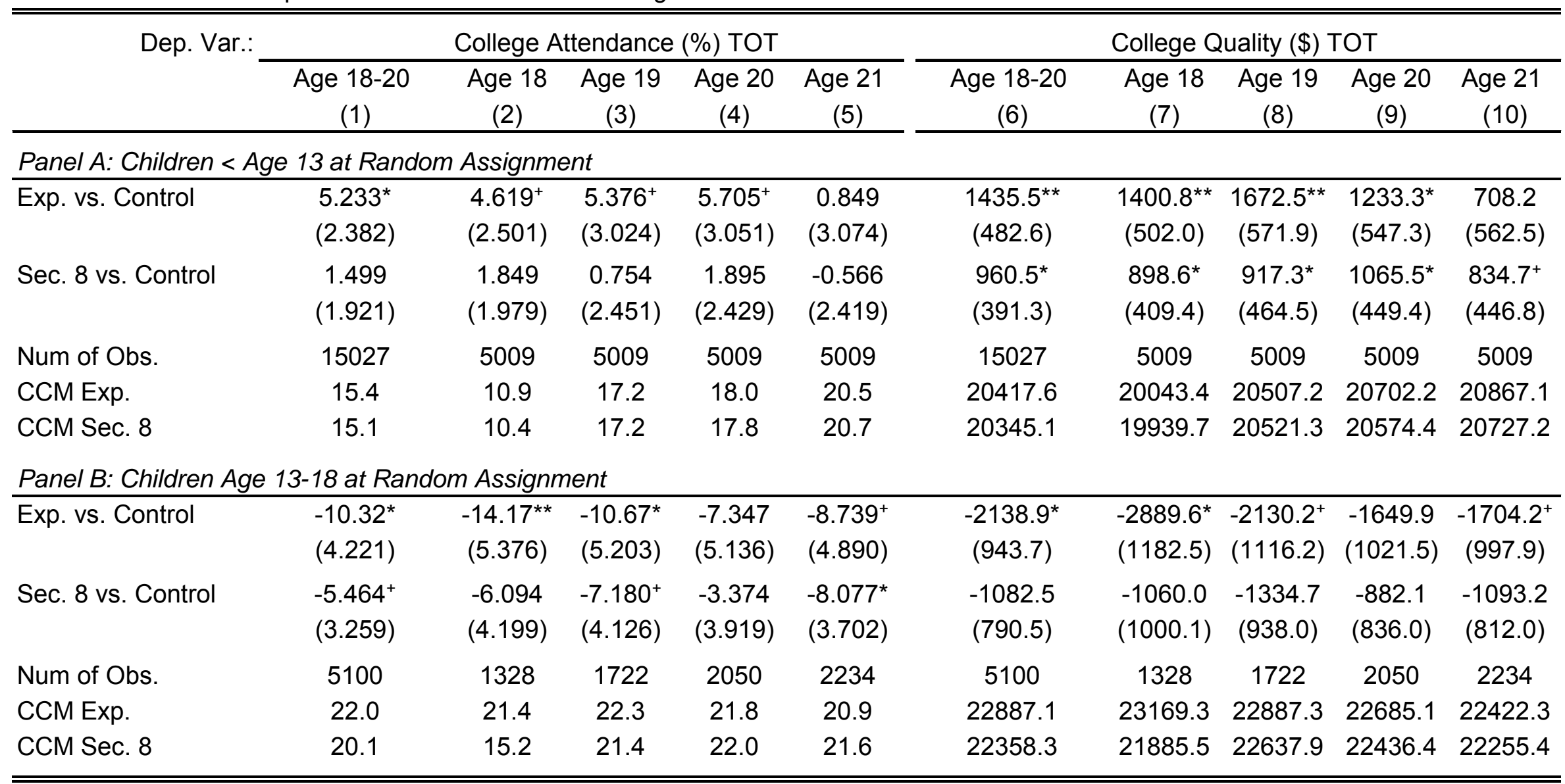

Notes: This table replicates Table 4 in the text, but reports treatment-on-the-treated (TOT) estimates instead of ITT estimates in all columns. The TOT coefficients are estimated using a 2SLS specification (weighted to adjust for differences in sampling probabilities across sites and over time and including randomization site fixed effects), instrumenting for voucher takeup with the experimental and section 8 assignment indicators. Standard errors, reported in parentheses, are clustered by family $\left(^{+}=p<0.10,{ }^{*}=p<0.05,{ }^{* *}=p<0.01\right)$. CCM Exp. denotes the control complier mean corresponding to the experimental voucher group. CCM Exp. is constructed as the mean value of the dependent variable in the estimation sample among compliers (i.e., those who took up the voucher) in the experimental group minus the TOT estimate of the experimental effect. CCM Sec. 8. denotes the control complier mean corresponding to the Section 8 group, constructed analogously. See notes to Table 4 for further details on variable definitions and specifications. 
APPENDIX TABLE 5a

Impacts of MTO on Marriage and Fertility: Estimates with Controls

\begin{tabular}{|c|c|c|c|c|c|c|c|}
\hline \multirow{2}{*}{$\begin{array}{l}\text { Sample: } \\
\text { Dep. Var.: }\end{array}$} & \multirow{2}{*}{$\begin{array}{c}\text { All } \\
\text { Married } \\
(\%) \\
(1) \\
\end{array}$} & \multirow{2}{*}{$\begin{array}{c}\text { Males } \\
\text { Married } \\
(\%) \\
(2)\end{array}$} & \multicolumn{5}{|c|}{ Females } \\
\hline & & & $\begin{array}{c}\text { Married } \\
(\%) \\
(3) \\
\end{array}$ & $\begin{array}{c}\text { Has } \\
\text { Birth } \\
(\%) \\
(4)\end{array}$ & $\begin{array}{c}\text { Teen } \\
\text { Birth } \\
(\%) \\
(5) \\
\end{array}$ & $\begin{array}{c}\text { Father on } \\
\text { Birth Cert. } \\
\begin{array}{c}(\%) \\
(6)\end{array}\end{array}$ & $\begin{array}{c}\text { Birth with No } \\
\text { Father Present } \\
(\%) \\
(7)\end{array}$ \\
\hline \multicolumn{8}{|c|}{ Panel A: Children < Age 13 at Random Assignment } \\
\hline Exp. vs. Control & $\begin{array}{c}1.658^{+} \\
(0.887)\end{array}$ & $\begin{array}{c}0.148 \\
(1.029)\end{array}$ & $\begin{array}{c}3.163^{*} \\
(1.513)\end{array}$ & $\begin{array}{c}-0.671 \\
(2.434)\end{array}$ & $\begin{array}{c}-0.299 \\
(2.097)\end{array}$ & $\begin{array}{c}4.776 \\
(3.321)\end{array}$ & $\begin{array}{l}-3.510 \\
(2.330)\end{array}$ \\
\hline Sec. 8 vs. Control & $\begin{array}{c}2.419^{*} \\
(1.054)\end{array}$ & $\begin{array}{c}0.325 \\
(1.109)\end{array}$ & $\begin{array}{l}4.601^{* *} \\
(1.756)\end{array}$ & $\begin{array}{l}0.0764 \\
(2.561)\end{array}$ & $\begin{array}{c}2.967 \\
(2.372)\end{array}$ & $\begin{array}{c}1.733 \\
(3.564)\end{array}$ & $\begin{array}{c}-1.463 \\
(2.525)\end{array}$ \\
\hline Num of Obs. & 8420 & 4384 & 4036 & 2409 & 2379 & 1410 & 2409 \\
\hline Control Group Mean & 3.4 & 2.7 & 4.1 & 59.1 & 19.9 & 44.1 & 33.0 \\
\hline \multicolumn{8}{|c|}{ Panel B: Children Age 13-18 at Random Assignment } \\
\hline Exp. vs. Control & $\begin{array}{c}0.129 \\
(1.308)\end{array}$ & $\begin{array}{c}-1.176 \\
(1.737)\end{array}$ & $\begin{array}{c}1.382 \\
(1.994)\end{array}$ & $\begin{array}{c}-2.676 \\
(3.070)\end{array}$ & $\begin{array}{c}-0.947 \\
(3.203)\end{array}$ & $\begin{array}{l}-9.971^{*} \\
(4.241)\end{array}$ & $\begin{array}{c}5.534 \\
(3.654)\end{array}$ \\
\hline Sec. 8 vs. Control & $\begin{array}{l}0.0124 \\
(1.411)\end{array}$ & $\begin{array}{l}-0.638 \\
(1.858)\end{array}$ & $\begin{array}{c}0.398 \\
(2.094)\end{array}$ & $\begin{array}{l}-1.966 \\
(3.247)\end{array}$ & $\begin{array}{l}-0.495 \\
(3.664)\end{array}$ & $\begin{array}{l}-3.229 \\
(4.479)\end{array}$ & $\begin{array}{c}0.632 \\
(3.827)\end{array}$ \\
\hline Num of Obs. & 11623 & 5852 & 5771 & 1158 & 1141 & 888 & 1158 \\
\hline Control Group Mean & 9.3 & 9.3 & 9.2 & 77.8 & 24.7 & 46.7 & 41.4 \\
\hline
\end{tabular}

Notes: This table replicates Table 5 in the text, including controls for the baseline covariates listed in Appendix Table 1a in every regression specification. Standard errors, reported in parentheses, are clustered by family $\left(^{+}=\right.$ $\left.p<0.10,{ }^{*}=p<0.05,{ }^{* *}=p<0.01\right)$. See notes to Table 5 for details on variable definitions and specifications. 
APPENDIX TABLE 5b

Impacts of MTO on Marriage and Fertility: Treatment-on-Treated Estimates

\begin{tabular}{|c|c|c|c|c|c|c|c|}
\hline \multirow{2}{*}{$\begin{array}{l}\text { Sample: } \\
\text { Dep. Var.: }\end{array}$} & \multirow{2}{*}{$\begin{array}{c}\text { All } \\
\text { Married } \\
(\%) \\
(1) \\
\end{array}$} & \multirow{2}{*}{$\begin{array}{c}\text { Males } \\
\text { Married } \\
(\%) \\
(2) \\
\end{array}$} & \multicolumn{5}{|c|}{ Females } \\
\hline & & & $\begin{array}{c}\text { Married } \\
(\%) \\
(3) \\
\end{array}$ & $\begin{array}{c}\text { Has } \\
\text { Birth } \\
(\%) \\
(4) \\
\end{array}$ & $\begin{array}{c}\text { Teen } \\
\text { Birth } \\
(\%) \\
(5) \\
\end{array}$ & $\begin{array}{c}\text { Father on } \\
\text { Birth Cert. } \\
(\%) \\
(6) \\
\end{array}$ & $\begin{array}{l}\text { Birth with No } \\
\text { Father Present } \\
(\%) \\
(7)\end{array}$ \\
\hline \multicolumn{8}{|c|}{ Panel A: Children < Age 13 at Random Assignment } \\
\hline Exp. vs. Control & $\begin{array}{c}4.153^{*} \\
(1.923)\end{array}$ & $\begin{array}{c}1.589 \\
(2.226)\end{array}$ & $\begin{array}{c}7.137^{*} \\
(3.186)\end{array}$ & $\begin{array}{c}-4.661 \\
(5.198)\end{array}$ & $\begin{array}{l}-1.350 \\
(4.391)\end{array}$ & $\begin{array}{c}14.82^{*} \\
(7.242)\end{array}$ & $\begin{array}{l}-9.958^{*} \\
(4.881)\end{array}$ \\
\hline Sec. 8 vs. Control & $\begin{array}{l}4.425^{\star *} \\
(1.655)\end{array}$ & $\begin{array}{c}1.641 \\
(1.767)\end{array}$ & $\begin{array}{l}7.134^{*} \\
(2.788)\end{array}$ & $\begin{array}{l}-0.425 \\
(4.101)\end{array}$ & $\begin{array}{c}3.710 \\
(3.645)\end{array}$ & $\begin{array}{c}4.035 \\
(5.382)\end{array}$ & $\begin{array}{c}-1.996 \\
(3.923)\end{array}$ \\
\hline Num of Obs. & 8420 & 4384 & 4036 & 2409 & 2379 & 1410 & 2409 \\
\hline CCM Exp. & 1.0 & 2.2 & -0.5 & 61.4 & 18.9 & 36.3 & 37.7 \\
\hline CCM Sec. 8 & 1.5 & 2.2 & 0.9 & 60.0 & 20.8 & 40.8 & 34.9 \\
\hline \multicolumn{8}{|c|}{ Panel B: Children Age 13-18 at Random Assignment } \\
\hline Exp. vs. Control & $\begin{array}{c}-0.162 \\
(3.434)\end{array}$ & $\begin{array}{l}-3.727 \\
(4.781)\end{array}$ & $\begin{array}{c}2.845 \\
(4.821)\end{array}$ & $\begin{array}{l}-6.299 \\
(7.560)\end{array}$ & $\begin{array}{l}-5.818 \\
(7.681)\end{array}$ & $\begin{array}{l}-20.06^{*} \\
(10.08)\end{array}$ & $\begin{array}{c}10.35 \\
(8.782)\end{array}$ \\
\hline Sec. 8 vs. Control & $\begin{array}{c}1.183 \\
(2.648)\end{array}$ & $\begin{array}{l}-1.071 \\
(3.656)\end{array}$ & $\begin{array}{c}3.158 \\
(3.790)\end{array}$ & $\begin{array}{c}-0.976 \\
(5.730)\end{array}$ & $\begin{array}{l}-1.141 \\
(6.269)\end{array}$ & $\begin{array}{l}-0.512 \\
(7.672)\end{array}$ & $\begin{array}{l}-1.170 \\
(6.594)\end{array}$ \\
\hline Num of Obs. & 11623 & 5852 & 5771 & 1158 & 1141 & 888 & 1158 \\
\hline CCM Exp. & 10.5 & 12.4 & 8.9 & 83.3 & 30.6 & 59.5 & 36.2 \\
\hline CCM Sec. 8 & 9.7 & 9.3 & 10.3 & 77.9 & 26.3 & 50.9 & 39.4 \\
\hline
\end{tabular}

Notes: This table replicates Table 5 in the text, but reports treatment-on-the-treated (TOT) estimates instead of ITT estimates in all columns. The TOT coefficients are estimated using a 2SLS specification (weighted to adjust for differences in sampling probabilities across sites and over time and including randomization site fixed effects), instrumenting for voucher takeup with the experimental and section 8 assignment indicators. Standard errors, reported in parentheses, are clustered by family $\left(^{+}=p<0.10,{ }^{*}=p<0.05,{ }^{* *}=p<0.01\right)$. CCM Exp. denotes the control complier mean corresponding to the experimental voucher group. CCM Exp. is constructed as the mean value of the dependent variable in the estimation sample among compliers (i.e., those who took up the voucher) in the experimental group minus the TOT estimate of the experimental effect. CCM Sec. 8. denotes the control complier mean corresponding to the Section 8 group, constructed analogously. See notes to Table 5 for further details on variable definitions and specifications. 


\section{APPENDIX TABLE 6a}

Impacts of MTO on Children's Neighborhood Characteristics: Estimates with Controls

\begin{tabular}{|c|c|c|c|c|}
\hline Dep. Var.: & $\begin{array}{c}\text { Poverty Share in } \\
\text { ZIP 2008-12 (\%) } \\
(1)\end{array}$ & $\begin{array}{c}\text { Mean Income in } \\
\text { ZIP 2008-12 (\$) } \\
(2)\end{array}$ & $\begin{array}{c}\text { Black Share in } \\
\text { ZIP 2008-12 (\%) } \\
(3)\end{array}$ & $\begin{array}{c}\text { Single Mother Share } \\
\text { in ZIP 2008-12 (\%) } \\
(4)\end{array}$ \\
\hline \multicolumn{5}{|c|}{ Panel A: Children < Age 13 at Random Assignment } \\
\hline Exp. vs. Control & $\begin{array}{c}-1.651^{* *} \\
(0.589)\end{array}$ & $\begin{array}{c}1252.3^{\star *} \\
(472.6)\end{array}$ & $\begin{array}{l}-2.735^{*} \\
(1.390)\end{array}$ & $\begin{array}{l}-1.849^{*} \\
(0.838)\end{array}$ \\
\hline Sec. 8 vs. Control & $\begin{array}{l}-1.547^{*} \\
(0.677)\end{array}$ & $\begin{array}{l}1317.0^{*} \\
(542.0)\end{array}$ & $\begin{array}{l}-5.750 * * \\
(1.625)\end{array}$ & $\begin{array}{l}-3.177^{* *} \\
(0.950)\end{array}$ \\
\hline $\begin{array}{l}\text { Num of Obs. } \\
\text { Control Group Mean }\end{array}$ & $\begin{array}{l}6649 \\
23.8\end{array}$ & $\begin{array}{c}6649 \\
25014.3\end{array}$ & $\begin{array}{l}6651 \\
43.0\end{array}$ & $\begin{array}{l}6648 \\
42.0\end{array}$ \\
\hline \multicolumn{5}{|c|}{ Panel B: Children Age 13-18 at Random Assignment } \\
\hline Exp. vs. Control & $\begin{array}{l}-0.385 \\
(0.625)\end{array}$ & $\begin{array}{c}487.0 \\
(468.8)\end{array}$ & $\begin{array}{c}0.798 \\
(1.510)\end{array}$ & $\begin{array}{l}-0.110 \\
(0.909)\end{array}$ \\
\hline Sec. 8 vs. Control & $\begin{array}{l}-0.357 \\
(0.676)\end{array}$ & $\begin{array}{c}106.5 \\
(520.3)\end{array}$ & $\begin{array}{l}-1.009 \\
(1.608)\end{array}$ & $\begin{array}{l}-1.068 \\
(0.942)\end{array}$ \\
\hline Num of Obs. & 9149 & 9149 & 9149 & 9148 \\
\hline Control Group Mean & 23.6 & 25170.5 & 39.6 & 40.1 \\
\hline
\end{tabular}

Notes: This table replicates Table 6 in the text, including controls for the baseline covariates listed in Appendix Table 1a in every regression specification. Standard errors, reported in parentheses, are clustered by family $\left(^{+}=\right.$ $\left.p<0.10,{ }^{*}=p<0.05,{ }^{* *}=p<0.01\right)$. See notes to Table 6 for details on variable definitions and specifications. 
APPENDIX TABLE 6b

Impacts of MTO on Children's Neighborhood Characteristics: Treatment-on-Treated Estimates

\begin{tabular}{|c|c|c|c|c|}
\hline Dep. Var.: & $\begin{array}{c}\text { Poverty Share in } \\
\text { ZIP 2008-12 (\%) } \\
(1)\end{array}$ & $\begin{array}{c}\text { Mean Income in } \\
\text { ZIP 2008-12 (\$) } \\
(2)\end{array}$ & $\begin{array}{c}\text { Black Share in } \\
\text { ZIP 2008-12 (\%) } \\
(3)\end{array}$ & $\begin{array}{c}\text { Single Mother Share } \\
\text { in ZIP 2008-12 (\%) } \\
(4)\end{array}$ \\
\hline \multicolumn{5}{|c|}{ Panel A: Children < Age 13 at Random Assignment } \\
\hline Exp. vs. Control & $\begin{array}{c}-3.378^{* *} \\
(1.255)\end{array}$ & $\begin{array}{l}2857.2^{* *} \\
(1034.9)\end{array}$ & $\begin{array}{l}-6.067^{*} \\
(2.989)\end{array}$ & $\begin{array}{l}-3.855^{\star} \\
(1.805)\end{array}$ \\
\hline Sec. 8 vs. Control & $\begin{array}{l}-2.148^{*} \\
(1.076)\end{array}$ & $\begin{array}{l}2038.0^{*} \\
(864.5)\end{array}$ & $\begin{array}{l}-8.728^{* *} \\
(2.659)\end{array}$ & $\begin{array}{c}-4.765^{\star *} \\
(1.548)\end{array}$ \\
\hline Num of Obs. & 6649 & 6649 & 6651 & 6648 \\
\hline CCM Exp. & 23.3 & 24190.4 & 43.2 & 40.5 \\
\hline CCM Sec. 8 & 24.0 & 24195.9 & 47.6 & 43.3 \\
\hline \multicolumn{5}{|c|}{ Panel B: Children Age 13-18 at Random Assignment } \\
\hline Exp. vs. Control & $\begin{array}{l}-1.272 \\
(1.551)\end{array}$ & $\begin{array}{c}1468.9 \\
(1154.8)\end{array}$ & $\begin{array}{c}1.126 \\
(4.025)\end{array}$ & $\begin{array}{l}-0.717 \\
(2.278)\end{array}$ \\
\hline Sec. 8 vs. Control & $\begin{array}{l}-1.679 \\
(1.257)\end{array}$ & $\begin{array}{c}802.0 \\
(946.1)\end{array}$ & $\begin{array}{l}-4.746 \\
(3.107)\end{array}$ & $\begin{array}{l}-3.351^{+} \\
(1.757)\end{array}$ \\
\hline $\begin{array}{l}\text { Num of Obs. } \\
\text { CCM Exp. }\end{array}$ & $\begin{array}{l}9149 \\
22.3\end{array}$ & $\begin{array}{c}9149 \\
25573.2\end{array}$ & $\begin{array}{l}9149 \\
36.7\end{array}$ & $\begin{array}{l}9148 \\
37.7\end{array}$ \\
\hline CCM Sec. 8 & 23.7 & 24737.6 & 40.8 & 39.5 \\
\hline
\end{tabular}

Notes: This table replicates Table 6 in the text, but reports treatment-on-the-treated (TOT) estimates instead of ITT estimates in all columns. The TOT coefficients are estimated using a 2SLS specification (weighted to adjust for differences in sampling probabilities across sites and over time and including randomization site fixed effects), instrumenting for voucher takeup with the experimental and section 8 assignment indicators. Standard errors, reported in parentheses, are clustered by family $\left(^{+}=p<0.10,{ }^{*}=p<0.05,{ }^{* *}=p<0.01\right)$. CCM Exp. denotes the control complier mean corresponding to the experimental voucher group. CCM Exp. is constructed as the mean value of the dependent variable in the estimation sample among compliers (i.e., those who took up the voucher) in the experimental group minus the TOT estimate of the experimental effect. CCM Sec. 8. denotes the control complier mean corresponding to the Section 8 group, constructed analogously. See notes to Table 6 for further details on variable definitions and specifications. 
APPENDIX TABLE 7a

Heterogeneity of Treatment Effects by Race: Intent-to-Treat Estimates

\begin{tabular}{|c|c|c|c|c|c|c|}
\hline & Exper & imental & Control & $\mathrm{Sec}$ & tion 8 vs. & ontrol \\
\hline & $\begin{array}{c}\text { Hispanic } \\
(1) \\
\end{array}$ & $\begin{array}{c}\text { Non-Black } \\
\text { Non-Hisp. } \\
(2) \\
\end{array}$ & $\begin{array}{c}\text { Black } \\
\text { Non-Hisp. } \\
(3)\end{array}$ & $\begin{array}{c}\text { Hispanic } \\
(4) \\
\end{array}$ & $\begin{array}{c}\text { Non-Black } \\
\text { Non-Hisp. } \\
(5)\end{array}$ & $\begin{array}{c}\text { Black } \\
\text { Non-Hisp. } \\
(6)\end{array}$ \\
\hline Panel A: Children $<$ Age 13 at $R$ & dom Assigr & iment & & & & \\
\hline Individual Earnings 2008-12 (\$) & $\begin{array}{c}3306.2^{*} \\
(1492.3) \\
{[13735.9]}\end{array}$ & $\begin{array}{c}4019.8 \\
(2979.4) \\
{[11687.1]}\end{array}$ & $\begin{array}{c}627.2 \\
(704.6) \\
{[10069.3]}\end{array}$ & $\begin{array}{c}353.9 \\
(1326.2) \\
{[13735.9]}\end{array}$ & $\begin{array}{c}4683.3 \\
(3112.2) \\
{[11687.1]}\end{array}$ & $\begin{array}{c}1041.5 \\
(796.5) \\
{[10069.3]}\end{array}$ \\
\hline College Quality $18-20(\$)$ & $\begin{array}{c}779.6 \\
(542.0) \\
{[21356.4]}\end{array}$ & $\begin{array}{c}3191.8^{* *} \\
(1099.8) \\
{[21009.8]}\end{array}$ & $\begin{array}{c}470.8^{+} \\
(245.7) \\
{[20698.7]}\end{array}$ & $\begin{array}{c}697.0 \\
(524.2) \\
{[21356.4]}\end{array}$ & $\begin{array}{c}5080.7^{* *} \\
(1510.5) \\
{[21009.8]}\end{array}$ & $\begin{array}{c}109.5 \\
(271.1) \\
{[20698.7]}\end{array}$ \\
\hline Married 2008-12 (\%) & $\begin{array}{c}3.234 \\
(2.123) \\
{[5.9]}\end{array}$ & $\begin{array}{c}0.190 \\
(4.153) \\
{[8.0]}\end{array}$ & $\begin{array}{c}1.655^{+} \\
(0.922) \\
{[1.8]}\end{array}$ & $\begin{array}{c}3.900 \\
(2.478) \\
{[5.9]}\end{array}$ & $\begin{array}{c}-1.562 \\
(4.424) \\
{[8.0]}\end{array}$ & $\begin{array}{c}2.738^{*} \\
(1.108) \\
{[1.8]}\end{array}$ \\
\hline ZIP Poverty Share 2008-12 (\%) & $\begin{array}{c}-1.123 \\
(0.921) \\
{[23.5]}\end{array}$ & $\begin{array}{c}0.127 \\
(1.811) \\
{[17.0]}\end{array}$ & $\begin{array}{c}-1.846^{* *} \\
(0.667) \\
{[24.2]}\end{array}$ & $\begin{array}{c}-0.700 \\
(0.976) \\
{[23.5]}\end{array}$ & $\begin{array}{c}-2.279 \\
(1.955) \\
{[17.0]}\end{array}$ & $\begin{array}{c}-1.526^{*} \\
(0.771) \\
{[24.2]}\end{array}$ \\
\hline ane & ndom & gnment & & & & \\
\hline Individual Earnings 2008-12 (\$) & $\begin{array}{c}-1326.9 \\
(1811.9) \\
{[20501.1]}\end{array}$ & $\begin{array}{c}-1058.3 \\
(3701.2) \\
{[16689.5]}\end{array}$ & $\begin{array}{c}-652.1 \\
(931.3) \\
{[13369.9]}\end{array}$ & $\begin{array}{c}-1415.1 \\
(1867.2) \\
{[20501.1]}\end{array}$ & $\begin{array}{c}3083.0 \\
(4439.5) \\
{[16689.5]}\end{array}$ & $\begin{array}{c}-2162.0^{*} \\
(976.0) \\
{[13369.9]}\end{array}$ \\
\hline College Quality 18-20 (\$) & $\begin{array}{c}-607.6 \\
(801.1) \\
{[21694.8]}\end{array}$ & $\begin{array}{c}-3828.8^{*} \\
(1841.5) \\
{[24521.2]}\end{array}$ & $\begin{array}{c}-605.9 \\
(419.9) \\
{[21168.1]}\end{array}$ & $\begin{array}{c}308.4 \\
(931.2) \\
{[21694.8]}\end{array}$ & $\begin{array}{c}-290.7 \\
(2410.6) \\
{[24521.2]}\end{array}$ & $\begin{array}{c}-1171.3^{* *} \\
(387.1) \\
{[21168.1]}\end{array}$ \\
\hline Married 2008-12 (\%) & $\begin{array}{c}-3.391 \\
(3.083) \\
{[16.6]}\end{array}$ & $\begin{array}{c}6.279 \\
(6.505) \\
{[14.7]}\end{array}$ & $\begin{array}{c}0.452 \\
(1.291) \\
{[5.2]}\end{array}$ & $\begin{array}{c}2.331 \\
(3.333) \\
{[16.6]}\end{array}$ & $\begin{array}{c}-2.959 \\
(5.708) \\
{[14.7]}\end{array}$ & $\begin{array}{c}-0.965 \\
(1.360) \\
{[5.2]}\end{array}$ \\
\hline ZIP Poverty S & $\begin{array}{c}0.262 \\
(1.237) \\
{[21.7]}\end{array}$ & $\begin{array}{c}-1.161 \\
(2.368) \\
{[20.2]}\end{array}$ & $\begin{array}{c}-0.420 \\
(0.982) \\
{[24.4]}\end{array}$ & $\begin{array}{c}0.0336 \\
(1.316) \\
{[21.7]}\end{array}$ & $\begin{array}{c}-6.092^{* *} \\
(2.244) \\
{[20.2]}\end{array}$ & $\begin{array}{c}0.933 \\
(1.105) \\
{[24.4]}\end{array}$ \\
\hline
\end{tabular}

Notes: This table replicates the intent-to-treat (ITT) OLS regression specifications in Column 2 of Table 3 (individual earnings), Column 6 of Table 4 (college quality), Column 1 of Table 5 (married) and Column 1 of Table 6 (poverty share), separately by racial group. Columns 1-3 report estimates on the indicator being assigned to the experimental group, while columns 4-6 report estimates on the indicator for being assigned to the Section 8 group. The estimates in Columns 1 and 4 are for Hispanic children and the two estimates in each row of these columns come from a single OLS regression analogous to that in Column 1 of Table 3. The estimates in Columns 2 and 5 for Non-black, Non-Hispanics and 3 and 6 for Black NonHispanics are constructed analogously. Standard errors, reported in parentheses, are clustered by family $\left(^{+}=p<0.10,{ }^{*}=\right.$ $\left.p<0.05,{ }^{* *}=p<0.01\right)$. Control group means for each estimation sample are reported in square brackets. See the notes to Tables 3-6 for further details on specifications and variable definitions. 
APPENDIX TABLE 7b

Heterogeneity of Treatment Effects by Site: Intent-to-Treat Estimates

\begin{tabular}{|c|c|c|c|c|c|c|c|c|c|c|}
\hline & \multicolumn{5}{|c|}{ Experimental vs. Control } & \multicolumn{5}{|c|}{ Section 8 vs. Control } \\
\hline & $\begin{array}{c}\text { Baltimore } \\
\text { (1) }\end{array}$ & $\begin{array}{c}\text { Boston } \\
(2)\end{array}$ & $\begin{array}{c}\text { Chicago } \\
(3) \\
\end{array}$ & $\begin{array}{l}\text { LA } \\
(4) \\
\end{array}$ & $\begin{array}{c}\text { New York } \\
(5) \\
\end{array}$ & $\begin{array}{c}\text { Baltimore } \\
(6)\end{array}$ & $\begin{array}{c}\text { Boston } \\
(7)\end{array}$ & $\begin{array}{c}\text { Chicago } \\
(8) \\
\end{array}$ & $\begin{array}{l}\text { LA } \\
(9) \\
\end{array}$ & $\begin{array}{c}\text { New York } \\
(10)\end{array}$ \\
\hline \multicolumn{11}{|c|}{ Panel A: Children < Age 13 at Random Assignment } \\
\hline Individual Earnings 2008-12 (\$) & $\begin{array}{c}414.9 \\
(1435.8)\end{array}$ & $\begin{array}{c}2618.7 \\
(1713.2)\end{array}$ & $\begin{array}{c}681.2 \\
(877.8)\end{array}$ & $\begin{array}{l}2791.5^{+} \\
(1554.9)\end{array}$ & $\begin{array}{c}1652.4 \\
(1612.4)\end{array}$ & $\begin{array}{c}865.1 \\
(1587.3)\end{array}$ & $\begin{array}{c}3028.6^{+} \\
(1824.3)\end{array}$ & $\begin{array}{c}797.2 \\
(1096.1)\end{array}$ & $\begin{array}{c}964.7 \\
(1413.7)\end{array}$ & $\begin{array}{c}-353.5 \\
(1428.2)\end{array}$ \\
\hline & [10942.8] & {$[12414.6]$} & {$[8927.5]$} & [11139.6] & [12516.9] & [10942.8] & [12414.6] & [8927.5] & [11139.6] & [12516.9] \\
\hline College Quality 18-20 (\$) & $\begin{array}{c}909.4^{*} \\
(457.6) \\
{[20163.5]}\end{array}$ & $\begin{array}{c}561.4 \\
(607.6) \\
{[21707.4]}\end{array}$ & $\begin{array}{c}250.2 \\
(406.1) \\
{[20546.0]}\end{array}$ & $\begin{array}{c}1090.5^{\star} \\
(492.6) \\
{[20740.7]}\end{array}$ & $\begin{array}{c}569.8 \\
(570.1) \\
{[21216.6]}\end{array}$ & $\begin{array}{c}413.7 \\
(464.8) \\
{[20163.5]}\end{array}$ & $\begin{array}{c}2200.0^{* *} \\
(777.4) \\
{[21707.4]}\end{array}$ & $\begin{array}{c}-258.0 \\
(465.7) \\
{[20546.0]}\end{array}$ & $\begin{array}{c}342.3 \\
(447.9) \\
{[20740.7]}\end{array}$ & $\begin{array}{c}476.9 \\
(604.6) \\
{[21216.6]}\end{array}$ \\
\hline Married 2008-12 (\%) & $\begin{array}{c}2.204 \\
(2.105) \\
{[2.0]}\end{array}$ & $\begin{array}{c}2.229 \\
(2.008) \\
{[4.2]}\end{array}$ & $\begin{array}{c}1.004 \\
(1.073) \\
{[1.2]}\end{array}$ & $\begin{array}{c}4.371 \\
(2.653) \\
{[4.7]}\end{array}$ & $\begin{array}{c}0.0605 \\
(1.828) \\
{[4.5]}\end{array}$ & $\begin{array}{c}1.844 \\
(2.055) \\
{[2.0]}\end{array}$ & $\begin{array}{c}3.165 \\
(2.379) \\
{[4.2]}\end{array}$ & $\begin{array}{c}4.812^{\star} \\
(2.143) \\
{[1.2]}\end{array}$ & $\begin{array}{c}0.950 \\
(2.494) \\
{[4.7]}\end{array}$ & $\begin{array}{c}3.189 \\
(2.684) \\
{[4.5]}\end{array}$ \\
\hline ZIP Poverty Share 2008-12 (\%) & $\begin{array}{c}-1.738 \\
(1.202) \\
{[22.3]}\end{array}$ & $\begin{array}{c}-1.139 \\
(0.823) \\
{[18.6]}\end{array}$ & $\begin{array}{c}-1.440 \\
(1.174) \\
{[24.3]}\end{array}$ & $\begin{array}{c}-3.517^{* *} \\
(1.072) \\
{[26.1]}\end{array}$ & $\begin{array}{c}0.446 \\
(1.399) \\
{[26.3]}\end{array}$ & $\begin{array}{c}-4.416^{* *} \\
(1.354) \\
{[22.3]}\end{array}$ & $\begin{array}{c}-1.510 \\
(0.920) \\
{[18.6]}\end{array}$ & $\begin{array}{c}-3.306^{\star} \\
(1.526) \\
{[24.3]}\end{array}$ & $\begin{array}{c}0.343 \\
(1.182) \\
{[26.1]}\end{array}$ & $\begin{array}{c}0.987 \\
(1.470) \\
{[26.3]}\end{array}$ \\
\hline \multicolumn{11}{|c|}{ Panel B: Children Age 13-18 at Random Assignment } \\
\hline Individual Earnings 2008-12 (\$) & $\begin{array}{c}2720.4 \\
(2235.1) \\
{[13440.0]}\end{array}$ & $\begin{array}{c}-3456.7 \\
(2105.8) \\
{[19020.8]}\end{array}$ & $\begin{array}{c}-2336.1 \\
(1467.8) \\
{[12861.2]}\end{array}$ & $\begin{array}{c}-508.3 \\
(1629.8) \\
{[15958.1]}\end{array}$ & $\begin{array}{c}-583.2 \\
(2051.0) \\
{[17237.7]}\end{array}$ & $\begin{array}{c}-1120.4 \\
(1903.2) \\
{[13440.0]}\end{array}$ & $\begin{array}{c}-1410.0 \\
(2339.6) \\
{[19020.8]}\end{array}$ & $\begin{array}{c}-4631.9^{* *} \\
(1525.2) \\
{[12861.2]}\end{array}$ & $\begin{array}{c}936.9 \\
(1699.8) \\
{[15958.1]}\end{array}$ & $\begin{array}{c}206.5 \\
(2423.6) \\
{[17237.7]}\end{array}$ \\
\hline College Quality $18-20(\$)$ & $\begin{array}{c}512.0 \\
(854.0) \\
{[20678.6]}\end{array}$ & $\begin{array}{c}-3106.0^{*} \\
(1287.4) \\
{[24366.3]}\end{array}$ & $\begin{array}{c}-611.4 \\
(649.8) \\
{[20804.8]}\end{array}$ & $\begin{array}{c}-298.8 \\
(649.8) \\
{[20991.2]}\end{array}$ & $\begin{array}{c}-855.4 \\
(825.2) \\
{[21534.5]}\end{array}$ & $\begin{array}{c}291.1 \\
(856.1) \\
{[20678.6]}\end{array}$ & $\begin{array}{c}-2708.5^{+} \\
(1415.4) \\
{[24366.3]}\end{array}$ & $\begin{array}{c}-1221.3^{*} \\
(601.8) \\
{[20804.8]}\end{array}$ & $\begin{array}{c}707.7 \\
(852.5) \\
{[20991.2]}\end{array}$ & $\begin{array}{c}-272.2 \\
(926.5) \\
{[21534.5]}\end{array}$ \\
\hline Married 2008-12 (\%) & $\begin{array}{c}1.937 \\
(2.795) \\
{[5.4]}\end{array}$ & $\begin{array}{c}-2.529 \\
(3.641) \\
{[14.0]}\end{array}$ & $\begin{array}{c}1.557 \\
(1.948) \\
{[3.6]}\end{array}$ & $\begin{array}{c}0.415 \\
(3.575) \\
{[12.5]}\end{array}$ & $\begin{array}{c}-1.108 \\
(2.866) \\
{[9.5]}\end{array}$ & $\begin{array}{c}-3.356 \\
(2.186) \\
{[5.4]}\end{array}$ & $\begin{array}{c}-1.448 \\
(3.898) \\
{[14.0]}\end{array}$ & $\begin{array}{c}-0.309 \\
(2.109) \\
{[3.6]}\end{array}$ & $\begin{array}{c}0.772 \\
(3.590) \\
{[12.5]}\end{array}$ & $\begin{array}{c}5.485 \\
(3.374) \\
{[9.5]}\end{array}$ \\
\hline ZIP Poverty Share 2008-12 (\%) & $\begin{array}{c}-2.547 \\
(1.785) \\
{[23.6]}\end{array}$ & $\begin{array}{c}-0.0498 \\
(1.190) \\
{[17.5]}\end{array}$ & $\begin{array}{c}1.014 \\
(1.891) \\
{[23.5]}\end{array}$ & $\begin{array}{c}-1.005 \\
(1.393) \\
{[25.8]}\end{array}$ & $\begin{array}{c}0.494 \\
(1.670) \\
{[24.6]}\end{array}$ & $\begin{array}{c}-1.942 \\
(2.200) \\
{[23.6]}\end{array}$ & $\begin{array}{c}-1.109 \\
(1.244) \\
{[17.5]}\end{array}$ & $\begin{array}{c}1.293 \\
(2.145) \\
{[23.5]}\end{array}$ & $\begin{array}{c}-1.703 \\
(1.587) \\
{[25.8]}\end{array}$ & $\begin{array}{c}1.414 \\
(1.821) \\
{[24.6]}\end{array}$ \\
\hline
\end{tabular}

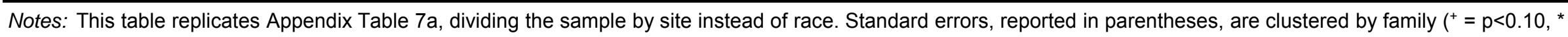
$=p<0.05,{ }^{*}=p<0.01$ ). Control group means for each estimation sample are in square brackets. See notes to Appendix Table 7a for further details. 


\section{APPENDIX TABLE 8a}

Linear Exposure Effect Estimates: Estimates with Controls

\begin{tabular}{|c|c|c|c|c|c|c|c|}
\hline \multirow[t]{2}{*}{ Dep. Var.: } & \multirow{2}{*}{$\begin{array}{c}\text { Indiv. Earn. (\$) } \\
\text { 2008-2012 ITT } \\
(1)\end{array}$} & \multicolumn{2}{|c|}{ Household Income (\$) } & \multirow{2}{*}{$\begin{array}{c}\text { Coll. Qual. } \\
\text { 18-20 ITT (\$) } \\
(4)\end{array}$} & \multirow{2}{*}{$\begin{array}{c}\text { Married } \\
\text { ITT (\%) } \\
(5)\end{array}$} & \multirow{2}{*}{$\begin{array}{c}\text { ZIP Poverty } \\
\text { Share ITT (\%) } \\
(6)\end{array}$} & \multirow{2}{*}{$\begin{array}{c}\text { Taxes Paid } \\
\text { ITT (\$) } \\
(7) \\
\end{array}$} \\
\hline & & $\begin{array}{c}2008-2012 \text { ITT } \\
(2) \\
\end{array}$ & $\begin{array}{c}\text { Age } 26 \text { ITT } \\
(3) \\
\end{array}$ & & & & \\
\hline Experimental $\times$ Age at $\mathrm{RA}$ & $\begin{array}{l}-299.6 \\
(190.8)\end{array}$ & $\begin{array}{l}-652.3^{* *} \\
(245.0)\end{array}$ & $\begin{array}{l}-480.4^{+} \\
(272.4)\end{array}$ & $\begin{array}{c}-154.0^{* *} \\
(53.44)\end{array}$ & $\begin{array}{l}-0.536^{+} \\
(0.284)\end{array}$ & $\begin{array}{l}0.260^{+} \\
(0.135)\end{array}$ & $\begin{array}{l}-59.13^{*} \\
(23.18)\end{array}$ \\
\hline Section $8 \times$ Age at RA & $\begin{array}{l}-241.1 \\
(200.6)\end{array}$ & $\begin{array}{l}-403.5 \\
(255.8)\end{array}$ & $\begin{array}{c}105.3 \\
(291.7)\end{array}$ & $\begin{array}{l}-113.4^{+} \\
(61.03)\end{array}$ & $\begin{array}{l}-0.549^{+} \\
(0.305)\end{array}$ & $\begin{array}{l}0.0634 \\
(0.151)\end{array}$ & $\begin{array}{l}-41.93^{+} \\
(24.42)\end{array}$ \\
\hline Experimental & $\begin{array}{l}3968.9^{+} \\
(2304.6)\end{array}$ & $\begin{array}{l}8490.0^{* *} \\
(2922.6)\end{array}$ & $\begin{array}{l}6933.5^{+} \\
(3618.9)\end{array}$ & $\begin{array}{l}1713.4^{* *} \\
(559.1)\end{array}$ & $\begin{array}{l}7.724^{*} \\
(3.411)\end{array}$ & $\begin{array}{l}-4.293^{*} \\
(1.726)\end{array}$ & $\begin{array}{l}738.2^{* *} \\
(269.8)\end{array}$ \\
\hline Section 8 & $\begin{array}{c}2837.5 \\
(2431.9)\end{array}$ & $\begin{array}{l}5179.3^{+} \\
(3029.2)\end{array}$ & $\begin{array}{c}-693.3 \\
(3756.1)\end{array}$ & $\begin{array}{l}1366.5^{\star} \\
(643.6)\end{array}$ & $\begin{array}{l}8.358^{*} \\
(3.695)\end{array}$ & $\begin{array}{l}-1.625 \\
(1.968)\end{array}$ & $\begin{array}{l}504.6^{+} \\
(284.4)\end{array}$ \\
\hline Number of Observations & 20043 & 20043 & 3956 & 20127 & 20043 & 15798 & 20043 \\
\hline Control Group Mean & 13807.1 & 16259.9 & 14692.6 & 21085.1 & 6.6 & 23.7 & 627.8 \\
\hline
\end{tabular}

Notes: This table replicates Table 8 in the text, including controls for the baseline covariates listed in Appendix Table 1a in every regression specification. Standard errors, reported in parentheses, are clustered by family $\left({ }^{+}=p<0.10,{ }^{*}=p<0.05,{ }^{* *}=p<0.01\right)$. See notes to Table 8 for details on variable definitions and specifications. 
APPENDIX TABLE 8b

Linear Exposure Effect Estimates: Treatment-on-Treated Estimates

\begin{tabular}{|c|c|c|c|c|c|c|c|}
\hline Dep. Var.: & $\begin{array}{c}\text { Indiv. Earn. (\$) } \\
\text { 2008-2012 TOT } \\
(1)\end{array}$ & $\begin{array}{c}\text { Household } \\
2008-2012 \text { TO } \\
(2)\end{array}$ & $\begin{array}{c}\text { come }(\$) \\
\text { Age } 26 \text { TOT } \\
(3)\end{array}$ & $\begin{array}{c}\text { Coll. Qual. } \\
\text { 18-20 TOT (\$) } \\
(4)\end{array}$ & $\begin{array}{c}\text { Married } \\
\text { TOT (\%) } \\
(5) \\
\end{array}$ & $\begin{array}{c}\text { ZIP Poverty } \\
\text { Share TOT (\%) } \\
(6)\end{array}$ & $\begin{array}{c}\text { Taxes Paid } \\
\text { TOT }(\$) \\
(7)\end{array}$ \\
\hline Experimental $\times$ Age at $\mathrm{RA}$ & $\begin{array}{l}-839.2^{+} \\
(492.0)\end{array}$ & $\begin{array}{c}-1682.7^{* *} \\
(637.6)\end{array}$ & $\begin{array}{c}-1292.7^{+} \\
(684.6)\end{array}$ & $\begin{array}{c}-361.6^{\star *} \\
(122.5)\end{array}$ & $\begin{array}{c}-1.281^{+} \\
(0.721)\end{array}$ & $\begin{array}{c}0.503 \\
(0.316)\end{array}$ & $\begin{array}{c}-155.5^{\star *} \\
(59.44)\end{array}$ \\
\hline Section $8 \times$ Age at RA & $\begin{array}{l}-393.8 \\
(362.8)\end{array}$ & $\begin{array}{l}-561.7 \\
(466.3)\end{array}$ & $\begin{array}{c}309.8 \\
(512.0)\end{array}$ & $\begin{array}{l}-175.0^{+} \\
(103.6)\end{array}$ & $\begin{array}{l}-0.635 \\
(0.550)\end{array}$ & $\begin{array}{c}-0.0456 \\
(0.258)\end{array}$ & $\begin{array}{l}-72.52^{+} \\
(43.57)\end{array}$ \\
\hline Experimental & $\begin{array}{l}10834.5^{+} \\
(5656.5)\end{array}$ & $\begin{array}{c}21385.3^{* *} \\
(7250.1)\end{array}$ & $\begin{array}{l}18095.4^{*} \\
(8711.4)\end{array}$ & $\begin{array}{l}4036.4^{* *} \\
(1202.7)\end{array}$ & $\begin{array}{c}17.95^{*} \\
(8.195)\end{array}$ & $\begin{array}{l}-8.625^{*} \\
(3.809)\end{array}$ & $\begin{array}{c}1913.2^{* *} \\
(671.3)\end{array}$ \\
\hline Section 8 & $\begin{array}{c}4626.4 \\
(4178.7)\end{array}$ & $\begin{array}{c}7219.2 \\
(5253.6)\end{array}$ & $\begin{array}{l}-2544.4 \\
(6331.0)\end{array}$ & $\begin{array}{l}2156.7^{*} \\
(1025.2)\end{array}$ & $\begin{array}{c}10.72^{+} \\
(6.331)\end{array}$ & $\begin{array}{l}-1.251 \\
(3.193)\end{array}$ & $\begin{array}{l}869.7^{+} \\
(489.6)\end{array}$ \\
\hline Number of Observations & 20043 & 20043 & 3956 & 20127 & 20043 & 15798 & 20043 \\
\hline Control Group Mean & 13807.1 & 16259.9 & 14692.6 & 21085.1 & 6.6 & 23.7 & 627.8 \\
\hline
\end{tabular}

Notes: This table replicates Table 8 in the text, but reports treatment-on-the-treated (TOT) estimates instead of ITT estimates in all columns. The TOT coefficients are estimated using a 2SLS specification (weighted to adjust for differences in sampling probabilities across sites and over time and including randomization site fixed effects). In this specification, we instrument for four variables -- takeup of each type of voucher and interactions of these two takeup indicators with age at random assignment -- with the experimental and section 8 assignment indicators and their interactions with age at random assignment. Standard errors, reported in parentheses, are clustered by family $\left(^{+}=p<0.10,{ }^{*}=p<0.05,{ }^{* *}=\right.$ $\mathrm{p}<0.01$ ). See notes to Table 8 for further details on variable definitions and specifications. 


\section{APPENDIX TABLE 9a}

Impacts of MTO on Adults' Income: Estimates with Controls

\begin{tabular}{lccccc}
\hline \hline \multirow{2}{*}{ Dep. Var.: } & \multicolumn{3}{c}{ Individual Earnings (\$) } & \multirow{2}{*}{ Employed (\%) } & Hhold. Inc. (\$) \\
\cline { 2 - 4 } & $2008-12$ ITT & ITT w/Cntrls. & 2012 ITT & ITT & ITT \\
& $(1)$ & $(2)$ & $(3)$ & $(4)$ & $(5)$ \\
\hline Exp. vs. Control & -168.7 & -168.7 & -468.9 & -0.534 & -136.2 \\
& $(558.2)$ & $(558.2)$ & $(625.9)$ & $(1.524)$ & $(668.3)$ \\
Sec. 8 vs. Control & 468.1 & 468.1 & 166.7 & -0.0955 & 653.3 \\
& $(609.0)$ & $(609.0)$ & $(709.3)$ & $(1.668)$ & $(756.1)$ \\
Num of Obs. & 21075 & 21075 & 4215 & 21075 & 21075 \\
Control Group Mean & 14381.0 & 14381.0 & 13700.6 & 54.9 & 17951.5 \\
\hline \hline
\end{tabular}

Notes: This table replicates Table 9 in the text, including controls for the baseline covariates listed in Appendix Table 1a in every regression specification. Standard errors, reported in parentheses, are clustered by family $\left(^{+}=p<0.10,{ }^{*}=p<0.05,{ }^{* *}=p<0.01\right)$. Note that Columns 1 and 2 are identical to make the structure of this table match that of Table 9 in the text. See notes to Table 9 for details on variable definitions and specifications. 
APPENDIX TABLE 9b

Impacts of MTO on Adults' Income: Treatment-on-Treated Estimates

\begin{tabular}{|c|c|c|c|c|c|}
\hline \multirow[t]{2}{*}{ Dep. Var.: } & \multicolumn{3}{|c|}{ Individual Earnings (\$) } & \multirow{2}{*}{$\begin{array}{l}\text { Employed }(\%) \\
\text { TOT } \\
(4)\end{array}$} & \multirow{2}{*}{$\begin{array}{c}\text { Hhold. Inc. (\$) } \\
\text { TOT } \\
(5)\end{array}$} \\
\hline & $\begin{array}{c}2008-12 \text { TOT } \\
\text { (1) }\end{array}$ & $\begin{array}{c}\text { TOT w/Cntrls. } \\
(2)\end{array}$ & $\begin{array}{c}2012 \text { TOT } \\
(3)\end{array}$ & & \\
\hline Exp. vs. Control & $\begin{array}{c}-734.4 \\
(1290.3)\end{array}$ & $\begin{array}{c}-351.2 \\
(1159.6)\end{array}$ & $\begin{array}{l}-1414.0 \\
(1400.5)\end{array}$ & $\begin{array}{l}-1.961 \\
(3.538)\end{array}$ & $\begin{array}{c}-702.1 \\
(1535.8)\end{array}$ \\
\hline Sec. 8 vs. Control & $\begin{array}{c}396.7 \\
(1069.1)\end{array}$ & $\begin{array}{c}741.2 \\
(965.2)\end{array}$ & $\begin{array}{c}-155.9 \\
(1200.5)\end{array}$ & $\begin{array}{l}-1.110 \\
(2.904)\end{array}$ & $\begin{array}{c}820.4 \\
(1314.1)\end{array}$ \\
\hline Num of Obs. & 21075 & 21075 & 4215 & 21075 & 21075 \\
\hline CCM Exp. & 15582.8 & 15199.7 & 15246.2 & 59.8 & 18766.7 \\
\hline CCM Sec. 8 & 14521.8 & 14177.3 & 13940.5 & 57.4 & 17134.6 \\
\hline
\end{tabular}

Notes: This table replicates Table 9 in the text, but reports treatment-on-the-treated (TOT) estimates instead of ITT estimates in all columns. The TOT coefficients are estimated using a 2SLS specification (weighted to adjust for differences in sampling probabilities across sites and over time and including randomization site fixed effects), instrumenting for voucher takeup with the experimental and section 8 assignment indicators. Standard errors, reported in parentheses, are clustered by family $\left(^{+}=p<0.10,{ }^{*}=p<0.05,{ }^{* *}=p<0.01\right)$. CCM Exp. denotes the control complier mean corresponding to the experimental voucher group. CCM Exp. is constructed as the mean value of the dependent variable in the estimation sample among compliers (i.e., those who took up the voucher) in the experimental group minus the TOT estimate of the experimental effect. CCM Sec. 8. denotes the control complier mean corresponding to the Section 8 group, constructed analogously. See notes to Table 9 for further details on variable definitions and specifications. 
APPENDIX TABLE 10a

Impacts of MTO on Federal Income Tax Payments: Estimates with Controls

\begin{tabular}{|c|c|c|c|}
\hline \multirow{2}{*}{\multicolumn{2}{|c|}{$\begin{array}{c}\text { Dep. Var.: Filing a Tax Return (\%) } \\
2008-12 \text { ITT } \\
(1) \\
\end{array}$}} & \multicolumn{2}{|c|}{ Total Income Taxes Paid (\$) } \\
\hline & & $\begin{array}{c}2008-12 \text { ITT } \\
(2) \\
\end{array}$ & $\begin{array}{c}2008-12 \text { TOT } \\
(3) \\
\end{array}$ \\
\hline \multicolumn{4}{|c|}{ Panel A: Children < Age 13 at Random Assignment } \\
\hline Exp. vs. Control & $\begin{array}{l}5.073^{* *} \\
(1.924)\end{array}$ & $\begin{array}{l}156.6^{*} \\
(61.45)\end{array}$ & $\begin{array}{l}337.2^{*} \\
(131.8)\end{array}$ \\
\hline Sec. 8 vs. Control & $\begin{array}{l}4.078^{*} \\
(2.014)\end{array}$ & $\begin{array}{l}96.40^{+} \\
(54.04)\end{array}$ & $\begin{array}{l}151.3^{+} \\
(84.53)\end{array}$ \\
\hline $\begin{array}{l}\text { Num of Obs. } \\
\text { Control Group Mean }\end{array}$ & $\begin{array}{l}8420 \\
59.3\end{array}$ & $\begin{array}{l}8420 \\
447.5\end{array}$ & $\begin{array}{l}8420 \\
447.5\end{array}$ \\
\hline \multicolumn{4}{|c|}{ Panel B: Children Age 13-18 at Random Assignment } \\
\hline Exp. vs. Control & $\begin{array}{l}-1.643 \\
(1.880)\end{array}$ & $\begin{array}{l}-175.0^{+} \\
(93.11)\end{array}$ & $\begin{array}{l}-442.1^{+} \\
(236.5)\end{array}$ \\
\hline Sec. 8 vs. Control & $\begin{array}{l}-1.935 \\
(2.091)\end{array}$ & $\begin{array}{l}-132.2 \\
(91.51)\end{array}$ & $\begin{array}{l}-233.2 \\
(162.9)\end{array}$ \\
\hline Num of Obs. & 11623 & 11623 & 11623 \\
\hline Control Group Mean & 65.6 & 775.2 & 775.2 \\
\hline
\end{tabular}

Notes: This table replicates Table 12 in the text, including controls for the baseline covariates listed in Appendix Table 1a in every regression specification. Standard errors, reported in parentheses, are clustered by family $\left(^{+}=p<0.10,{ }^{*}=p<0.05,{ }^{* *}=p<0.01\right)$. See notes to Table 12 for details on variable definitions and specifications. 
APPENDIX TABLE 10b

Impacts of MTO on Federal Income Tax Payments: Treatment-on-Treated Estimates

\begin{tabular}{|c|c|c|c|}
\hline \multirow[t]{2}{*}{ Dep. Var.: } & \multirow{2}{*}{$\begin{array}{c}\text { Filing a Tax Return (\%) } \\
\text { 2008-12 TOT } \\
(1) \\
\end{array}$} & \multicolumn{2}{|c|}{ Total Income Taxes Paid (\$) } \\
\hline & & $\begin{array}{c}2008-12 \text { TOT } \\
(2) \\
\end{array}$ & $\begin{array}{c}2008-12 \text { TOT } \\
(3) \\
\end{array}$ \\
\hline \multicolumn{4}{|c|}{ Panel A: Children < Age 13 at Random Assignment } \\
\hline Exp. vs. Control & $\begin{array}{l}12.31^{* *} \\
(4.444)\end{array}$ & $\begin{array}{l}393.6^{\star *} \\
(134.1)\end{array}$ & $\begin{array}{l}393.6^{* *} \\
(134.1)\end{array}$ \\
\hline Sec. 8 vs. Control & $\begin{array}{l}7.448^{*} \\
(3.471)\end{array}$ & $\begin{array}{l}169.1^{*} \\
(85.48)\end{array}$ & $\begin{array}{c}169.1^{*} \\
(85.48)\end{array}$ \\
\hline $\begin{array}{l}\text { Num of Obs. } \\
\text { CCM Exp. } \\
\text { CCM Sec. } 8\end{array}$ & $\begin{array}{l}8420 \\
51.1 \\
57.5\end{array}$ & $\begin{array}{l}8420 \\
300.6 \\
365.5\end{array}$ & $\begin{array}{l}8420 \\
300.6 \\
365.5\end{array}$ \\
\hline \multicolumn{4}{|c|}{ Panel B: Children Age 13-18 at Random Assignment } \\
\hline Exp. vs. Control & $\begin{array}{l}-5.220 \\
(5.171)\end{array}$ & $\begin{array}{l}-441.6^{+} \\
(230.8)\end{array}$ & $\begin{array}{l}-441.6^{+} \\
(230.8)\end{array}$ \\
\hline Sec. 8 vs. Control & $\begin{array}{l}-4.070 \\
(4.083)\end{array}$ & $\begin{array}{l}-230.1 \\
(173.2)\end{array}$ & $\begin{array}{l}-230.1 \\
(173.2)\end{array}$ \\
\hline $\begin{array}{l}\text { Num of Obs. } \\
\text { CCM Exp. } \\
\text { CCM Sec. } 8\end{array}$ & $\begin{array}{c}11623 \\
69.9 \\
69.3\end{array}$ & $\begin{array}{c}11623 \\
1099.3 \\
900.1\end{array}$ & $\begin{array}{c}11623 \\
1099.3 \\
900.1\end{array}$ \\
\hline
\end{tabular}

Notes: This table replicates Table 12 in the text, but reports treatment-on-the-treated (TOT) estimates instead of ITT estimates in all columns. The TOT coefficients are estimated using a 2SLS specification (weighted to adjust for differences in sampling probabilities across sites and over time and including randomization site fixed effects), instrumenting for voucher takeup with the experimental and section 8 assignment indicators. Standard errors, reported in parentheses, are clustered by family $\left(^{+}=p<0.10,{ }^{*}=p<0.05,{ }^{* *}=p<0.01\right)$. CCM Exp. denotes the control complier mean corresponding to the experimental voucher group. CCM Exp. is constructed as the mean value of the dependent variable in the estimation sample among compliers (i.e., those who took up the voucher) in the experimental group minus the TOT estimate of the experimental effect. CCM Sec. 8. denotes the control complier mean corresponding to the Section 8 group, constructed analogously. Note that Columns 2 and 3 are identical to make the structure of this table match that of Table 12 in the text. See notes to Table 12 for further details on variable definitions and specifications. 
APPENDIX TABLE 11

Robustness Checks: Varying Age Cutoffs and Pooling Section 8 and Experimental Groups

\begin{tabular}{|c|c|c|c|c|c|c|c|c|}
\hline & \multicolumn{2}{|c|}{$<$ Age 12 at RA } & \multicolumn{2}{|c|}{$<$ Age 13 at RA } & \multicolumn{2}{|c|}{$<$ Age 14 at RA } & \multicolumn{2}{|c|}{ Pooled Sec. 8 \& Exp } \\
\hline & $\begin{array}{c}\text { Exp. vs. } \\
\text { Control } \\
(1)\end{array}$ & $\begin{array}{c}\text { Sec. } 8 \text { vs. } \\
\text { Control } \\
(2) \\
\end{array}$ & $\begin{array}{c}\text { Exp. vs. } \\
\text { Control } \\
(3)\end{array}$ & $\begin{array}{c}\text { Sec. } 8 \text { vs. } \\
\text { Control } \\
(4) \\
\end{array}$ & $\begin{array}{c}\text { Exp. vs. } \\
\text { Control } \\
(5)\end{array}$ & $\begin{array}{c}\text { Sec. } 8 \text { vs. } \\
\text { Control } \\
(6) \\
\end{array}$ & $\begin{array}{c}\text { Baseline } \\
\text { ITT } \\
(7)\end{array}$ & $\begin{array}{c}\text { ITT with } \\
\text { Controls } \\
(8)\end{array}$ \\
\hline Individual Earnings (\$) & $\begin{array}{l}1416.3^{+} \\
(723.7)\end{array}$ & $\begin{array}{l}1414.8^{+} \\
(764.8)\end{array}$ & $\begin{array}{l}1624.0^{*} \\
(662.4)\end{array}$ & $\begin{array}{l}1109.3 \\
(676.1)\end{array}$ & $\begin{array}{c}1034.4^{+} \\
(623.8)\end{array}$ & $\begin{array}{c}216.2 \\
(624.2)\end{array}$ & $\begin{array}{l}1393.5^{*} \\
(569.8)\end{array}$ & $\begin{array}{l}1124.1^{*} \\
(553.6)\end{array}$ \\
\hline College Quality 18-20 (\$) & $\begin{array}{l}697.1^{* *} \\
(244.0)\end{array}$ & $\begin{array}{l}587.9^{*} \\
(274.3)\end{array}$ & $\begin{array}{l}686.7^{* *} \\
(231.2)\end{array}$ & $\begin{array}{l}632.7^{*} \\
(256.3)\end{array}$ & $\begin{array}{c}555.5^{\star} \\
(220.5)\end{array}$ & $\begin{array}{l}524.5^{*} \\
(246.7)\end{array}$ & $\begin{array}{l}662.8^{* *} \\
(201.0)\end{array}$ & $\begin{array}{l}537.1^{* *} \\
(192.6)\end{array}$ \\
\hline Married (\%) & $\begin{array}{l}2.217^{*} \\
(0.911)\end{array}$ & $\begin{array}{c}2.686^{*} \\
(1.087)\end{array}$ & $\begin{array}{c}1.934^{*} \\
(0.892)\end{array}$ & $\begin{array}{l}2.840 * * \\
(1.055)\end{array}$ & $\begin{array}{c}1.804^{+} \\
(0.936)\end{array}$ & $\begin{array}{l}2.526^{*} \\
(1.043)\end{array}$ & $\begin{array}{l}2.340 * * \\
(0.792)\end{array}$ & $\begin{array}{c}1.999 * \\
(0.793)\end{array}$ \\
\hline Poverty Share (\%) & $\begin{array}{l}-1.481^{*} \\
(0.650)\end{array}$ & $\begin{array}{l}-1.029 \\
(0.764)\end{array}$ & $\begin{array}{c}-1.592^{\star *} \\
(0.602)\end{array}$ & $\begin{array}{l}-1.394^{*} \\
(0.699)\end{array}$ & $\begin{array}{c}-1.624^{* *} \\
(0.569)\end{array}$ & $\begin{array}{c}-1.129^{+} \\
(0.661)\end{array}$ & $\begin{array}{c}-1.503^{* *} \\
(0.552)\end{array}$ & $\begin{array}{c}-1.605^{\star *} \\
(0.535)\end{array}$ \\
\hline Income Taxes Paid (\$) & $\begin{array}{c}159.4^{*} \\
(73.98)\end{array}$ & $\begin{array}{c}120.2^{+} \\
(66.27)\end{array}$ & $\begin{array}{l}183.9^{* *} \\
(62.80)\end{array}$ & $\begin{array}{c}109.0^{*} \\
(54.76)\end{array}$ & $\begin{array}{l}151.7^{* *} \\
(56.05)\end{array}$ & $\begin{array}{c}75.14 \\
(48.95)\end{array}$ & $\begin{array}{l}150.3^{* *} \\
(48.32)\end{array}$ & $\begin{array}{l}129.6^{* *} \\
(48.34)\end{array}$ \\
\hline
\end{tabular}

Notes: Columns 1-6 of this table replicate the intent-to-treat (ITT) OLS regression specifications in Column 2 of Table 3 (individual earnings), Column 6 of Table 4 (college quality), Column 1 of Table 5 (married), Column 1 of Table 6 (poverty share), and Column 2 of Table 12 (income taxes paid) varying the age restriction used to define "young" children. The first two columns include children below age 12 at random assignment (RA), Columns 3 and 4 include children below age 13 at RA (the specification used in the main text), and Columns 5 and 6 include children below age 14 at RA. Columns 1, 3, and 5 report ITT estimates on the indicator for being assigned to the experimental group, while Columns 2, 4, and 6 report estimates on the indicator for being assigned to the Section 8 group. Column 7 replicates the same regression specifications as in Columns 3 and 4 (using children below age 13 at RA), but pools the Section 8 and Experimental treatment groups by using a single indicator for being assigned to either of the two groups as the independent variable in each regression. Column 8 replicates Column 7 including controls for the baseline covariates listed in Appendix Table 1a. Standard errors, reported in parentheses, are clustered by family $\left({ }^{+}=p<0.10,{ }^{*}=p<0.05,{ }^{* *}=p<0.01\right)$. See the notes to Tables 3-6 and 12 for further details on specifications and variable definitions. 